\title{
A calcium lowering factor from the stomach : an experimental study in rats
}

Citation for published version (APA):

Klementschitsch, P. (1982). A calcium lowering factor from the stomach : an experimental study in rats. [Doctoral Thesis, Maastricht University]. Rijksuniversiteit Limburg. https://doi.org/10.26481/dis.19820312pk

Document status and date:

Published: 01/01/1982

DOI:

10.26481/dis.19820312pk

Document Version:

Publisher's PDF, also known as Version of record

\section{Please check the document version of this publication:}

- A submitted manuscript is the version of the article upon submission and before peer-review. There can be important differences between the submitted version and the official published version of record.

People interested in the research are advised to contact the author for the final version of the publication, or visit the DOI to the publisher's website.

- The final author version and the galley proof are versions of the publication after peer review.

- The final published version features the final layout of the paper including the volume, issue and page numbers.

Link to publication

\footnotetext{
General rights rights.

- You may freely distribute the URL identifying the publication in the public portal. please follow below link for the End User Agreement:

www.umlib.nl/taverne-license

Take down policy

If you believe that this document breaches copyright please contact us at:

repository@maastrichtuniversity.nl

providing details and we will investigate your claim.
}

Copyright and moral rights for the publications made accessible in the public portal are retained by the authors and/or other copyright owners and it is a condition of accessing publications that users recognise and abide by the legal requirements associated with these

- Users may download and print one copy of any publication from the public portal for the purpose of private study or research.

- You may not further distribute the material or use it for any profit-making activity or commercial gain

If the publication is distributed under the terms of Article $25 \mathrm{fa}$ of the Dutch Copyright Act, indicated by the "Taverne" license above, 


\section{A Calcium Lowering \\ Factor From The Stomach}

An Experimental Study in Rats 



\title{
A Calcium Lowering Factor From The Stomach
}

\author{
An Experimental Study in Rats
}

PROEFSCHRIFT

Ter verkrijging van de graad van doctor in de geneeskunde

aan de Rijksuniversiteit Limburg te Maastricht, op gezag van de rector magnificus Prof.Dr.H.C.Hemker, volgens besluit van het College van Dekanen in het openbaar te verdedigen in de aula van de universiteit op vrijdag 12 maart 1982 des namiddags te vier uur.

door

Peter Klementschitsch geboren te Dordrecht. 
Promotoren

Prof.Dr.J.M.Greep

Prof. E.L. Kaplan

\section{Referenten}

Prof.Dr.H.Hulsmans

Dr.B.M.Goslings 
To the memory of my parents,

to Jeannine, $y$ and ? 
The experiments underlying this thesis were performed at the Department of Surgery of the University of Chicago, Pritzker School of Medicine, Chicago, Ill., U.S.A. 


\section{CONTENTS}

I INTRODUCTION

I.1. Calcium homeostasis

I.1.1. Parathyroid Hormone

I.1.2. Vitamin D

I.1.3. Calcitonin

I.2. References

II BACKGROUND DATA AND GOALS OF THIS STUDY

II.1. Gastrointestinal influences on calcitonin secretion

II.2. Previous experiments

II.3. Questions to be answered

II.4. References

III INHIBITORS OF GASTRIC ACID SECRETION

III.1. Introduction

III.2. Experiments III.2.1. Material and Methods

III.2.2. Results

III.3. Discussion

III.4. Conclusion

III.5. References

IV THE ROLE OF CALCITONIN

IV.1. Introduction

IV.2. Experiments

IV.2.1. Material and Methods

IV.2.2. Results

IV.3. Discussion

IV.4. Conclusion

IV.5. References 
ACH?

V.1. Introduction

V.2. Experiments

V.2.1. Material and methods

V.2.1.1. Surgical procedures

V.2.1.2. The perfusion system

V.2.2. Results

V.2.1.3. The bone tissue culture

V.3. Discussion

V.4. Conclusion

V.5. References

VI WHERE DOES CALCIUM GO WHEN HYPOCALCEMIA OCCURS?

VI.1. Introduction

VI.2. Experiments

VI.2.1. Calcium secretion into the gastric wall

VI.2.1.1. Material and methods

VI.2.1.2. Results

VI.2.2. Calcium in the gastric wall: gradient across the stomach VI.2.2.1. Material and methods

VI.2.2.2. Results

VI.2.3. Studies with tracer calcium

VI.2.3.1. Material and methods

VI.2.3.2. Results

VI.3. Discussion

VI.4. Conclusion

VI.5. References

VII THE ALKALINE TIDE

VIII.1. Introduction

VII.2. Experiments

VII.2.1. Material and methods

VII.2.2. Results

VII.3. Discussion

VII.4. Conclusion

VII.5. References 
VIII A PHYSIOLOGIC ROLE?

VIII.1. Introduction

VIII.2. Experiments

VIII.2.1. Material and methods

VIII.2.2. Results

VIII.3. Discussion

VIII 4. References

SUMMARY

SAMENVATTING

ACKNOWLEDGEMENTS

CURRICULUM VITAE 



\section{Chapter I}

\section{INTRODUCTION}

The calcium ion has been recognized to stand central in the control of a broad spectrum of fundamental cell activities. Although recent years have brought an explosion of new knowledge concerning calcium metabolism, for better appreciation of the work introduced here, an effort will be made to give a short overview of the different mechanisms governing it.

\section{I.1. CALCIUM HOMEOSTASIS}

The adult human body contains $1000-1200$ gm calcium. Approximately $99 \%$ of it participates, through the deposition of amorphous calcium phosphate, in the formation of the hydroxyapatite crystals $\left(\mathrm{Ca}_{10}\left(\mathrm{PO}_{4}\right)_{6}(\mathrm{OH})_{2}\right)$ of the skeleton. Only one gram is divided over the extracellular space and a similar amount is located in the soft tissue cells. The skeletal calcium serves mainly a major mechanical function; only less than $0.5 \%$ is located in the exchangeable pool and available for homeostasis.

The plasma calcium concentration is critical and regulated within narrow limits - approximately $8.8-10.5 \mathrm{mg} / 100 \mathrm{ml}$ in healthy man (1). About $60 \%$ of the plasma calcium is ionized and physiologically active. Not only is its constancy vital to nerve and muscle function but it has become increasingly clear that whenever excitation of tissue coupled to a response takes place, a calcium dependency exists. When a nerve or muscle cell is stimulated, a marked, brisk increase in free intracellular calcium is one of the essential changes to occur. For instance, in resting muscle cells intracellular free calcium ion concentration in the cytosol is less than $10^{-7} \mathrm{M}$. This increases tenfold during excitation as calcium ions are released from the sarcoplasmatic reticulum in response to cell depolarisation (2). It then assumes the role of "second" or "third messenger" (3) and the cells are being instructed to produce the appropriate response, such as the release of neurotransmittor or muscle contraction. Similarily, most hormones studied trigger transient increases in the calcium concentration of their target cells. Also, all endocrine glands thus far tested have been shown to have a calcium dependent secretion step and a number of enzymes are activated and stabilized by calcium (4).

How calcium is involved in these mechanisms is not known but increased secretory responses have been demonstrated in the presence of hypercalcemia for cells producing glucocorticoids (5) and renin (6), while hypercalcemic challenges are frequently used in the diagnosis of gastrin- (7), insulin- (8) and calcitonin- (9) secreting tumors. 
Moreover, calcium is needed for intercellular bridging, essential to nutrition as well as to communication and for control of growth and cellular movement, including the chromosomal separation during cell division and the beating of the flagellae or cilia that propel single-celled organisms $(10,11)$.

Although the matter of the exact mechanism by which calcium produces its diverse effects lies beyond the scope of this study, it is interesting to note the recent discovery of a multifunctional intracellular calcium receptor protein, calmodulin, that promises to completely convert the ruling insights in intracellular calcium homeostasis.

Availability of calcium in the blood is secured by two sources of supply, the diet and the calcium reservoir in bone. Calcium homeostasis is regulated through the mechanisms of gut absorption, tubular reabsorption in the kidney and bone resorption. These processes are influenced by many factors, the most important of which are the parathyroid hormone (PTH) and the hormones derived from the renal metabolism of vitamin $\mathrm{D}$. The role of endogenous calcitonin is still controversial, but there are several other hormones which have some influence on calcium metabolism, including thyroid hormone, growth hormone and the adrenal and gonadal steroids.

The daily dietary intake of calcium in adult man is about $600-1000 \mathrm{mg}$. Sodium is required for active transport and phosphate is usually absorbed with calcium. Although calcium is most efficiently absorbed by the duodenal mucosa, the small bowel distal to this is the site of most calcium absorption in man, due largely to the much greater length of time of contact. Absorption varies during life. Adults absorb about $20 \%$ of their dietary intake while in growing children absorption can be as much as $90 \%$. These variations are mediated chiefly by changes in the activation of vitamin $\mathrm{D}$ which stands central in the active transport mechanism. Calcium is also secreted into the intestinal tract by the cells lining it and in bile but much of it is reabsorbed later. It is estimated that in man only about $130 \mathrm{mg} /$ day appears in the feces under normal circumstances (12). Urinary output of $100 \mathrm{mg} /$ day usually is sufficient to balance intestinal absorption and excretion. The most important regulators of calcium homeostasis will be discussed briefly.

\section{I.I.I. PARATHYROID HORMONE (PTH)}

Prior to 1962, the regulation and homeostasis of serum calcium concentration was ascribed primarily to the parathyroid glands through a negative feedback system, which works in the following way: a fall in serum calcium ion concentration stimulates secretion of PTH, which than acts on the bone, kidney and the G.I. tract to raise the serum calcium to normal. These interrelationships between serum calcium ion and PTH secretion are still valid and it now seems likely that the calcium ion also influences PTH synthesis (13). More recently, another feed back system has been proposed in which PTH stimulates 1,25 $(\mathrm{OH})_{2} \mathrm{D}_{3}$ synthesis, $1,25(\mathrm{OH})_{2} \mathrm{D}_{3}$ in turn increases $24,25(\mathrm{OH})_{2} \mathrm{D}_{3}$ formation; and PTH secretion is blocked by $24,25(\mathrm{OH})_{2} \mathrm{D}_{3}$ (14). 


\section{Chemistry}

PTH is a 84 amino acid, single-chain polypeptide; only the 34 terminal amino acids are necessary for biological activity. There is evidence that cleavage occurs naturally to produce a short $\mathrm{N}$-terminal, biologically active fragment and larger, inactive $\mathrm{C}$-terminal and $\mathrm{C}$-regional fragments. The $\mathrm{C}$-terminal fragment represents the major component that is measured in most radioimmunoassays for PTH.

\section{Source}

PTH is synthesized in and released from the parathyroid glands.

Mechanism of action

PTH stimulates adenyl cyclase activity and formation of cyclic 3', 5'-AMP in both bone and kidney $(15,16)$. Increased urinary AMP can be detected after administration of PTH.

\section{Actions}

1. Kidney:

- increases phosphate and potassium excretion by inhibition of tubular reabsorption (17).

- increases calcium and magnesium net-reabsorption (18).

- decreases bicarbonate reabsorption and inhibits $\mathrm{H}^{+}$excretion (acidosis) (19).

2. Bone:

The effect of PTH on bone is still controversial and can be both anabolic and catabolic (20).

- increases release of calcium and phosphate mediated by cyclic AMP through its action on osteocytes and stimulation of osteocytic osteolysis $(16,21,22)$.

- possibly influences bone remodeling through osteoblast an osteoclast stimulation and formation $(23,24)$.

3. Gut:

Although the effects of PTH on calcium absorption are unsettled, some evidence exists to suggest that it increases calcium and phosphate transport through its inotropic effect on the hydroxylation of $25(\mathrm{OH}) \mathrm{D}_{3}$ into 1,25 $(\mathrm{OH})_{2} \mathrm{D}_{3}$ in the kidneys.

\subsubsection{VITAMIN D}

The other agent long recognized to play a basic role in calcium homeostasis is vitamin D. Mainly through the important work of Lund and DeLuca e.a. it has become clear that this sterol hormone is undoubtedly a major physiologic regulator of mineral metabolism in man (25). At least two forms, vitamin $\mathrm{D}_{2}$ and vitamin $D_{3}$ play a role.

\section{Chemistry and metabolism}

U.V.-radiation breaks carbon-carbon bond at positions 9 and 10 converting 7 hydroxy-cholesterol in the skin to cholecalciferol (vitamin $D_{3}$ ). In order for vitamin $\mathrm{D}$ to be active in moving calcium, it must first be transformed by hydroxylation in the liver into 25 -hydroxycholecalciferol $\left(25(\mathrm{OH}) \mathrm{D}_{3}\right)$. This me- 
tabolite proves to be 1,5 times more active than vitamin $\mathrm{D}$ but it was discovered that it is converted very rapidly to more polar metabolites prior to its initiation of intestinal calcium transport $(26,27,28)$. Finally, conclusive evidence was found that by 1-hydroxylation of $25(\mathrm{OH}) \mathrm{D}_{3}$ the most biologically potent form of vitamin $\mathrm{D}$ is formed, $1,25(\mathrm{OH})_{2} \mathrm{D}_{3}(29)$, ten times more active than vitamin $\mathrm{D}_{y}$ itself in the stimulation of intestinal calcium transport, the mobilisation of calcium from bone and the prevention and cure of rickets. This hydroxylation takes place uniquely in the kidney $(30,31)$ and an attractive model in which the hydroxylation of $25(\mathrm{OH}) \mathrm{D}_{3}$ in the kidney becomes the control point in a feedback system for regulating serum calcium and phosphate levels was proposed $(32,33)$. Serum calcium levels are proposed to modulate PTH release such that enhanced secretion in response to low serum Ca stimulates 1,25 $(\mathrm{OH})_{2} \mathrm{D}_{3}$ production by the kidney. Interestingly, low serum phosphate may directly stimulate $1,25(\mathrm{OH})_{2} \mathrm{D}_{3}$ production as well. Increased intestinal absorption of both calcium and phosphate follow in response to a rise in 1,25 $(\mathrm{OH})_{2} \mathrm{D}_{3}$. PTH, which is secreted only in response to low serum calcium, may correct overshoots in serum phosphate by inhibiting renal reabsorption of this anion (34).

\section{Sources}

- Dietary absorption for which bile salts and dietary fat are necessary.

- Conversion of provitamins 7 dehydrocholesterol and ergosterol in the epidermal layers of the skin by $U-V$ light to vitamin $D_{3}$ and $D_{2}$ respectively.

\section{Mechanism of action, action}

1. Kidney:

$99 \%$ of the calcium filtered by the kidney is reabsorbed even in vitamin $D$ deficiency, rendering any influence of vitamin $D$ on calcium reabsorption of questionable importance (35). Also, the hypercalcemic effect of vitamin $D$ in hypoparathyroidism is accompanied by hypercalcuria (36). Nevertheless, an effect of $1,25(\mathrm{OH})_{2} \mathrm{D}_{3}$ to stimulate the renal reabsorption of calcium has been reported (37). Also direct promotion of phosphate retention in the proximal tubules $(38,39)$ and suppression of the phosphaturia caused by PTH take place (33).

2. Bone:

$1,25(\mathrm{OH})_{2} \mathrm{D}_{3}$ is the active metabolite that has been identified to mobilize calcium and possibly phosphorus from bone $(40,41)$. The involvement of PTH in this resorption has not been clarified. New mineralisation of bone with the mobilized calcium may be regulated by a different metabolite of vitamin $\mathrm{D}$ than $1,25(\mathrm{OH})_{2} \mathrm{D}_{3}$.

3. Gut:

The main action of vitamin $D$ takes place in the gut where two distinct transport systems are being directed for the absorption of calcium and phosphate. Vitamin D is essential for adequate calcium absorption. The net result of its action on the gut is the raising of serum calcium and phosphorus to permit normal skeletal mineralisation, as well as other physiologic functions of these minerals. The vitamin is capable of doing this by altering the properties of the microvillar surface at the intestinal brush-bor- 
der membrane (35) to allow entry of these ions into the cell against an electrochemical gradient (42). Also calcium-binding protein, which binds one mole calcium per mole, and other components of the intestinal transport systems for calcium and phosphate are promoted by binding of the vitamin to a specific cytosol protein (41).

\subsubsection{CALCITONIN}

In 1962, Copp and his group (44) first proposed the secretion of a factor which actively lowered the serum calcium concentration. By perfusing the canine thyroid and parathyroid glands with hypercalcemic blood, they demonstrated a significant fall in systemic serum calcium greater in magnitude and earlier in time than occurred following parathyroidectomy. They termed this calciumlowering factor calcitonin. In 1973 Hirsch e.a. (45) reported that parathyroidectomy by cautery was much more effective in lowering the serum calcium concentration of rats than removal of these glands by excision. Cauterization of other areas of the thyroid gland also resulted in a similar lowering of serum calcium. Extracts of rat thyroid glands were found to produce hypocalcemia and hypophosphatemia when injected into other experimental animals. They called this active product thyrocalcitonin. Since that time, thyroid extracts of each mammal studied, including man, have been found to contain this hypocalcemic substance.

\section{Source and chemistry}

In fish, fowl and amphibians $(46,47)$ calcitonin is found primarily in the ultimobranchial bodies - glandular structures derived from the lowest branchial pouches embryologically. The cells which secrete calcitonin were previously known as parafollicular, epifollicular or light cells $(48,49)$. Now they are referred to as C-cells $(49,50)$. They originate in the neural crest (51) and migrate to the ultimobranchial body. In mammals, C-cells are incorporated into the lateral thyroid lobes during embryonic development. In lower animals, they are found within the ultimobranchial body which remains as a separate glandular structure. Calcitonin has been purified from many different mammalian species (52-55) and from salmon ultimobranchial glands as well $(56,57)$. In man, medullary carcinoma of the thyroid has been found to be a C-cell tumor and to contain and secrete calcitonin. Calcitonin $\mathrm{M}$ has been purified from this tumor (58). Each of the calcitonins has a molecular weight of about 3500 and consists of 32 amino acids with a 1-7 disulfide bridge at the amino terminal end and a prolinamide as the carboxyl terminal residue. Numerous amino acid differences are present within the calcitonin molecules of different species, however. Porcine and Salmon CT are active in man; of the two, Salmon CT has a longer half-life and produces a more prolonged hypocalcemia in man.

\section{Mechanism of action}

Calcitonin results in a decrease in serum calcium and phosphorus when injected into the experimental animal. These effects are the result of an inhibition of 
bone resorption (59). This hypocalcemic action has been utilized as a bioassay of calcitonin activity (60). More recently, radioimmunoassay systems have been developed for the measurement of porcine (61-63) human $(9,64,65)$, salmon (66) and rat (67) calcitonin. These are much more specific and sensitive than bioassay. Interestingly, there is now evidence that calcitonin may be involved in zink $(\mathrm{Zn})$ metabolism and may be diabetogenic as well.

\section{Secretion}

Numerous substances have been found to influence the release of calcitonin from the thyroid gland. Calcium ion was the first of these to be recognized. Primarily calcitonin secretion is stimulated by increased calcium concentration, and there is a proportional relationship between serum calcium concentration and secretion of calcitonin. At normal serum calcium levels it is measurable in the circulation of animals and man.

In in vitro studies using slices of pig thyroid glands, it has been found that magnesium ion, theophylline, glucagon and dibutyryl-cyclic AMP (68) also stimulate the release of this peptide. Calcium and cyclic AMP have been shown to stimulate synthesis as well as release of calcitonin (69). More recently (70), it has been demonstrated in vitro that calcitonin release may be increased by the pituitary hormones TSH and prolactin, prostaglandin $\mathrm{E}_{\mathrm{n}}$, thyroxin, and the adrenergic agents, ephinephrine and norepinephrine. In this system release is inhibited by dopamine and by propranolol under specific circumstances, while secretin, parathyroid hormone, $25(\mathrm{OH}) \mathrm{D}_{3}, \mathrm{FSH}, \mathrm{LH}, \mathrm{GH}$ and insulin do not influence release of this polypeptide. In in vivo studies, increased calcitonin secretion has been shown to occur in response of calcium and magnesium ions (71), catecholamines (72) and dibutyryl-cyclic AMP (73). The effects of gastrointestinal hormones on calcitonin secretion will be discussed in chapter II.

Although calcitonin is clearly present in human thyroid and secreted under certain circumstances, its physiologic role in man is unknown. Total removal of the thyroid gland does not cause impairment of calcium homeostasis, whereas parathyroidectomy causes hypocalcemia. Administration of calcitonin in pharmacologic doses can be useful in disorders with very high rates of bone turnover (such as Paget's disease), but the hormone seems to have little or no effect on normal bone. It may play an as yet unidentified role in skeletal development but whereas the effects of PTH and vitamin D on calcium and phosphorus transport in bone, kidney, and gut play a major role in maintaining a normal serum calcium, the exact physiologic significance of calcitonin remains unresolved.

\subsection{REFERENCES}

1. McLean, F.C. and Urist, M.R. (1955): Bone. Chicago, University of Chicago Press, 1955.

2. Ebashi, S. (1976): Excitation - contracting coupling. Ann. Rev. Physiol. 38, p. 293.

3. Berridge, M.J. (1975): The interaction of cyclic nucleotides and calcium in the control of cellular activity. In: Advances in cyclic nucleotide Research 6, ed. by Greengard, P. and Robison, G.A., New York, Raven Press, p. 1. 
4. Bondy, P. $\mathbb{K}$. and Rosenberg, L.E. (1980): Molecular basis for homone action. In: Metabolic control and disease, ed. by W.B. Saunders Comp., p. 126.

5. Cushing, P. and David, D. (1972): Stimulation of adrenal corticosteroid secretion by hypercalcemia in the dog. Proc. Soc. Exp. Biol. Med. 139, p. 709.

6. Llach, F., Weidmann, P., Reinhart, R., Maxwell, M.H., Colwin, J.W. and Massry, S.G. (1974): Effect of acute and longstanding hypercalcenia on blood pressure and plasma renin activity in man. J. Clin. Endocrinol. Metab. 38, p. 841.

7. Passaro, E. Jr., Basso, N., Sanchez, R.E. and Gordon, H.E. (1970): Newer studies in the Zollinger-Ellison syndrome. Am. J. Surg. 120, p. 138.

8. Kaplan, E.L., Rubenstein, A.H., Evans, R., Lee, C.H. and Klementschitsch, P. (1979): Calcium infusion, a new provocative test for insulinomas. Ann. Surg. 190 , p. 501 .

9. Tashjian, A.H. Jr., Howland, B.G., Melvin, K.E.W. and Stratton Hill, C. (1970): Immuno assay of human calcitonin: clinical measurement, relation to serum calcium and studies in patients with medullary carcinoma. N. Engl. J. Med. 283, p. 890.

10. Pastan, I.H., Johnson, G.S. and Anderson, W.B. (1975): Role of cyclic nucleotides in growth control. Ann. Rev. Biochem. 44, p. 491.

11. Rasmussen, H. and Goodman, D.B.P. (1975): Calcium and CAMP as interrelated intracellular messengers. Ann. N.Y. Acad. Sci. 253, p. 789.

12. Bondy, P.K. and Rosenberg, L.E. (1980): Bone metabolism and disease. In: Metabolic control and disease, ed. by W.B. Saunders Comp., p. 1719.

13. Raisz, L.G., Au, W.Y.W. and Stern, P.H. (1965): Regulation of parathyroid activity. In: The parathyroid glands: Ultrastructure, secretion and function, ed. by Gaillard, P.J., Talmage, R.V. and Bundy, A.M., Chicago, University of Chicago Press.

14. Canterbury, J.M., Lermin, S., Claflin, A.J., Henry, H. and Norman, A. W. (1978): Inhibition of parathyroid hormone secretion by 24,25 dillydroxy vitamin D3 in the dog. J. Clin. Invest. 61, p. 1375.

15. Chase, L.R. and Aurbach, G.D. (1970): The effect of parathyroid hormone on the concentration of adenosine 3' 5' monophosphate in skeletal tissue in vitro. J. Biol. Chem. 245, p. 1520.

16. Biddulph, D.M. and Wrenn, R.W. (1977): Effects of parathyroid hormone on cyclic AMP, cyclic GMP and efflux of calcium in isolated renal tubules. Cyclic Nucleotide Res. 3, p. 129.

17. Dennis, V.W., Bello-Reuss, E and Robinson, R.R. (1977): Response of phosphate transport to parathyroid hormone in segments of rabbit nephron. Am. J. Physiol. 233 , P. F29.

18. Bondy, P.K and Rosenberg, L.E. (1980): Bone metabolism and disease. In: Metabolic control and disease, ed. by W.B. Saunders Comp., p. 1723.

19. Arruda, J.A.L., Mascimento, L., Westenfelder, C, and Kurtzman, N.A. (1977): Enfect of parathyroid hormone on urinary acidification. Am. J. Physiol. 232, p. F429.

20. Parsons, J.A. (1976): Parathyroid physiology and the skeleton. In: Biochemistry and Physiology, ed. by Bourne, G.H., New York, Academic Press, p. 159.

21. Nijweide, P.J. and van der Plas, A. (1977): Effects of parathyroid hormone and calcitonin on calcium transport and other metabolic functions in different types of bone cells. Calcif. Tissue Res. (Suppl.) 24, p. R19.

22. Reynolds, J.J. and Dingle, J.T. (1970): A sensitive in vitro method for studying the induction and inhibition of bone resorption. Calcif. Tissue Res. 4, p. 339.

23. Herrmann-Erlee, M.P.M., Heersche, J.N.M., Hekkelman, J.W., Gaillard, P.J., Tregear, G.W., Parsons, J.A. and Potts, J.T. Jr. (1976): Effects on bone in vitro of bovine parathyroid hormone and synthetic fragments representing residues $1-34$, 2-34 and 3-34. Endocrinol. Res. Comm. 3, p. 21.

24. Roberts, W.E. (1975): Cell population dynamics of periodontal ligament stimulated with parathyroid extract. Am. J. Anat. 143, p. 363. 
25. Lund, J. and DeLuca, H.F. (1966): Biologically active metabolite of vitamin D3 from bone, liver and blood serum. J. Lipid. Res. 7, p. 739.

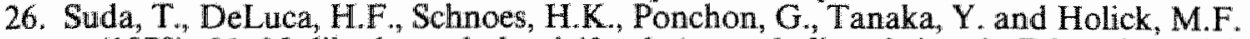
(1970): 21, 25-dihydroxycholecalciferol. A metabolite of vitamin D3 preferentially active on bone. Biochemistry 9, p. 2917.

27. Cousins, R.J., Deluca, H.F. and Gray, R.W. (1970): Metabolism of 25-hydroxycholecalciferol in target and non-target tissues. Biochemistry 9, p. 3649.

28. DeLuca, H.F., Suda, T., Schnoes, H.K., Tanaka, Y. and Holick, M.F. (1970): 25, 26dihydroxycholecalciferol, a metabolite of vitamin D3 with intestinal calcium transport activity. Biochemistry 9, p. 4776.

29. Tanaka, Y., Frank, H. and DeLuca, H.F. (1973): Biological activity of 1, 25-dihydroxy vitamin D3 in the rat. Endocrinology 92, p. 417.

30. Tanaka, Y. and DeLuca, H.F. (1971): Inhibition of the metabolism of 25-hydroxycholecalciferal by actinomycin $\mathrm{D}$ and cycloheximide. Proc. Nat. Acad. Sci. U.S.A. 68 , p. 1286.

31. Boyle, I.T., Miravet, L., Gray, R.W., Holick, M.F. and DeLuca, H.F. (1972): The response of intestinal calcium transport to 25 -hydroxy and 1,25 dihydroxy vitamin D3 in nephrectomized rats. Endocrinology 90, p. 605.

32. Norman, A.W. and Henry, H.L. (1974): 1, 25-dihydroxycholecalciferol - a hormonally active form of Vitamin D. Rec. Prog. Horm. Res. 30, p. 431.

33. DeLuca, H.F. and Schnoes, H.K. (1976): Metabolism and mechanism of action of Vitamin D. Am. Rev. Biochem. 45, p. 631.

34. Nellans, H.N., Kimberg, D.V. (1979): Intestinal calcium transport, absorption, secretion and vitamin D. Int. Rev. Physiol., Gastro-intestinal Physiology III, p. 227, ed. by Crane, R.K.

35. Haussler, M.R. and McCain, T.A. (1977): Basic and clinical concepts related to vitamin D metabolism and action (first of two parts). N. Engl. J. Med. 297, p. 974.

36. Rizzoli, R., Fleisch, H. and Bonjour, J.P. (1977): Effect of thyroparathyroidectomy on calcium metabolism in rats: role of 1,25-dihydroxy vitamin D3. Am. J. Physiol. 233 , p. El60.

37. Steele, T.H., Engle, J.E., Tanaka, Y., Lorence, R.S., Dudgeon, K.L. and DeLuca, H.F. (1975): Phosphatemic action of 1, 25 dihydroxy vitamin D3. Am. J. Physiol. 229, p. 489.

38. Pushett, J.B., Morantz, J. and Kurnick, W.S. (1972): Evidence for a direct action of cholecalciferol and 25-hydrocholecalciferol on the renal transport of phosphate, sodium and calcium. $J$. Clin. Invest. 51, p. 373.

39. Costanzo, L.S., Sheehe, P.R. and Weiner, I.M. (1974): Renal actions of vitamin D in D-deficient rats. Am. J. Physiol. 226, p. 1490.

40. Raisz, L.G., Trummel, C.L., Holick, M.F. and DeLuca, H.F. (1972): 1, 25-dihydrocholecalciferol: a potent stimulator of bone resorption in tissue culture. Science $175, \mathrm{p} .768$.

41. Garabedian, M., Tanaka, Y., Holick, M.F. and DeLuca, H.F. (1974): Response of intestinal calcium transport and bone calcium mobilization to 1, 25-dihydroxy vitamin D3 in thyroparathyroidectomized rats. Endocrinology 94, p. 1022.

42. Freedman, R.A., Weiser, M.M. and Isselbacker, K.J. (1977): Calcium transllocation by Golgi and lateral-basal membrane vesicles from rat intestine: decrease in vitamin D deficient rats. Proc. Nat. Acad. Sci. U.S.A. 74, p. 3612.

43. Taylor, C.M., Hughes, S.E. and DeSilva, P. (1976): Competitive protein binding assay for 24,25-dihydroxycholecalciferol. Biochem. Biophys. Res. Commun. 70, p. 1243.

44. Copp, D.H., Cameron, E.C., Cheney, B.A., Davidson, A.G.F. and Henze, K.G. (1962): Evidence for calcitonin - A new hormone from the parathyroid that lowers blood calcium. Endocrinology 70 , p. 368.

45. Hirsch, P.F., Gauthier, G.F. and Munson, P.L. (1963): Thyroid hypocalcemic principle and recurrent laryngea] nerve injury as factors affecting the response to parathyroidectomy in rats. Endocrinology 73, p. 244. 
46. Copp, D.H., Cockeroft, D.W. and Kueh, Y. (1967): Calcitonin from ultimobranchial glands of dogfish and chickens. Science 158, p. 924 .

47. Foster, G.V. (1968): Calcitonin (Thyrocalcitonin). N. Engl. J. Med. 279, p. 349.

48. Nonidez, J.F. (1932): The origin of the "Parafollicular" cell, a second epithelial component of the thyroid gland of the dog. Am. J. Anat. 49, p. 479.

49. Solcia, E., Capella, C., Sampietro, R. and Vasallo, G. (1970): The distribution of human C-cells and their relationship to osteopetrosis and medullary carcinoma of the thyroid, in: Calcitonin, 1969, Proceedings of the Second International Symposium, London, Heinemann.

50. Bussolati, G. and Pearse, A.G.E. (1967): Immunofluorescent localization of calcitonin in the "C" cells of pig and dog thyroid. J. Endocrinol. 37, p. 205.

51. Pearse, A.G.E. and Polak, J.M. (1971): Cytochemical evidence for the neural crest origin of mammalian ultimobranchial C cells. Histochemie 27, p. 96.

52. Potts, J.T. Jr., Niall, H.D., Kneutmann, H.B., Brewer, H.B. Jr. and Deftos, L.J. (1968): The amino acid sequence of porcine calcitonin. Proc. Natl. Acad. Sci. U.S.A. 59 , p. 1321.

53. Neher, R., Riniker, H., Zuber, H., Rittel, W. and Kahnt, F.W. (1968): Thyrocalcitonin. II. Struktur von Thyrocalcitonin. Helw. Chim. Acta 51, p. 917.

54. Bell, N.H., Barg, W.R., Colucci, D.F., Daview, G.M., Dziobkowski, C, Englert, M.E., Heyder, E., Paul, R. and Snedeker, E.H. (1968): Purification and structure of porcine calcitonin-1. J. Am. Chem. Soc. 90, p. 2704.

55. Brewer, H.B. Jr, and Ronan, R. (1969): The amino acid sequence of bovine thyrocalcitonin. Proc. Nat. Acad. Sci. U.S.A. 68, p. 862.

56. O'Dor, R.K., Parkes, C.O. and Copp, D.H. (1969): Amino acid composition of salmon calcitonins. Canad. J. Biochem. 47, p. 823.

57. Keutmann, H.T., Parsons, J.A., Potts, J.T. Jr., and Schluester, R.J. (1970): Isolation and chemical properties of two calcitonins from salmon ultimobranchial glands. J. Biol. Chem. 245, p. 1491.

58. Neher, R., Riniker, B., Rittel, W. and Zuber, H. (1968): Menschliches calcitonin III. Struktur von Calleitonin M und D. Helv. Chim. Acta 51, p. 1900.

59. Aliapoulios, M.A., Goldhaber, P. and Munson, P.L. (1966): Thyrocalcitonin inhibition of bone resorption induced by parathyroid hormone in tissue culture. Science 151, p. 330.

60. Kumar, M.A., Slack, E., Edwards, A., Soliman, H.A., Baghdiantz, A., Foster, G.V. and MacIntyre, I. (1965): A biological assay for calcitonin. J. Endocrinol. 33, p. 469.

61. Arnaud, C.D., Littledike, T., Tsao, H.S. and Kaplan, E.L. (1968): Radioimmunoassay for calcitonin - A prelliminary report. Proc. Mayo Clinic 43, p. 496.

62. Deftos, L.J., Lee, M.R. and Potts, J.T. Jr. (1968): A radioimmunoassay for thyrocalcitonin. Proc. Nat. Acad. Sci. U.S.A. 60, p. 293.

63. Tashjian, A.H. Jr. (1969): Immunoassay for thyrocalcitonin I - the method and its serological specificity. Endocrinology 84, p. 140.

64. Deftos, L.J., Bury, A.E., Haebner, J.F., Slinger, F.R. and Potts, J.T. Jr. (1971): Immunoassay for human calcitonin. 1I. Clinical studies. Metabolism 20, p. 1129.

65. Sizemore, G., Arnaud, C., Goldsmith, R., Jordan, H. and Sheps, S. (1972): Calcium and parathyroid hormone (PTH) homeostasis in medullary thyroid carcinoma patients (MCT). Clin. Res. 20, p. 727.

66. Haebner, J.F., Singer, F.R., Neer, R.M., Deftos, L.J. and Potts, J.T. Jr. (1972): Metabolism of salmon and porcine calcitonin, in: Calcium, parathyroid hormone and the parathyroids and calcitonins, ed. by Talmage, R.V. and Munson, P.L., Amsterdam, Excerpta Medica, p. 152.

67. Burford, H.J., Ontjes, D.A., Cooper, C.W., Parlow, A.F. and Hirsch, P.F. (1975): Purification, characterization and radioimmunoassay of thyrocalcitonin from rat thyroid glands. Endocrinology 96, p. 340. 
68. Bell, N.H. (1970): Effects of glucagon, dibutyryl-cyclic AMP, 3', 5' adenosine monophosphate and theophylline on calcitonin secretion in vitro. J. Clin. Invest. 49, p. 1368.

69. Bell, N.H. and Queener, S. (1974): Stimulation of calcitonin synthesis and release in vitro by calcium and dibutyryl-cyclic AMP. Nature 248, p. 343 .

70. Bell, N.H. (1975): Further studies on the regulation of calcitonin release in vitro. Horm. Metabl. Res. 7, p. 77.

71. Care, A.D., Bell, N.H. and Bates, R.F.L. (1971): The effects of hypermagnesemia on calcitonin secretion in vivo. J. Endocrinol. 51, p. 381.

72. Avioli, L.V., Shieber, W. and Kipnis, D.M. (1971): Role of glucagon and adrenergic receptors in thyrocalcitonin release in the dog. Endocrinology 88, p. 1337.

73. Care, A.D., Bates, R.F.L. and Gitelman, H.J. (1971): Evidence for a role of cyclic AMP in the release of calcitonin. Ann. N.Y. Acad. Sci. 185, p. 317. 
Chapter II

\section{BACKGROUND DATA AND GOALS OF THIS STUDY}

\section{II.1. GASTROINTESTINAL INFLUENCES ON CALCITONIN SECRETION}

Interest in the gastrointestinal tract and in G.I. hormones as stimulators of calcitonin secretion was prompted by a study of Gray and Munson (1) which suggested that a major role of calcitonin might be the prevention of hypercalcemia after eating. Munson, Cooper and Gray (2) in 1971 found that the administration of calcium chloride into the jejunum stimulated calcitonin secretion, although the amount of calcium administered was insufficient to increase the serum calcium concentration in peripheral plasma. They suggested that the signal to the thyroid was probably a humoral factor derived from the G.I. tract and not the rise in serum calcium itself. Various gastrointestinal hormones have been studied. In perfusion studies of the pig thyroid, it has been demonstrated that cholecystokinin (CCK), the C-terminal octapeptide of cholecystokinin (octa-CCK) $(3,5)$ and pentagastrin and other gastrins (4-7) resulted in an increase in calcitonin secretion. Endogenous secretion of G.I. hormones has also been demonstrated to release calcitonin. It has been shown in the pig, that endogenous gastrin rellease (stimulated by meat extracts or glycine instillation into the stomach or by gastric distention) is associated with elevated calcitonin secretion rates (8). The instillation of either fat or glucose in the duodenum has also been demonstrated to result in an increase in calcitonin secretion presumably due to the effects of CCK and glucagon respectively (8). $\ln$ in vitro studies using rat thyroid slices, calcitonin has been demonstrated to be released by gastrin, CCK, glucagon and serotonin (7). In addition, acetylcholine and methacholine resulted in a release of this polypeptide, which led Bell (9) to suggest that vagal stimulation might also play a role in the thyroid release of calcitonin. In man, pentagastrin has been demonstrated to release calcitonin from medullary carcinomas of the thyroid and is now one of the most reliable provocative agents for diagnosis of this tumor (10).

Thus, a great deal of evidence exists that some G.I. polypeptides administered in vivo and in vitro result in the release of calcitonin (CT). However, is the release and action of calcitonin the only mechanism which results in the hypocalcemia of G.I. origin? 


\section{II.2. PREVIOUS EXPERIMENTS}

Preliminary studies from the laboratory of E.L. Kaplan et al. (11-15,17,18) suggested that, in the rat, a mechanism of hypocalcemia related to the stomach might be important, perhaps even more important than the secretion of thyroid calcitonin.

It had been reported that in the rat, gastrin administration induces transient hypocalcemia similar to that observed following the injection of calcitonin and that this response is abolished by thyroparathyroidectomy (TPTX) (11).

Kaplan became interested in this, because previously in his laboratory, it was demonstrated that the injection of a tumor extract from an islet-cell carcinoma of the pancreas which resulted in the Zollinger-Ellison syndrome resulted in hypocalcemia in TPTX as well as in intact rats (12). The identity of this tumor-derived hypocalcemic factor was unknown; however, since gastrin was identified

Table 11.1: The effect of synthetic human gastrin (SHG) and porcine gastrin ( $P G)$ on serum calcium in both thyroid intact and thyroparathyroidectomized (TPTX) rats."

Serum calcium concentration $(\mathrm{mg} / 100 \mathrm{ml}$ )

Time after injection ( $\mathrm{min}$ )

Experiment

$30 \quad 60$

Thyroid Intact:

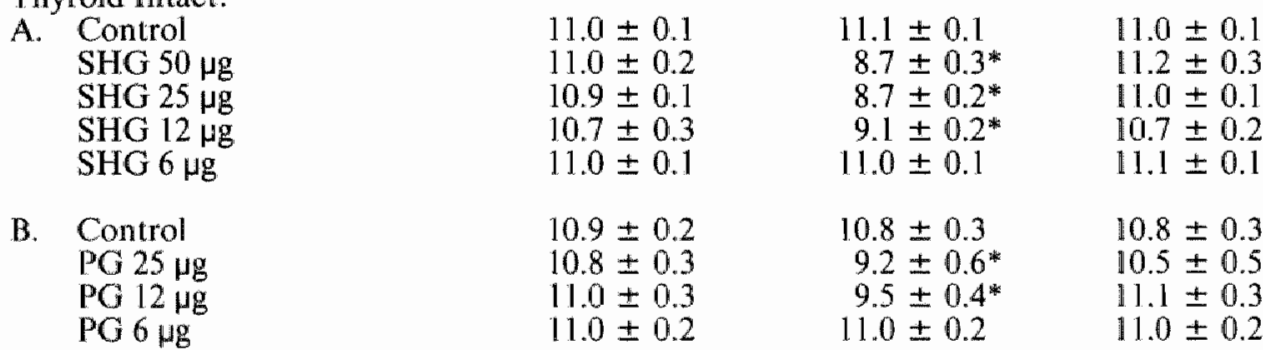

TPTX:

\begin{tabular}{|c|c|c|c|}
\hline $\begin{array}{l}\text { C. Control } \\
\text { SHG } 25 \mu \mathrm{g}\end{array}$ & $\begin{array}{l}8.4 \pm 0.3 \\
8.4 \pm 0.3\end{array}$ & $\begin{array}{l}8.7 \pm 0.2 \\
7.3 \pm 0.2^{*}\end{array}$ & $\begin{array}{l}8.6 \pm 0.2 \\
8.3 \pm 0.3\end{array}$ \\
\hline $\begin{array}{l}\text { D. Control } \\
\text { PG } 25 \mu \mathrm{g} \\
\text { PG } 12 \mu \mathrm{g}\end{array}$ & $\begin{array}{l}7.3 \pm 0.3 \\
6.9 \pm 0.4 \\
7.4 \pm 0.4\end{array}$ & $\begin{array}{l}7.3 \pm 0.2 \\
5.7 \pm 0.5^{* *} \\
6.5 \pm 0.6^{* * *}\end{array}$ & $\begin{array}{l}7.3 \pm 0.2 \\
6.8 \pm 0.4 \\
7.3 \pm 0.2\end{array}$ \\
\hline
\end{tabular}

Each value represents the mean plus and minus the SD for experimental groups of five rats each. Statistical significance was determined using the Student's t Test.

* $\mathrm{p}<0.001$

$* * \mathrm{p}<0.01$

$* * * \mathrm{p}<0.05$

From: Schulak, J.A. and Kaplan, E.L., 1974: Metabolism 23, p. 1103 (13).

A) All tables in this chapter were reproduced with permission of the authors. 
with certainty from the tumor, the effect of this peptide in intact and TPTX rats was investigated. It was found (13) that both synthetic human gastrin 1 and porcine gastrin administered to the rat resulted in striking hypocalcemia. In animalls in which TPTX was performed 18 hours previously, a hypocalcemic response to gastrin was still clearly demonstrable (table 1).

On the basis of these experiments, it was suggested that while gastrin might act as a calcitonin secretagogue in the rat, it was unlikely that this was the sole mechanism of gastrin-induced hypocalcemia. Since removal of the thyroid gland did not abolish the hypocalcemic response of gastrin, a mechanism other than the release of thyroid calcitonin seemed likely. In order to clarify the mechanism by which gastrin produces hypocalcemia, further studies were performed (14). Gastrin was administered to animals in whom other organ resections had been performed. As demonstrated in table 2, in thyroid-intact animals, neither nephrectomy nor enterocolectomy (defined as the removal of the small and large intestines, pancreas and spleen), altered the effectiveness of gastrin in producing hypocalcemia.

Table II.2: The effect of gastrin on serum calcium in rats after various organ resections.

Serum calcium concentration $(\mathrm{mg} / 100 \mathrm{ml}$ )

Time after injection ( $\mathrm{min})$

Experiment

0

30

60

A. Thyroid intact:

Control $(\mathrm{NaCl})$

No resection

Nephrectomy

Enterocolectomy

Gastrectomy (NaCl)

Gastrectomy

B. TPTX:

Control ( $\mathrm{NaCl})$

No resection

Adrenalectomy

Enterocolectomy

Gastrectomy $(\mathrm{NaCl})$

Gastrectomy Exp. 1

Gastrectomy Exp. 2
$10.8 \pm 0.1$

$10.9 \pm 0.1$

$10.8 \pm 0.2$

$11.1 \pm 0.2$

$10.8 \pm 0.3$

$10.8 \pm 0.2$
$10.8 \pm 0.1$

$8.5 \pm 0.2^{*}$

$7.9 \pm 0.2^{*}$

$9.2 \pm 0.3^{*}$

$10.8 \pm 0.3$

$10.7 \pm 0.2$

$7.9 \pm 0.4$

$6.6 \pm 0.4 *$

$8.4 \pm 0.3^{*}$

$6.4 \pm 0.4^{*}$

$7.8 \pm 0.2$

$8.2 \pm 0.7$

$7.7 \pm 0.6$
$10.8 \pm 0.1$

$10.8 \pm 0.1$

$10.5 \pm 0.3$

$11.0 \pm 0.3$

$11.0 \pm 0.2$

$10.7 \pm 0.3$

Synthetic human gastrin I was used except in Section A, nephrectomy, where porcine gastrin was substituted. Gastrin dose was $25 \mu \mathrm{g} / \mathrm{rat}$ and control solution was normal saline adjusted to $\mathrm{pH} 8.0$. All injections were intravenous, in a volume of $0.2 \mathrm{ml} / \mathrm{rat}$. Values represent the mean $\pm \mathrm{SD}$ for experimental groups of 5 rats each.

${ }^{*} \mathrm{p}<0.001$, Student's $\mathrm{t}$ test.

From: Schulak, J.A. and Kaplan, E.L. (1975), Endocrinology 96, p. 1217 (14). 
Similary, hypocalcemia was noted to be present following gastrin administration to TPTX, TPTX-adrenalectomy and TPTX-enterocolectomy animals. However, whether the thyroid gland was present or absent, gastrectomy inhibited all gastrin induced hypocalcemia. Gastrectomy appeared to abolish the hypocalcemic response rather than to change the sensitivity of the animals to gastrin since doses of porcine gastrin which were clearly supraphysiologic $(50-100 \mu \mathrm{g}$ resulted in no change in serum $\mathrm{Ca}$.

The important site of origin for the gastrin-induced hypocalcemia appeared to be the proximal stomach since following resection of the gastric antrum gastrin injection still produced the hypocalcemia. When the antrum was present and the parietal cell mass excised, however, gastrin no longer produced a change in serum $\mathrm{Ca}$ concentration (Table 3 ).

Table 11.3: The effect of porcine gastrin (PG) on serum calcium in thyroid intact rats after sublotal gastrectomy.

Serum calcium concentration $(\mathrm{mg} / 100 \mathrm{ml})$

Time after injection (min)

Experiment

0

30

60

Experiment No. 1:

Thyroid intact control

Stomach intact - PG

Distal resection - $\mathrm{PG}$

Proximal resection - PG

$11.0 \pm 0.2$

$10.9 \pm 0.3$

$11.0 \pm 0.2$

$10.8 \pm 0.2$

$10.9 \pm 0.2$

$11.0 \pm 0.3$

$9.6 \pm 0.6^{*}$

$10.9 \pm 0.1$

$9.8 \pm 0.6^{*}$

$11.0 \pm 0.1$

$10.8 \pm 0.2$

$11.0 \pm 0.1$

Experiment No. 2:

Stomach intact - control

Stomach intact - PG

Distal resection - $\mathrm{PG}$

Proximal resection - $\mathrm{PG}$

$10.4 \pm 0.3$

$10.7 \pm 0.2$

$10.6 \pm 0.2$

$10.6 \pm 0.4$

ND

$10.8 \pm 0.4$

$9.4 \pm 0.2^{*}$

ND

$9.7 \pm 0.3 *$

ND

$10.9 \pm 0.4$

ND

N.D. assay not done.

Values represent the mean \pm SD for experimental groups of 5 rats each. Gastrin dose was $25 \mu \mathrm{g} / \mathrm{rat}$ and control solution was normal saline adjusted to $\mathrm{pH} 8$. All injections were intravenous and in a volume of $0.2 \mathrm{ml} / \mathrm{rat}$. Proximal resection (75\%) was equated to a parietal cell resection while distal resection (25\%) to an antrectomy.

* $\mathrm{p}<0.01$, Student's I test.

From: Schulak, J.A. and Kaplan, E.L. (1975): Endocrinology 96, p. 1217 (1.4).

Finally, in this study, Kaplan et al. demonstrated that the decrease in serum Ca following gastrin administration was not accompanied by a corresponding fall in serum phosphorus in either thyroid intact or "TPTX rats.

Thus, in the rat given gastrin: 1. the lack of hypophosphatemia with hypocallcemia, 2. the presence of hypocalcemia even after TPTX, and 3. the abolition of all hypocalcemia following gastrectomy in thyroid-intact animals, all suggested that thyroid release of calcitonin was not the major cause of the hypocalcemia. Rather a factor associated with the stomach seemed most important. The 
Table 11.4: The effect of histamine base, histamine phosphate, and betasole hydrochloride (histalog) on serum calcium concentration in the rat.

Serum calcium concentration $(\mathrm{mg} / 100 \mathrm{ml})$

Time after injection (min)

Experiment

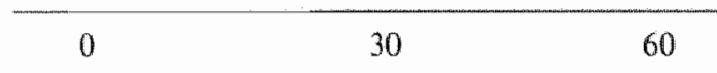

A. Histamine Base

(Exp. 1)

$0.125 \mathrm{mg}$

$0.250 \mathrm{mg}$

$0.500 \mathrm{mg}$

$1.000 \mathrm{mg}$

$2.000 \mathrm{mg}$

Control

$10.8 \pm 0.2$
$10.7 \pm 0.3$
$10.7 \pm 0.2$
$10.8 \pm 0.2$
$10.7 \pm 0.2$
$10.7 \pm 0.2$

$10.8 \pm 0.1$

$10.5 \pm 0.3$

$10.7 \pm 0.3$

$8.2 \pm 0.2^{*}$

$10.7 \pm 0.2$

$8.7 \pm 0.3^{*}$

$10.0 \pm 0.1$

$8.7 \pm 0.8^{*}$

$10.2 \pm 0.7$

$10.6 \pm 0.2$

$10.7 \pm 0.1$

$10.8 \pm 0.1$

(Exp. 2)

$0.250 \mathrm{mg}$

$0.500 \mathrm{mg}$

$10.8 \pm 0.1$

$10.8 \pm 0.1$

$10.8 \pm 0.1$

$10.8 \pm 0.1$

$8.3 \pm 0.3^{\text {* }}$

$10.8 \pm 0.1$

$10.7 \pm 0.1$

$10.8 \pm 0.2$

Control

$10.7 \pm 0.2$

$8.1 \pm 0.2^{*}$

$10.8 \pm 0.1$

B. Histamine Phosphate

(Exp. 1)

$0.687 \mathrm{mg}$

$1.375 \mathrm{mg}$

$11.0 \pm 0.3$

$10.8 \pm 0.4$

$10.8 \pm 0.2$

$9.6 \pm 0.7^{* *}$

$10.9 \pm 0.2$

Control

$11.0 \pm 0.2$

$10.8 \pm 0.1$

$11.1 \pm 0.3$

$11.0 \pm 0.2$

(Exp. 2)

$0.687 \mathrm{mg}$

$1.375 \mathrm{mg}$

$10.9 \pm 0.2$

$10.9 \pm 0.1$

$10.9 \pm 0.1$

Control

$10.8 \pm 0.1$

$10.9 \pm 0.2$

$9.1 \pm 0.6^{* *}$

$10.9 \pm 0.1$

$11.0 \pm 0.3$

$10.9 \pm 0.1$

C. Betazole Hydrochloride

(Exp. 1)

$2.5 \mathrm{mg}$

$5.0 \mathrm{mg}$

$10.0 \mathrm{mg}$

Control

$10.9 \pm 0.3$

$10.9 \pm 0.2$

$10.9 \pm 0.2$

$10.7 \pm 0.4$

$10.9 \pm 0.2$

$11.0 \pm 0.2$

$11.0 \pm 0.2$

$10.9 \pm 0.1$

$11.1 \pm 0.4$

$10.9 \pm 0.3$

$10.7 \pm 0.4$

$11.0 \pm 0.2$

(Exp. 2)

$2.5 \mathrm{mg}$

$5.0 \mathrm{mg}$

$11.0 \pm 0.2$

$10.9 \pm 0.2$

$10.9 \pm 0.2$

$10.9 \pm 0.3$

$10.9 \pm 0.2$

$11.0 \pm 0.2$

$10.8 \pm 0.3$

$10.9 \pm 0.1$

$10.9 \pm 0.3$

$10.7 \pm 0.4$

$11.1 \pm 0.4$

Control

Each value represents the mean plus and minus the standard deviation for experimental groups of five rats each. The control solution in experiments $\mathrm{A}$ and $\mathrm{C}$ was physiologic saline, while in $B$ it was $0.5 \mathrm{ml}$ of a $1.78 \mathrm{mM} \mathrm{NaH} \mathrm{PO}_{4}$ solution. Statistical significance was determined using the Student's t test.

* $\mathrm{p}<0.001$

$* * \mathrm{p}<0.05$

From: Norberg, H.P., Schulak, J.A., Atlas, B. and Kaplan, E.L. (1976): Metabolism 25, p. 131 (15). 
mechanism by which the stomach influenced calcium homeostasis was unknown. Since one possibility related to changes associated with gastric acid secretion, other gastric acid secretagogues were tried in the same rat model. Histamine (15) given either as histamine base or histamine phosphate resulted in a hypocalcemic response, similar in magnitude and in its time course to that which follows gastrin administration (Table 4).

Table II.5: The effect of thyroparathyroidectomy (TPTX) and gastrectomy on the response of rats to histamine.

Serum calcium concentration $(\mathrm{mg} / 100 \mathrm{ml}$ )

Time after injection ( $\mathrm{min})$

Experiment

$0 \quad 30$

60

A. TPTX 2 hr pre-assay:

(Exp. No. I)

Intact - Control

Intact - $1.0 \mathrm{mg}$ Histamine

TPTX - Control

$10.9 \pm 0.1$

$10.8 \pm 0.2$

$10.8 \pm 0.1$

$10.9 \pm 0.1$

TPTX - $1.0 \mathrm{mg}$ Histamine

$9.4 \pm 0.3$

$8.6 \pm 0.6^{* *}$

$10.7 \pm 0.2$

$9.3 \pm 0.4$

$9.5 \pm 0.3$

$9.5 \pm 0.4$

$7.9 \pm 0.4^{*}$

$8.5 \pm 0.2 * * *$

(Exp. No. 2)

TPTX - Control

TPTX $-1.0 \mathrm{mg}$ Histamine

$9.2 \pm 0.6$

$9.1 \pm 0.6$

$8.9 \pm 0.5$

$7.3 \pm 0.6^{*}$

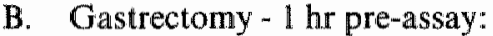

(Exp. $\mathrm{No}_{n}$ 1)

Stomach intact

Control

$11.0 \pm 0.2$

$10.9 \pm 0.2$

$10.8 \pm 0.2$

$9.0 \pm 0.3^{*}$

$10.8 \pm 0.3$

$1.0 \mathrm{mg}$ Histamine

$0.8 \pm 0.2$

$10.9 \pm 0.1$

$10.7 \pm 0.3$

$10.8 \pm 0.1$

Gastrectomy

Control

$1.0 \mathrm{mg}$ Histamine

$10.7 \pm 0.1$

$10.8 \pm 0.1$

$10.8 \pm 0.2$

(Exp. No. 2)

Stomach intact

Control

$1.0 \mathrm{mg}$ Histamine

$11.0 \pm 0.2$

$10.8 \pm 0.2$

$10.9 \pm 0.2$

$10.8 \pm 0.1$

$9.4 \pm 0.8^{*}$

$10.8 \pm 0.3$

$2.0 \mathrm{mg}$ Histamine

$9.1 \pm 0.6^{*}$

$10.7 \pm 0.3$

Gastrectomy

Control

$10.7 \pm 0.2$

$10.8 \pm 0.2$

$10.6 \pm 0.3$

$1.0 \mathrm{mg}$ Histamine

$2.0 \mathrm{mg}$ Histamine

$10.7 \pm 0.3$

$10.8 \pm 0.1$

$10.7 \pm 0.1$

$10.8 \pm 0.3$

$10.8 \pm 0.2$

$10.8 \pm 0.1$

$10.9 \pm 0.2$

The values represent mean \pm standard deviation for groups of 5-7 rats. Control solution was physiologic saline and all injections were intravenous and in a volume of $0.5 \mathrm{ml} / \mathrm{rat}$.

* $\mathrm{p}<0.001$

$* * \mathrm{p}<0.005$

***p $<<0.025$

From: Kaplan, E.L., Norberg, H.P., Schulak, J.A. and Hill, B.J. (1976): Metabolism 25, p. 1151 (17). 
The effect of histamine was not due to hemodilution, for at the time of hypocalcemia, neither hematocrit nor total protein concentrations differed from control values.

However, betazole hydrochloride (Histalog) administration, in doses up to $10 \mathrm{mg} / \mathrm{rat}$, did not result in any change in serum calcium concentration. Perhaps this failure can be explained by the fact that, although it acts as a potent gastric acid stimulator in man, this drug is not effective in the rat (16).

In order to clarify the mechanism by which histamine induces hypocalcemia in the rat, the effect of this drug given after various organ resections was studied (17). Thyroparathyroidectomy, performed two hours previously, did not abolish the calcium lowering action of histamine. However, following gastrectomy, histamine administration resulted in no change in the serum calcium concentration (Table 5).

In addition, it was demonstrated (18) that cholecystokinin and the C-terminal octapeptide (octa-CCK) are also hypocalcemic agents in the rat. The hypocal-

Table II.6: The effect of thyroparathyroidectomy and gastrectomy on CCK-and octa-CCKinduced hypocalcemia.

Serum calcium concentration $(\mathrm{mg} / 100 \mathrm{ml})$

Time after injection (min)

Experiment

0

30

60

A. Intact

Saline

$\mathrm{CCK}, 10$ units

Octa-CCK, $0.5 \mu \mathrm{g}$

$10.7 \pm 0.3$

$10.9 \pm 0.1$

$10.7 \pm 0.3$

$10.7 \pm 0.3$

$10.8 \pm 0.4$

$9.0 \pm 0.5^{*}$

$10.7 \pm 0.4$

TPTX

Saline:

CCK, 10 units

Octa-CCK, $0.5 \mu \mathrm{g}$

$10.4 \pm 0.3$

$10.3 \pm 0.6$

$8.8 \pm 0.2 *$

$10.5 \pm 0.3$

B. Intact:

Saline

CCK, 10 units

Octa-CCK, $0.5 \mu \mathrm{g}$

$10.4 \pm 0.4$

$10.1 \pm 0.5$

$10.2 \pm 0.5$

$9.0 \pm 0.6^{* *}$

$10.4 \pm 0.5$

$8.9 \pm 0.5^{* *}$

$10.2 \pm 0.1$

Gastrectomy:

Saline

$10.9 \pm 0.2$

$10.9 \pm 0.1$

$10.9 \pm 0.1$

$10.9 \pm 0.1$

$8.8 \pm 0.2^{*}$

$10.7 \pm 0.4$

$10.8 \pm 0.1$

$8.3 \pm 0.2^{*}$

$10.7 \pm 0.4$

CCK, 10 units

Octa-CCK, $0.5 \mu \mathrm{g}$

$10.9 \pm 0.1$

$10.9 \pm 0.1$

$10.8 \pm 0.1$

$10.8 \pm 0.1$

$10.8 \pm 0.1$

$10.8 \pm 0.1$

$10.4 \pm 0.1$

$10.9 \pm 0.1$

$10.9 \pm 0.1$

Each value represents the mean \pm standard deviation of groups of five rats. Student's $t$ test.

* $\mathrm{p}<0.001$

* $\mathrm{p}<0.05$

From: Stulberg, B., Norberg, H.P. and Kaplan, E.L. (1976): Surgical Forum 27, p. 430 (18). 
cemic effect of these two agents was not abolished by thyroparathyroidectomy performed two hours prior to assay (Table 6).

However, gastrectomy completely eliminated all hypocalcemia.

\subsection{QUESTIONS TO BE ANSWERED}

Gastrin, CCK and octa-CCK are known calcitonin secretagogues. However, these data offer strong evidence that the hypocalcemia associated with their administration in the rat is not due to the thyroid release of calcitonin but rather is dependent upon a factor associated with the stomach. In order to further investigate this mechanism the following questions will have to be answered:

1. If, during administration of acid secretagogues, acid secretion is blocked, will hypocalcemia still occur?

2. Is calcitonin indeed unimportant in this mechanism, - or is it being secreted "ectopically" by the stomach,

- or is it being secreted elsewhere and does it need the stomach to be effective?

3. Is the hypocalcemia induced by acid secretagogues the result of stimulation of secretion of another calcium-lowering amine or peptide from the proximal stomach?

4. Where does calcium go when hypocalcemia occurs? From previous experiments it is known that renal excretion or intestinal absorption/excretion are not involved.

- Is calcium being secreted into the gastric juice,

- or does it accumulate in the stomach wall as a second messenger to acid secretion,

- or is it primarily controled by the bone metabolism, in other words, how is the bone metabolism affected by the injection of acid secretagogues?

5. What is the exact role of the gastric acid secretory process in the hypocalcemia?

6. If this hypocalcemic principle can be identified, what is its significance?

\subsection{REFERENCES}

1. Gray, T.K. and Munson, P.L. (1969): Thyrocalcitonin: Evidence for physiological function. Science 166, p. 112.

2. Munson, P.L., Cooper, G.W. and Gray, T.K. (1971): Physiological importance of thyrocalcitonin. In: Cellular mechanism for calcium transfer and homeostasis. Ed. by Nicols, C.J. and Wasserman, R.H., N.Y. Acad. Press, p. 404.

3. Care, A.D., Bruce, J.B., Boelkins, J., Kenny, A.D., Conaway, H. and Anast, C.S. (1971): Role of pancreozymin - cholecystokinin and structurally related compounds as calcitonin secretagogues. Endocrinology 89, p. 262.

4. Care, A.D., Bates, R.F.L., Swaminathan, R. and Ganguli, P.C. (1971): the role of gastrin as a calcitonin secretagogue. J. Endocrinol. 51 , p. 735. 
5. Cooper, C.W., Schwesinger, W.H., Ontjes, D.A., Mahgoub, A.M. and Munson, P.L. (1972): Stimulation of secretion of pig thyrocalcitonin by gastrin and related hormonal peptides. Endocrinology 91, p. 1079.

6. Care, A.D. and Bruce, J.B. (1971): Calcitonin-releasing substances: Structure-activity relationship. J. Endocrinol. 49, p. 8.

7. Cooper, C.W., Schwesinger, W.H., Mahgoub, A.M. and Ontjes, D.A. (1971): Thyrocalcitonin stimulation of secretion by pentagastrin. Science $172, \mathrm{p} .1238$.

8. Swaminathan, R., Bates, R.F.L., Bloom, S.R., Ganguli, P.C. and Care, A.D. (1973): The relationship between food, gastrointestinal hormones and calcitonin secretion. J. Endocrinol. 59, p. 217.

9. Bell, N.H. and Queener, S. (1974: Stimulation of calcitonin synthesis and release in vitro. Horm. Metabl. Res. 7, p. 77.

10. Sizemore, G.W. and Go, V.L.W. (1975): Stimulation tests for diagnosis of medullary thyroid carcinoma. Mayo Clin. Proc. 50 , p. 53.

11. Cooper, C.W., Biggerstaff, C.R., Wiseman, C.W. and Carlone, M.F. (1972): Hypocalcemic effect of pentagastrin and related gastrointestimal hormonal peptides in the rat. Endocrinology 91, p. 1455.

12. Kaplan, E.L., Hill, B.J. and Sizemore, G.W. (1973): Hypocalcemic, calcitonin-like factor from a Zollinger-Ellison tumor. Surg. Forum 24, p. 60.

13. Schulak, J.A. and Kaplan. E.L. (1974): Gastrin-induced hypocalcemia in thyroparathyroidectomized rats. Metabolism 23, p. 1103.

14. Schulak, J.A. and Kaplan, E.L. (1975): The importance of the stomach in gastrin-induced hypocalcemia in the rat. Endocrimology 96, p. 1217.

15. Norberg, H.P., Schulak, J.A., Atlas, B. and Kaplan, E.L. (1976): Histamine-induced hypocalcemia in the rat. Metabolism 25 , p. 131.

16. Personal Communication, A.F. Barbera, Eli Lilly And Company, 1975.

17. Kaplan, E. L., Norberg, H.P., Schulak, J.A. and Hill, B.J. (1976): The importance of the stomach in mediating histamine-induced hypocalcenia in the rat. Metabolism 25 , p. 1151.

18. Stulberg, B., Norberg, H.P. and Kaplan, E.L. (1976): Cholecystokinin, a new hypocalcemic agent. Surgical Forum 27, p. 430. 
Chapter III*

INHIBITORS OF GASTRIC ACID SECRETION

\section{III.1. INTRODUCTION}

Gastrin, histamine and (octo-) cholecystokinin (CCK and octo-CCK) are hypocalcemic agents in the rat. As discussed in chapters I and II, the calcium lowering effect of these gastrointestinal amines or peptides has generally been attributed to the release of calcitonin (CT) since both gastrin (1-5) and CCK $(6,7)$ are known CT secretagogues in man and several animals, and since thyroparathyroidectomy (TPTX) in the rat has been reported to eliminate all hypocalcemia produced by gastrin (8). In contrast, the work that was presented on the preceeding pages shows that after TPTX hypocalcemia still occurs in the rat when gastrin, histamine or CCK are administered. Proximal gastrectomy however, completely abolishes this effect despite the presence of an intact thyroid gland. Thus it appears that a factor related to the proximal stomach and not to the thyroid release of CT may be most important in mediating this calciumlowering response in the rat. Gastrin, histamine and CCK are all known acid secretagogues. This study was designed to evaluate the effect of gastric acid inhibitors on the hypocalcemia produced by these gastrointestinal hormones.

\section{III.2. EXPERIMENTS}

\section{III.2.1. MATERIAL AND METHODS}

Male Holtzman rats weighing 80-100 gm were utilized. All studies were performed after an overnight fast. They were randomly assigned to experimental groups of 5 to 8 rats/group. Following ether anesthesia, test solutions were administered into a surgically exposed jugular vein in a volume of $0.4 \mathrm{ml}$ or less. When the interaction of two agents was studied, each was injected separately from a different syringe. Test agents included pentagastrin (Ayerst Laboratorjes), histamine base, CCK, atropine sulphate, metiamide (Smith, Kline and French Laboratories, Philadelphia, PA) and G.I.H. secretin (Karolinska Inst., Stockholm, Sweden).

*) Parts of this chapter were published in: Klementschitsch, P. Kaplan, E.L., Heath III, H., North, Ph. and Lee, C: A gastric factor, calcitonin, and the hypocalcernia induced by gastrointestinal hormones. Endocrinology 105, p. 1243 (1979), and presented at the 12 th Annwal Meeting of the Association for Academic Surgery, Cleveland, Ohio, Now. 12-15, 1978. 
In some experiments animals were studied in a thyroid intact state. In other studies either TPTX, gastrectomy or small bowel resection (removal of about 8 $\mathrm{cm}$ of small intestine) was performed less than two hours before the administration of the test agents. Finally, transabdominal vagotomy was performed one day prior to study of some groups of rats. In the latter groups of rats, magnification with a dissecting microscope was utilized to assure a complete transsection of the vagal fibers and to verify that a complete thyroidectomy had been performed. Venous blood was drawn from the jugular vein before and at intervals after injection of the test solutions. Total serum calcium concentration was measured by atomic absorption spectrophotometry. Serum protein concentration was measured by the method of Lowry e.a. (9). Statistical analysis was carried out using Student's t test.

\section{III.2.2. RESULTS}

The changes in serum Ca concentration in these experiments are not the result of fluid and electrolyte shifts due to the magnitude of the various operative procedures. As demonstrated in Table 1, a decrease in serum Ca occurred 30 minutes after injection of pentagastrin in rats with small bowel resections but not in gastrectomized animals given this peptide.

Table III. I: Effect of pentagastrin on serum calcium and serum protein concentrations and hematocrit values in rats following gastrectomy or small bowel resection.

\begin{tabular}{lcccccc}
\hline & $\begin{array}{c}\text { Serum calcium, } \\
\mathrm{mg} / \mathrm{ml}\end{array}$ & $\begin{array}{c}\text { Serum proteins, } \\
\text { g/ml } \\
\text { Time after injection (min) }\end{array}$ & $\begin{array}{c}\text { Hematocrit, } \\
\% \text { RBC's }\end{array}$ \\
& 0 & 30 & 0 & 30 & 0 & 30 \\
\hline $\begin{array}{l}\text { Gastrectomy } \\
\text { Small bowel } \\
\text { resection }\end{array}$ & $9.3 \pm 0.1$ & $9.3 \pm 0.1$ & $6.2 \pm 0.2$ & $5.6 \pm 0.2$ & $41.6 \pm 0.9$ & $39.6 \pm 0.8$ \\
\hline
\end{tabular}

Each value represents the mean plus or minus the standard error of the mean for experimental groups of $8 \mathrm{rats}$, each given pentagastrin, $50 \mu \mathrm{g}$ intravenously. Statistical signilicance of the differences of the changes following gastrectomy or small bowel resection was determined using Student's t test.

${ }^{*} \mathrm{p}<0.001$.

At the time of hypocalcemia, neither serum protein concentrations nor hematocrit values differed between these groups of animals.

In the studies related to the effect of inhibitors of gastric acid secretion, the administration of $P G$ alone into sham-operated animals was followed by a decrease of serum $\mathrm{Ca}$ concentration of $2.1 \mathrm{mg} / 100 \mathrm{ml}$ or greater in each experiment (table 2). 
Table 11.2: The effect of atropine, secretin and metiamide on PG-induced hypocalcemia.

Serum calcium concentration $(\mathrm{mg} / 100 \mathrm{ml})$

Time after injection ( $m i n$ )

Experiment

0

30

60

A. Atropine sulfate:

Saline

Atropine $4 \mu \mathrm{g}$

$10.8 \pm 0.1$

$10.8 \pm 0.1$

$10.9 \pm 0.1$

PG $25 \mu \mathrm{g}$

$10.8 \pm 0.1$

$10.8 \pm 0.1$

$10.8 \pm 0.1$

$10.8 \pm 0.1$

$8.7 \pm 0.2 *$

$10.9 \pm 0.1$

PG $25 \mu \mathrm{g} \pm$ Atropine $0.4 \mu \mathrm{g}$

$10.7 \pm 0.1$

$8.6 \pm 0.1^{*}$

$10.7 \pm 0.1$

PG $25 \mu \mathrm{g} \pm$ Atropine $2 \mu \mathrm{g}$

$10.8 \pm 0.1$

$10.4 \pm 0.2$

$10.8 \pm 0.1$

PG $25 \mu \mathrm{g} \pm$ Atropine $4 \mu \mathrm{g}$

$10.8 \pm 0.1$

$10.8 \pm 0.1$

$10.9 \pm 0.1$

B. Metianide:

\begin{tabular}{|c|c|c|c|}
\hline Saline & $\llbracket 0.7 \pm 0.1$ & $10.8 \pm 0.1$ & $10.8 \pm 0.1$ \\
\hline Metiamide $0.12 \mathrm{mg}$ & $10.7 \pm 0.1$ & $10.7 \pm 0.1$ & $10.7 \pm 0.1$ \\
\hline Metiamide $0.48 \mathrm{mg}$ & $10.8 \pm 0.1$ & $10.9 \pm 0.1$ & $10.8 \pm 0.1$ \\
\hline $\mathrm{PG} 25 \mu \mathrm{g}$ & $10.8 \pm 0.1$ & $8.5 \pm 0.2^{*}$ & $10.7 \pm 0.2^{*}$ \\
\hline $\mathrm{PG} 25 \mathrm{ug} \pm$ Metiamide $0.048 \mathrm{mg}$ & $10.8 \pm 0.1$ & $9.1 \pm 0.2$ & $10.8 \pm 0.1$ \\
\hline $25 \mu \mathrm{g} \pm$ Metiamide $0.12 \mathrm{mg}$ & $10.8 \pm 0.1$ & $10.8 \pm 0.1$ & $10.9 \pm 0.1$ \\
\hline $25 \mu \mathrm{g} \pm$ Metiamide $0.48 \mathrm{mg}$ & $10.7 \pm 0.1$ & $10.6 \pm 0.1$ & $10.7 \pm 0.1$ \\
\hline
\end{tabular}

C. Secretin:

\begin{tabular}{|c|c|c|c|}
\hline Saline & $10.8 \pm 0.1$ & $10.8 \pm 0.1$ & $10.9 \pm 0.1$ \\
\hline Secretin, 1 unit & $10.8 \pm 0.1$ & $10.8 \pm 0.1$ & $10.9 \pm 0.1$ \\
\hline Secretin, 10 units & $10.9 \pm 0.1$ & $10.8 \pm 0.1$ & $10.9 \pm 0.1$ \\
\hline $\mathrm{PG} 25 \mu \mathrm{g}$ & $10.8 \pm 0.1$ & $8.5 \pm 0.1^{*}$ & $10.7 \pm 0.1$ \\
\hline PG $25 \mu \mathrm{g} \pm$ Secretin $\mathbb{1}$ unit & $10.7 \pm 0.1$ & $10.9 \pm 0.1$ & $10.8 \pm 0.1$ \\
\hline $\mathrm{PG}$ & $10.8 \pm 0.2$ & $10.8 \pm 0.1$ & $10.9 \pm$ \\
\hline
\end{tabular}

Each value represents the mean \pm SEM for experimental groups of five rats each. Statistical significance was determined using Student's $t$ test.

${ }^{*} \mathrm{p}<0.001$

However, this gastrin-induced hypocalcemia was completely inhibited by the administration of atropine, $4 \mu \mathrm{g}$; secretin, 1 unit; or metiamide, $0.12 \mathrm{mg}$, when these agents were administered with PG. None of these gastric acid inhibitors influenced the serum $\mathrm{Ca}$ when given alone.

The administration of histamine base, $1.0 \mathrm{mg}$ was followed by a decrease in serum Ca of at least $1.7 \mathrm{mg} / 100 \mathrm{ml}$ at 30 minutes (Table 3 ). 
Table 111.3: The effect of atropine, secretin and metiamide on histamine (Hist)-induced hypocalcemia.

\begin{tabular}{lcccc}
\hline & \multicolumn{3}{c}{$\begin{array}{c}\text { Serum calcium concentration }(\mathrm{mg} / 100 \mathrm{ml}) \\
\text { Time after injection (min) }\end{array}$} \\
\cline { 2 - 4 } Experiment & 0 & 30 & 60 \\
\hline
\end{tabular}

A. Atropine Sulfate:

\begin{tabular}{|c|c|c|c|}
\hline Saline & $10.7 \pm 0.1$ & $10.8 \pm 0.1$ & $10.8 \pm 0.1$ \\
\hline Atropine $4 \mu \mathrm{g}$ & $10.7 \pm 0.1$ & $10.7 \pm 0.1$ & $10.8 \pm 0.1$ \\
\hline Hist. $1 \mathrm{mg}$ & $10.7 \pm 0.1$ & $8.9 \pm 0.1^{*}$ & $10.9 \pm 0$ \\
\hline Hist. $1 \mathrm{mg} \pm$ Atropine $0.4 \mu \mathrm{g}$ & $10.7 \pm 0.1$ & $9.4 \pm 0.2^{*}$ & $10.6 \pm 0.1$ \\
\hline Hist. $1 \mathrm{mg} \pm$ Atropine $2 \mu \mathrm{g}$ & $10.9 \pm 0.1$ & $10.9 \pm 0.1$ & $10.8 \pm$ \\
\hline Hist. $1 \mathrm{mg} \pm$ Atropine $4 \mu \mathrm{g}$ & $10.8 \pm 0.1$ & $10.9 \pm 0.1$ & $10.9 \pm$ \\
\hline
\end{tabular}

B. Metiamide:

$\begin{array}{lccc}\text { Saline } & 10.8 \pm 0.1 & 10.8 \pm 0.1 & 10.8 \pm 0.1 \\ \text { Metiamide 0.048 mg } & 10.6 \pm 0.1 & 10.7 \pm 0.1 & 10.7 \pm 0.2 \\ \text { Metiamide 0.48 mg } & 10.8 \pm 0.1 & 10.7 \pm 0.1 & 10.8 \pm 0.1 \\ \text { Hist. 1 mg } & 10.9 \pm 0.1 & 9.1 \pm 0.3^{*} & 10.6 \pm 0.1 \\ \text { Hist. 1 mg } \pm \text { Metiamide 0.048 mg } & 10.8 \pm 0.1 & 9.0 \pm 0.2^{*} & 10.5 \pm 0.2 \\ \text { Hist. 1 mg } \pm \text { Metiamide 0.48 mg } & 10.9 \pm 0.1 & 10.8 \pm 0.1 & 10.9 \pm 0.1 \\ & & & \\ \text { Secretin: } & 10.8 \pm 0.1 & 10.8 \pm 0.1 & 10.9 \pm 0.1 \\ \text { Saline } & 10.8 \pm 0.1 & 10.8 \pm 0.1 & 10.9 \pm 0.1 \\ \text { Secretin, I unit } & 10.9 \pm 0.1 & 10.9 \pm 0.1 & 10.9 \pm 0.1 \\ \text { Secretin, 10 units } & 10.9 \pm 0.1 & 9.1 \pm 0.2^{* *} & 10.8 \pm 0.1 \\ \text { Hist. 1 mg } & 10.9 \pm 0.1 & 8.6 \pm 0.1^{*} & 10.8 \pm 0.1 \\ \text { Hist. 1 mg } \pm \text { Secretin, 1 unit } & 10.9 \pm 0.1 & 9.2 \pm 0.2^{*} & 10.8 \pm 0.1 \\ \text { Hist. } 1 \mathrm{mg} \pm \text { Secretin, 10 units } & 10.9 \pm 0.1 & \end{array}$

In these experiments the term histamine refers to histamine base.

Each value represents the mean \pm SEM for experimental groups of five rats each. Statistical significance was determined using Student's t test.

$* p<0.001$

$* *<<0.005$.

Table III.4: The effect of atropine on CCK-induced hypocalcernia.

Serum calcium concentration $(\mathrm{mg} / 100 \mathrm{ml})$

Time after injection ( $\mathrm{min}$ )

Experiment

$0 \quad 30$

Saline

Atropine, $4 \mu \mathrm{g}$

CCK, $1 \mu g$

$\mathrm{CCK} \pm$ Atropine

$\begin{array}{rl}9.3 \pm 0.1 & 9.3 \pm 0.1 \\ 9.6 \pm 0.1 & 9.6 \pm 0.1 \\ 10.0 \pm 0.1 & 9.3 \pm 0.2 * \\ 9.7 \pm 0.2 & 9.7 \pm 0.1\end{array}$

Each value represents the mean \pm SEM for experimental groups of 5 rats each. Statistical significance was determined using Student's $t$ test.

${ }^{*} \mathrm{p}<0.02$. 
The injection of either atropine, $2 \mu \mathrm{g}$, or metiamide, $0.48 \mathrm{mg}$, completely prevented the hypocalcemia resulting from histamine injection. However, secretin in doses as large as 10 units had no inhibitory effect on the lowering of $\mathrm{Ca}$ by histamine.

The administration of $\mathrm{CCK}, \mathbb{1} \mu \mathrm{g}$ ( 2.5 units), was followed by a decrease of serum $\mathrm{Ca}$ concentration of $0.7 \mathrm{mg} / 100 \mathrm{ml}$ (Table 4).

The injection of atropine, $4 \mu \mathrm{g}$ abolished this effect.

Finally, after transabdominal vagotomy the calcium lowering activity of both PG and histamine was significantly reduced (Fig. 1).

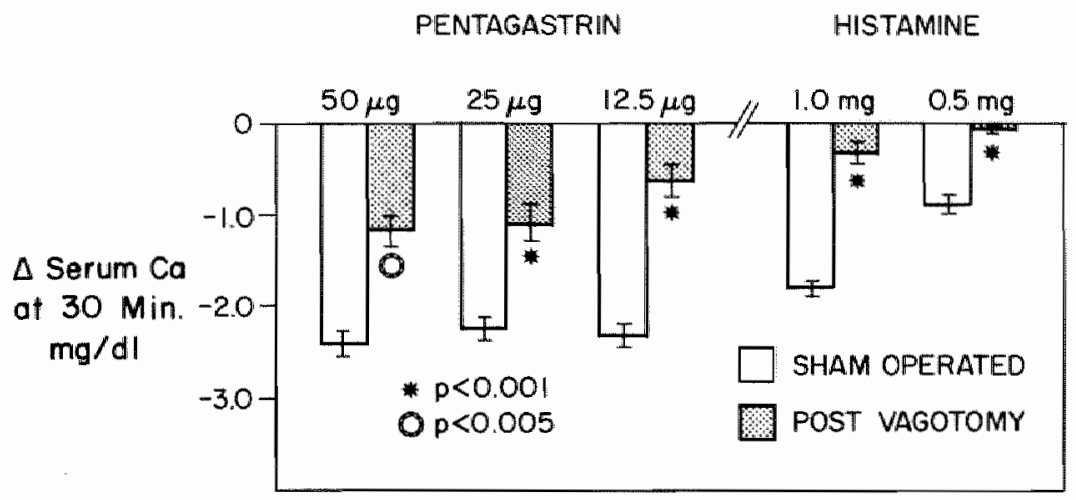

Figure III. I: The effect of vagotomy on $P G$-and histamine induced hypocalcemia measured 30 minutes after injection of the test agent.

Each bar represents the mean \pm SEM of groups of five rats each. Student's t test.

\section{III.3. DISCUSSION}

There are several possibilities to explain the hypocalcemia which follows PG-, histamine- and CCK administration in the rat.

Calcitonin release from the thyroid gland is a serious possibility since, as was mentioned before, gastrin and CCK are known CT secretagogues in the rat. Although thyroidectomy did not change this calcium lowering response in any of the experiments the role of CT was not studied specifically. Furthermore, as the importance of the stomach in mediating the effect seems unequivocal, another possible theory is the "ectopic" production and release of CT by the stomach or that the hypocalcemic action of CT occurs only in the presence of the stomach. The role of calcitonin will be addressed in chapter IV.

Another possibility for these data is that PG inhibits the secretion or the action of parathyroid hormone in the rat. This seems unlikely since in sheep (10) 
and man (unpublished results, G.W. Sizemore and H. Heath, III) the administration of PG has no effect on serum iPTH levels. The effect of PG on the peripheral action of PTH has not been studied, however.

Yet another possibility is that the hypocalcemia is due to the release of another calcium-lowering amine or peptide from the stomach. This interesting alternative will be discussed extensively in chapter $\mathrm{V}$.

Most strongly, however, the data presented thus far suggest that the hypocalcemia which follows gastrin, histamine or cholecystokinin administration in the rat is a manifestation of the gastric acid secretory process. Each of these agents is a known gastric acid secretagogue in the rat in the doses which were employed $(11,12)$. Following their injection, maximum acid secretion occurs in this animal at about 30 minutes, the same time as the lowest concentration of serum calcium concentration is found. Furthermore, as was previously demonstrated(Table I1.3), the proximal parietal cell portion of the stomach of the rat is most important in mediating this response since resection of this area eliminated all PG induced hypocalcemia while resection of the gastric antrum was without effect. The data presented in this chapter further support this hypothesis. Atropine and metiamide, a specific $\mathrm{H}_{2}$ inhibitor similar to cimetidine, are known inhibitors of both gastrin- and histamine-stimulated gastric acid secretion. Secretin, on the other hand, is an inhibitor of gastrin at the parietalcell level but does not inhibit histamine-stimulated acid secretion (13). Thus, the finding that atropine and metiamide completely abolished all gastrin- and histamine-induced hypocalcemia, but that secretin blocked only the PG-induced hypocalcemia, favors the relationship to gastric acid secretion.

Finally, transabdominal vagotomy decreased, and in some cases eliminated the hypocalcemia produced by $\mathrm{PG}$ or histamine. These findings are compatible with the gastric acid hypothesis, since following vagotomy both gastrin- and histamine-stimulated acid secretion are reduced from prevagotomy levels. The mechanism by which stimulation of the acid secretory process might lower serum $\mathrm{Ca}$ is uncertain.

\section{III.4. CONCLUSIONS}

1. The hypocalcemia following the administration of gastrin, histamine and CCK in the rat is not caused by the thyroid release of CT.

2. The role of CT remains unsettled. Ectopic production and release of this hormone, perhaps from the stomach, could be responsible.

3. The exact role of the stomach has to be studied further:

- does it mediate the effect of, or produce CT?

- does it produce and release a new Ca-lowering amine or peptide?

- how is the gastric acid secretory mechanism related to the observed hypocalcemia? 


\section{III.5. REFERENCES}

1. Cooper, C.W., Schwesinger, W.H., Mahgoub, A.M. and Ontjes, D.A. (1971): Thyrocalcitonin: Stimulation of secretion by pentagastrin. Science $172, \mathrm{p} .1238$.

2. Care, A.D., Bates, R.F.L., Swaminathan, R. and Ganguli, P.C. (1971): The role of gastrin as a calcitonin secretagogue. J. Endocrinol. 51 , p. 735.

3. Hennessey, J.F., Gray, T.K., Cooper, C.W. and Ontjes, D.A. (1973): Stimulation of thyrocalcitonin secretion by pentagastrin and calcium in two patients with medullary carcinoma of the thyroid. J. Clin. Endocrinol. Metab. 36, p. 200.

4. Sizemore, G.W. and Go, V.L.W. (1975): Stimulation tests for diagnosis of medullary thyroid carcinoma. Mayo Clinic. Proc. 50, p. 53.

5. Deftos, L.J., Roos, B.A., Knecht, G.L., Lee, J.C., Pavlinac, D., Bone, H.G. and Parthemore, J.G. (1978): Calcitonin secretion, in: Copp, D.H. and Talmage, R.V. (eds.): Endocrinology of calcium metabolism, Excerpta Medica, Amsterdam-Oxford, 1978 , p. 134.

6. Care, A.D., Bruce, J.B., Boelkins, J., Kenny, A.D., Conaway, H. and Anast, C.S. (1971): Role of pancreozymincholecystokinin and structurally related compounds as calcitonin secretagogues. Endocrinology 89, p. 262.

7. Cooper, C.W., Schwesinger, W.H., Ontjes, D.A., Mahgoub, A.M. and Munson, P.L. (1972): Stimulation of secretion of pig thyrocalcitonin by gastrin and related hormonal peptides. Endocrinology 91, p. 1079.

8. Cooper, C.W., Biggerstaff, C.R., Wiseman, C.W. and Carlone, M.F. (1972): Hypocalcemic effect of pentagastrin and related gastrointestinal hormonal peptides in the rat. Endocrinology 91, p. 1455.

9. Lowry, O.H., Rosebrough, N.J., Farr, A.L. and Randall, R.J. (1951): Protein measurement with the Folin phenol reagent. J. Biol. Chem. 193, p. 265.

10. Jaffe, B.M., Peskin, G.W. and Kaplan, E.L. (1974): The relationship of serum gastrin to parathyroid hormone in sheep. Metabolism 23, p. 307.

11. Barrett, A.M. (1966): Specific stimulation of gastric acid secretion by a pentapeptide derivative of gastrin. J. Pharm. Pharmac. 18, p. 633.

12. Chey, W.Y., Sivasomboon, B., Hendricks, J. and Lorber, S.H. (1970): Effects of secretin and cholecystokinin on gastric acid secretion in rats. Gastroenterology 58, p. 1037A.

13. Davenport, H.W. (1971): Control of secretion, in: Physiology of the Digestive Tract, 3rd ed., Year Book Medical Publishers, Chicago, 1971. 
Chapter IV*

THE ROLE OF CALCITONIN (CT)

\section{IV.1. INTRODUCTION}

Although thyroidectomy was performed in most of our experiments, little attention was paid to the possibility that calcitonin might be released from a different organ. If such a non-thyroid source of $\mathrm{CT}$ were to exist in the rat, it seemingly is located in the stomach itself or it needs the presence of this organ to be effective.

Three experiments were undertaken to establish the role of CT in the stomach-mediated hypocalcemia. The first experiment served to evaluate the hypocalcemic effect of crude porcine $\mathrm{CT}$ on the calcium homeostasis of intact and gastrectomized rats (GX).

In the second experiment endogenous CT was utilized as a more physiologic stimulant. Cautery of the thyroid gland as described by Hirsch was applied for this ( 1 ).

In the last experiment, serum iCT concentrations were determined in shamoperated, GX and TPTX rats after stimulation with pentagastrin. At this stage, it had become extremely interesting to see whether PG, given intravenously, indeed could act as a CT secretagogue, and if so, whether the CT serum levells thus established would influence serum calcium concentration in our rat model.

\section{IV.2. EXPERIMENTS}

\section{IV.2.1. MATERIAL AND METHODS}

\section{Experiment No. 1:}

4 groups of 5 rats weighing 60-70 grams were fasted for 18-20 hours. All surgical procedures and blood sampling were done under ether anesthesia. Gastrectomy was performed on 10 animals, a sham procedure on the other half. Gastrectomy was accomplished by transsecting the distal esophagus and the pylorus through a mid-abdominal incision. The stomach was then further mobil-

*) Parts of this chapter were published in: Klementschitsch, P., Kaplan, E.L., Heath III, H., North, Ph. and Lee, C. (1979): A gastric factor, calcitonin, and the hypocalcemia induced by gastrointestinal hormones. Endocrinology 105, p. 1243, 1979. 

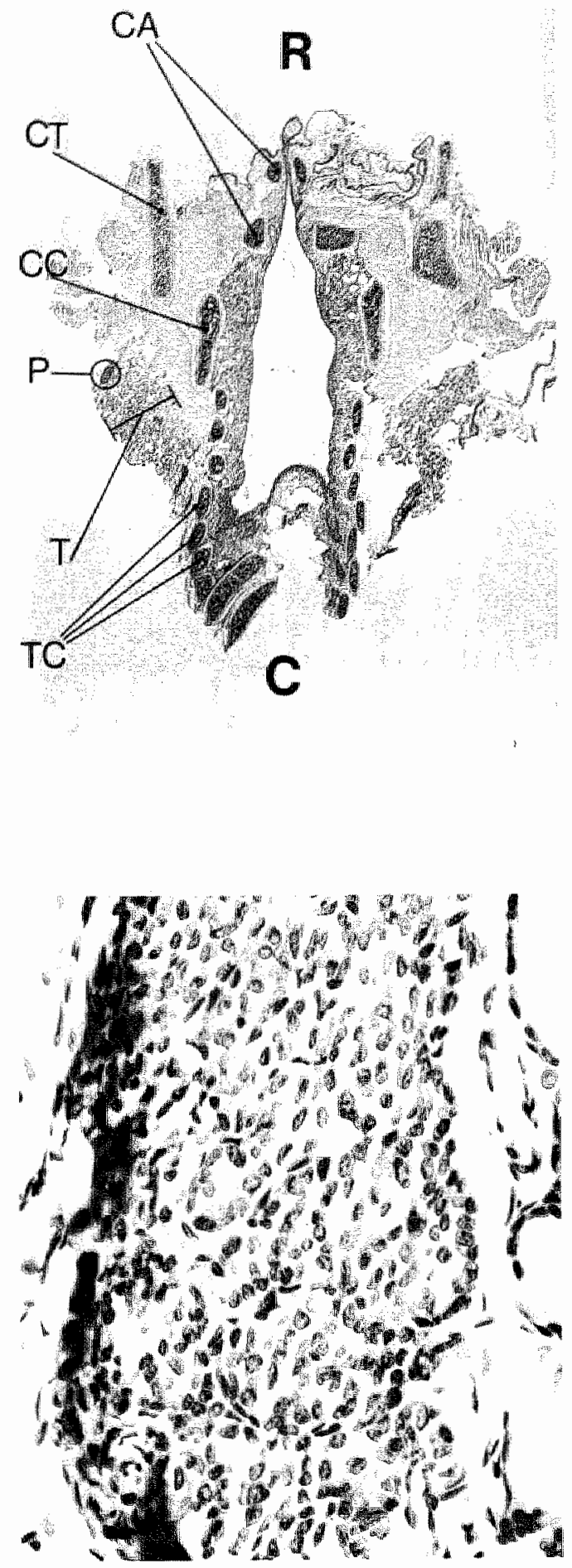

Figure IV.1A:

Thyroid region of the rat, frontal section.

$\mathrm{R}=$ Rostral

$\mathrm{C}=$ Caudal

$\mathrm{TC}=$ Tracheal cartilages

$C C=$ Cricoid cartilage

$C T=$ Thyroid cartilage

$\mathrm{CA}=$ Arytenoid cartilage

$\mathrm{T}=$ Thyroid gland

$\mathrm{P}$ = Parathyroid gland

Magnification x 10.
Figure IV.IB:

Detail of fig. IA: Parathyroid gland.

Magnification x 400 . 
ized and removed en bloc with the spleen. The pyloric channel was ligated, the esophagus left open to prevent aspiration of saliva. The abdomen was carefully closed. The sham operation consisted of resection of a length of about $8 \mathrm{~cm}$ of small bowel through a similar mid-abdominal approach. Both open ends adjacent to the resected bowel were ligated. One hour later, five animals of each surgical group (GX vs. sham) got $5 \mathrm{mU}(0.2 \mathrm{ml})$ crude porcine calcitonin injected into a jugular vein. The other five received $0.2 \mathrm{ml}$ physiological saline. Blood samples for serum Ca concentration were drawn from the opposite jugular vein before, and 30 and 60 minutes after the injection.

\section{Experiment No. 2:}

Under similar experimental conditions as described above, 10 rats were gastrectomized and 10 sham-operated. One half to one hour after surgery, the thyroid glands of all animals were exposed by a vertical muscle splitting incision in the neck. In five animals out of each surgical group the lower poles of the thyroid gland were lightly cauterized, carefully avoiding the parathyroid glands situated in the upper poles (fig. 1).

The remaining half of both groups served as controls ("sham-cautery"). Blood. samples for serum calcium determination were drawn from the jugular vein just before, and 30 and 60 minutes after cautery or sham-cautery.

\section{Experiment No. 3:}

80 to $100 \mathrm{mg}$ rats were used. The studies were performed after an overnight fast and all surgical and blood sampling procedures were conducted under ether anesthesia. Pentagastrin $25 \mu \mathrm{g}$ was administered into a surgically exposed jugular vein. The rats were randomly assigned to 3 experimental groups of 32 rats. Shortly before the injection of PG ( $1-2$ hours) one group underwent gastrectomy as described above, the second group underwent a sham-operation (abdominal incision) and the third group had TPTX performed. Blood was sampled at $0,2,5$ and 30 minutes following $\mathrm{PG}$ administration. Different animals were used for each time point ( 8 rats $/$ time point). Serum Ca was determined.

\section{CT Radioimmunoassay:}

Radioimmunoassay of calcitonin was done in the laboratories of The Endocrine Research Unit, Division of Endocrinology, Department of Medicine, Mayo Clinic and Mayo Medical School, Rochester, Minnesota by H. Heath III who earlier had succeeded in modifying his standard assay procedures to markedly decrease sample and reagent requirements. This had enabled him to reduce all reagent volumes to one-fourth the usual sample size. Studies in rats showed the sensitivity to match that of the usual assays, while making it possible to repeatedly draw samples from the same animal (2,3). Antiserum G-1701, raised in a goat by injection of synthetic hCT (Ciba), cross-reacts with CT. Calcitonin purified from rat thyroid glands (4) and normal fasting and stimulated (calcium, pentagastrin, feeding) serum yield immunodilution curves parallel to hCT standard. Because serum from TPTX rats causes some non-specific depression of $\mathrm{B} / \mathrm{F}$ (bound-free) ratio (5) pooled serum from TPTX rats was employed as the hypocalcitoninemic serum blank for "trace" B/F tubes (6). Induced hypercalcemia yields increased $\mathrm{iCT}$ values linearly related to serum calcium, and EDTA-induced hypocalcemia reduces CT to undetectable levels. All 
samples were assayed together at three dilutions $(50,25$ and $10 \mu \mathrm{l}$ sample additions) with no antibody ("damage") controls for each addition. Rat iCT values were expressed as picogram-equivalents of $\mathrm{hCT} / \mathrm{ml}(\mathrm{pgEq} / \mathrm{ml})$. Assay limit of detection in these studies was $25 \mathrm{pgEq} / \mathrm{ml}$, and intra-assay coefficient of variation $20 \%$.

In the three experiments serum calcium was measured by atomic absorption spectrophotometry. Statistical significance was determined with Student's t test.

\section{IV.2.2. RESULTS}

\section{Experiment No. 1:}

Mean basal calcium concentrations were the same in the sham-operated and gastrectomized groups. Saline administration did not alter serum calcium values in either surgical group. Calcitonin caused a significant fall of $2.5 \mathrm{mg} / 100$ $\mathrm{ml}$ at 30 minutes post i.v. injection in the sham-operated group $(\mathrm{p}<0.001)$ and an equally striking fall of $2.3 \mathrm{mg} / 100 \mathrm{ml}$ in the gastrectomized animals ( $\mathrm{p}<$ 0.001 ). 60 minutes after $\mathrm{CT}$ administration serum calcium values almost had returned to normal (Fig. 2).

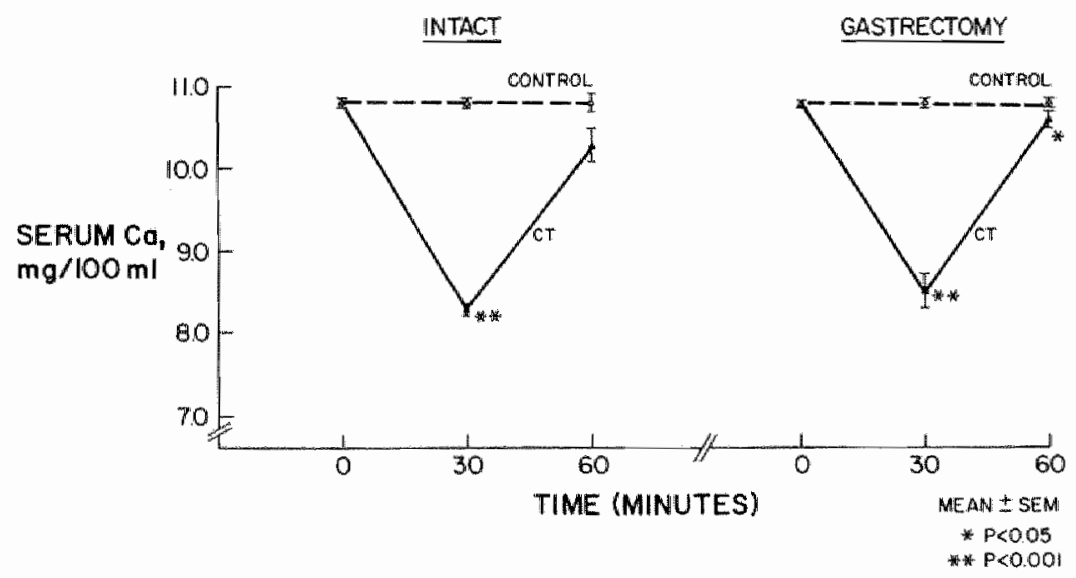

Figure IV.2: Effect of $20 \mathrm{mU}$ crude porcine calcitonin (CT) to intact and gastrectomized rats.

Each value represents the mean \pm SEM of 5 rats. Statistical analysis was carried out using Student's t test.

\section{Experiment No. 2:}

Burning of the thyroid gland caused a mean fall in serum calcium concentration of $1.8 \mathrm{mg} / 100 \mathrm{ml}(\mathrm{p}<0.001)$ and $2.4 \mathrm{mg} / 100 \mathrm{ml}(\mathrm{p}<0.001)$ in the rats that had undergone a laparotomy incision only at 30 and 60 minutes following 
the procedure respectively. Gastrectomy did not affect this reaction because at 30 and 60 minutes post cautery mean falls of $1.7 \mathrm{mg} / 100 \mathrm{ml}(\mathrm{p}<0.001)$ and $2.1 \mathrm{mg} / 100 \mathrm{ml}(\mathrm{p}<0.001)$ were measured respectively. Surgical exposure of the thyroid gland alone ("sham-cautery") did not cause a significant change in serum calcium levels (Fig. 3).

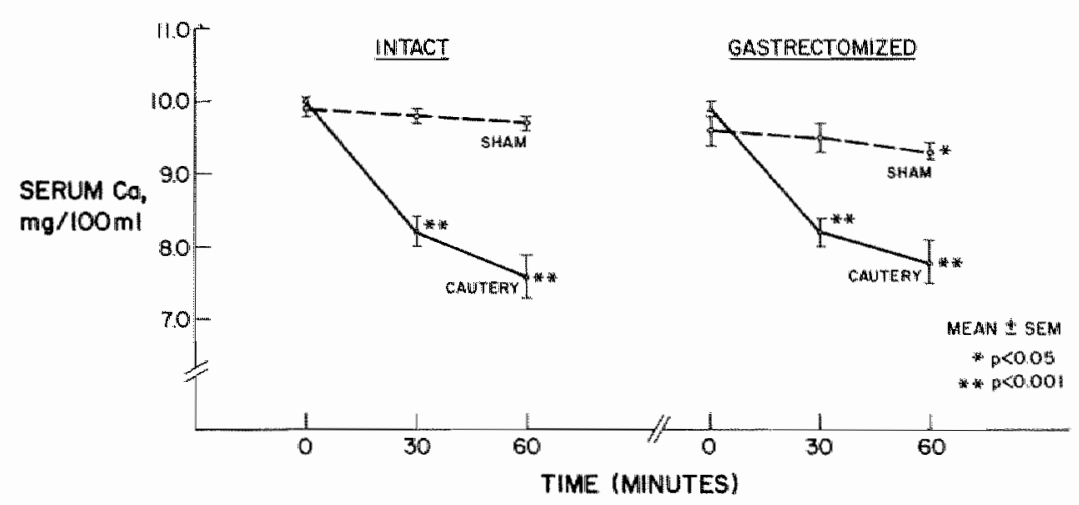

Figure IV.3: Effect of cautery of the thyroid gland in intact (laparotomy inctsion) and gastrectomized rats.

Each value represents the mean $\pm S E M$ of 5 rats. Student's $t$ test.

\section{Experiment No. 3:}

In thyroid intact, sham-operated rats (fig. 4) the administration of $25 \mu \mathrm{g}$ pentagastrin was followed by a rise of iCT from a basal value of $39 \pm 5 \mathrm{pgEq} / \mathrm{ml}$ (mean \pm SEM) to a peak concentration of $60 \pm 10 \mathrm{pgEq} / \mathrm{ml}$ at 2 minutes $(\mathrm{p}<$ 0.05 ).

In these animals the serum Ca decreased from a basal concentration of $10.2 \pm$ $0.12 \mathrm{mg} / 100 \mathrm{ml}$ to $8.3 \pm 0.12 \mathrm{mg} / 100 \mathrm{ml}(\mathrm{p}<0.001) 30$ minutes after injection. In gastrectomized, thyroid-intact animals iCT increased from $31 \pm 3$ $\mathrm{pgEq} / \mathrm{ml}$ to a peak value of $59 \pm 9 \mathrm{pgEq} / \mathrm{ml}$ at 5 minutes after pentagastrin ( $\mathrm{p}$ $<0.01$ ), a response not differing significantly from that observed in the shamoperated rats. Despite this, the serum Ca did not decrease from basal values at 30 minutes in the gastrectomized group. Finally, in acutely TPTX rats, iCT was undetectable both in the basal and post-gastrin periods. However, the serum calcium decreased from $9.1 \pm 0.2 \mathrm{mg} / 100 \mathrm{ml}$ to $8.0 \pm 0.2 \mathrm{mg} / 100 \mathrm{ml}$ at 30 minutes after $\mathbb{P G}$ administration $(\mathrm{p}<0.005)$ in these animals. 
SHAM-OF
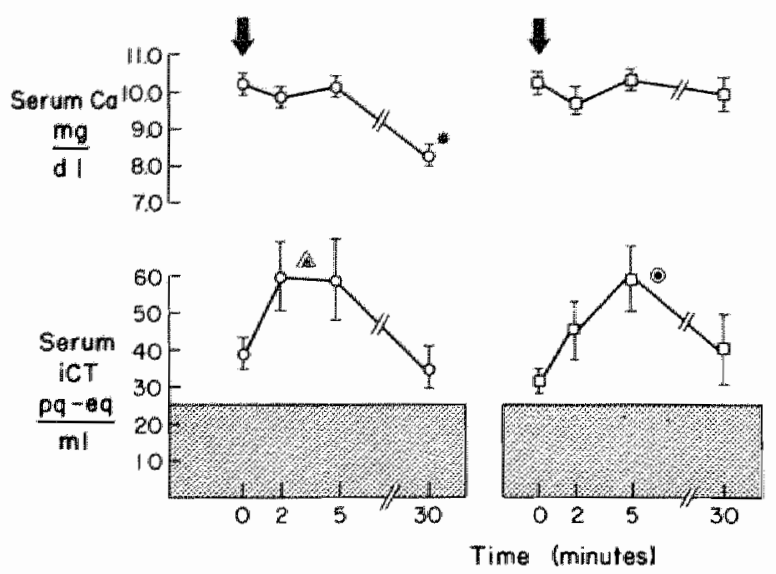

GASTRECTOMV
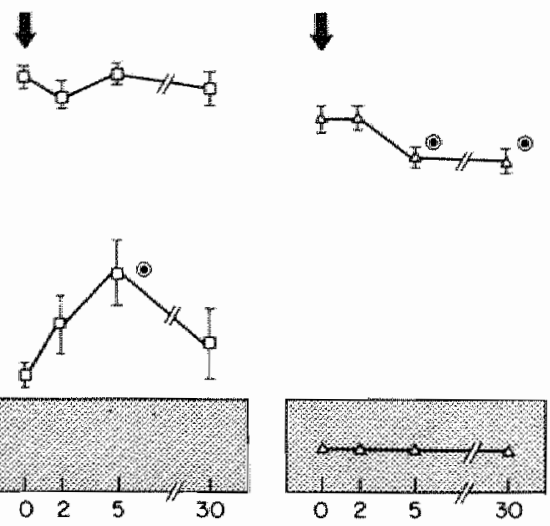

- $p<0001$

0 P $<0$ QI

a. $0<0.05$

Figure IV.4: The effect of intravenous injections of pentagastrin, $25 \mu \mathrm{g}$, on serum calcium and serum immunoreactive calcitonin (iCT) concentrations of rats following sham operation (laparotomy incision), gastrectomy or thyroparathyroidectomy (TPTX).

Each value represents the mean \pm SEM for groups of 8 rats. Values of serum iCT of $25 \mathrm{pgEq} / \mathrm{ml}$ or less were below the limit of detection of the assay, indicated by the shaded, hatched area. Student's t test.

\section{IV.3. DISCUSSION}

So far in the experiments, calcitonin had not been ruled out conclusively as being instrumental in the hypocalcemic effect of the acid secretagogues pentagastrin, CCK, octa-CCK and histamine. As was pointed out before, both (penta-) gastrin and CCK are known releasers of CT in man and other animals and the release of extrathyroidal calcitonin might have explained the experimental findings. Cells closely resembling the thyroid $\mathrm{C}$-cells have been identified in the oxyntic cell mass but no indication as to their function has yet been found ( 7$)$. In addition, there are several studies suggesting there may be sources of CT other than the thyroid gland from the porcine adrenal medulla $(8,9)$ and the anterior and posterior pituitary gland of the rabbit, rat and guinea-pig. $(10,11,12)$ a calcitonin-like principle has been isolated. However, these hypocalcemic factors have not yet been identified as calcitonin and, for example, in unpublished experiments, this author was unable to induce a significant gradient in iCT concentration between samples collected from the saphenous vein and the cavernous sinus of fasted, thyroidectomized female sheep during continuous systemic infusion of a hypercalcemic solution (13). Calcium infusion is a much more effective stimulus of CT secretion than pentagastrin in this animal (14). Recently, iCT was positively identified by radioimmunoassay methods in autopsy material of 23 patients (15): significant amounts of the hormone were 
found in the jejunum, thymus, bladder, lung, rectum, testis, skeletal muscle, the pituitary gland, hypothalamus, lymphnodes, liver, stomach, bronchial $\mathbb{K}$-cells and many other tissues. This study was performed in patients with intact thyroid glands, however, and C-cells were not looked for in these tissues.

Above experiments do not favor a role for CT in the hypocalcemia caused by PG and other acid secretagogues. In the first two experiments of this chapter it was demonstrated that gastrectomy did not influence the hypocalcemic reaction to either endogenous or exogenous $\mathrm{CT}$, while the hypocalcemic reaction to PG was completely blocked by gastrectomy. Therefore, it can safely be assumed that thyroid or non-thyroid calcitonin do not need the stomach for their hypocalcemic effect to take place. It is of interest to note the difference in duration of the hypocalcemia seen after stimulation with endogenous or exogenous CT. This may be explained by the fact that the crude porcine CT preparation is alien to the rat and its potency therefore short-lived.

The third study confirmed that pentagastrin is a calcitonin secretagogue in the rat $(16)$. Cooper et al $(17,18)$ were unable to demonstrate that porcine gastrin or pentagastrin stimulated the release of CT from rat thyroid in an in vitro and in vivo model. Those differences may be manifestations of the sensitivity of their assay system or result from immunochemical specificities of antisera used (19). The rise in serum iCT which we found following PG administration to the rat is small, however, when compared to changes in serum CT which follow PG injection into the pig, for example (20). Furthermore, as in other immunologic determinations, it is difficult to state with certainty that the CT which was measured is a biologically active fraction; however, previous studies using this assay demonstrated prompt elevations in serum $\mathrm{ICT}$ in the rat following calcium infusion, feeding and PG infusion (3,21).

Is the hypocalcemia which follows PG administration in the rat a consequence of the hypercalcitoninemia? The data from the third experiment once more suggest that this is unlikely. First of all, it is unknown whether changes in serum CT of this magnitude (approximately $30 \mathrm{pgEq} / \mathrm{ml}$ ) can affect the serum calcium concentration. Furthermore, as one would expect, peak serum iCT did not differ significantly in the sham operated and GX rats since both had normal thyroid glands. However, hypocalcemia occurred only in animals which had intact stomachs. Lastly, the absence of assayable CT in the serum of PG stimulated TPTX rats makes the existence of an alternative source of CT, like the stomach, the pituitary gland or the adrenals, unlikely and contradicts the role of calcitonin in the PG-mediated hypocalcemia.

\section{IV.4. CONCLUSION}

Calcitonin does not require the stomach to be effective.

Administration of pentagastrin to the rat causes a small rise in serum immunoreactive calcitonin. This rise is not inhibited by gastrectomy. It is ineffective in changing the serum calcium concentration. It may be assumed, therefore, 
that although calcitonin can act as a hypocalcemic agent in the rat and may play a role in the normal physiology of its calcium homeostasis, the major factor regulating $\mathrm{PG}$-mediated hypocalcemia appears to be gastric in origin and not related to calcitonin secretion from the thyroid gland or any other source.

\section{IV.5. REFERENCES}

1. Hirsch, P.F., Gauthier, G.F. and Munson, P.L. (1963): Thyroid hypocalcemic principle and recurrent laryngeal nerve injury as factors affecting the response to parathyroidectomy in rats. Endocrinology 73, p. 244.

2. Schedl, H.P., Heath, H.III and Wenger, J. (1978): Serum calcitonin and parathyroid hormone in experimental diabetes: effects of insulin treatment. Endocrinology 103, p. 1368.

3. Heath, H.III and Dibella, F.P. (1978): Reduced-volume radioimmunoassays for parathyrin and calcitonin in serum, for use in pediatric and small-animals studies. Clin. Chem. 24, p. 1833.

4. Burford, H.J., Ontjes, D.A., Cooper, C.W., Parlow, A.F. and Hirsch, P.F. (1975): Purification, characterization and radioimmunoassay of thyrocalcitonin from rat thyroid glands. Endocrinology 96, p. 340.

5. Roos, B.A. and Deftos, L.J. (1976): Radioimmunoassay of calcitonin in plasma, normal thyroid, and medullary thyroid carcinoma of the rat. J. Lab. Clin. Med. 88, p. 173.

6. Arnaud, C.D., Tsao, H.S., Littledike, T. (1971): Radioimmunoassay of human parathyroid hormone in serum. J. Clin. Invest. 50, p. 21.

7. Pearse, A.G.E (1974): Cytochemical and ultrastructural characteristics of cells producing polypeptide hormones and their relevance to gut hormones. In: Chey, W.Y. and Brooks, F.P. (eds.): Endocrinology of the gut, Charles B. Slack, Inc., New Jersey, p. 24.

8. Kaplan, E.L., Peskin, G.W. and Arnaud, C.D. (1969): Non-steroid, calcitonim-like factor from the adrenal gland. Surgery 66, p. 167.

9. Kaplan, E.L., Arnaud, C.D., Hill, B.J. and Peskin, G.W. (1970): Adrenal medullary calcitonin-like factor: a key to multiple endocrine neoplasia, type 2?. Surgery 68 , p. 146.

10. Natelson, S., Pincus, J.B. and Rannazzisi, G. (1963): A rabbit serum calcium lowering factor from the pituitary. Clin. Chem. 9, p. 631 .

11. Pincus, J.B., Feldman, R.G., Rannazzisi, G. and Natelson, S. (1965): Electromyographic studies with pituitary extracts which lower serum calcium and raise serum citrate levels. Endocrinology 76, p. 783.

12. Zilleli, M.S., Kanra, G., Urünay, G., Güner, T. and Caglar, S. (1967): Evidences for a hypocalcemic factor from pituitary gland. Experientia 24, p. 960.

13. Klementschitsch, P., Mcllhany, M., Defios, L.J. and Kaplan, E.L. (1979): Experiments on ICT release from the brain of the sheep. Unpublished.

14. Klementschitsch, P., Burrington, J.D., Loh, I., Shen, K., Deftos, L.J. and Kaplan, E. L. (1978): Differential release of calcitonin in sheep to calcium and pentagastrin stimulation. Surg. Forum XXIX, p. 107.

15. Becker, K.L., Snider, R.H., Moore, Ch.F., Monaghan, K.G. and Silva, O.L. (1979): Calcitonin in extrathyroidal tissues of man. Acta Endocrinol. 92, p. 746.

16. Roos, B.A. and Deftos, $L J$. (1976): Radioimmunoassay of calcitonin in plasma, normal thyroid and medullary thyroid carcinoma of the rat. J. Lab. and Clin. Med. 88, p. 173.

17. Cooper, C.W., Obie, J. and Hsu, W.H. (1976): Improvement and initial in vivo application of the radioimmunoassay of rat thyrocalcitonin. Proc. Soc. Exp. Biol. Med. 151, p. 183. 
18. Cooper, C.W., Ramp, W.K., Becker, D.I. and Ontjes, D.A. (1977): In vitro secretion of immunoreactive rat thyrocalcitonin. Endocrinology 101 , p. 304.

19. Sizemore, G.W. and Heath, H.III (1975): Immunochemical heterogeneity of calcitonin in plasma of patients with medullary thyroid carcinoma. J. Clin. Invest. 55, p. 1111.

20. Cooper, C.W., Schwesinger, W.H., Mahgoub, A.M. and Ontjes, D.A. (1971): Thyrocalcitonin: stimulation of secretion by pentagastrin. Science 172, p. 1238.

21. Jaffe, B.M., Peskin, G.W. and Kaplan, E.L. (1974): the relationship of serum gastrin to parathyroid hormone in sheep. Metabolism 23, p. 307. 
Chapter V

A CALCIUM LOWERING AMINE OR PEPTIDE FROM THE STOM$\mathrm{ACH}$ ?

\section{V.1. INTRODUCTION}

As was suggested in chapter II, in QUESTIONS TO BE ANSWERED, another explanation for the data sofar presented, is the intruiging possibility that the hypocalcemia following PG administration in the rat results from the release of a new amine or peptide from the stomach. The experiments presented in this chapter were designed to try to stimulate the release of this hypothetical agent and to test its effect on bone resorption in vitro. The secretion of the agent was promoted by perfusion of the gastric vascular bed with a perfusate containing high levels of PG. A detailed description of this perfusion system will be given. The effluent was then added to the culture medium of a sensitive bone tissue culture system which will be described as well.

Much of our present knowledge about factors influencing bone resorption was derived from experiments involving bone tissue cultures. Raisz, one of the early researchers and developers of the system that was used, gave a summary of the known substances influencing bone metabolism in 1970 (1) and several more have been added since then (Table 1).

Table V.I: Factors influencing bone resorption in vitro and/or in vivo. (adapted from Raisz, L.G., 1970).

\begin{tabular}{|c|c|c|c|c|}
\hline \multirow{3}{*}{$\begin{array}{l}\text { PHYSIOLOGIC } \\
\text { STIMULATOR }\end{array}$} & \multirow{3}{*}{$\begin{array}{l}\text { PHY SIOLOGIC } \\
\text { INHIBITOR }\end{array}$} & \multirow{3}{*}{$\begin{array}{l}\text { NTTRACELLLLAR } \\
\text { MEDIATOR }\end{array}$} & \multicolumn{2}{|c|}{ POSSIPLE PATHOLOOIC THERAPEUTIC FAC TORS } \\
\hline & & & STIMULATOR OF & INHHBTOK OF \\
\hline & & & BONE RESORPTION & BONE RESOHRTION \\
\hline 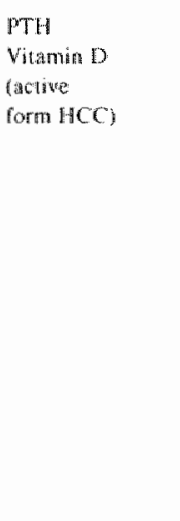 & 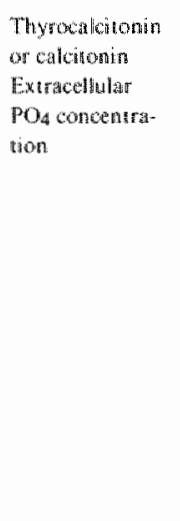 & $\begin{array}{l}\text { CAMP } \\
\text { Cat th or speci- } \\
\text { fic Ca-BP cal- } \\
\text { cium protuin } \\
\text { complexes }\end{array}$ & 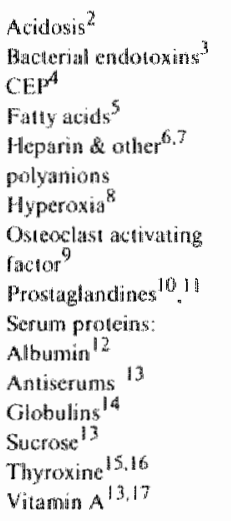 & 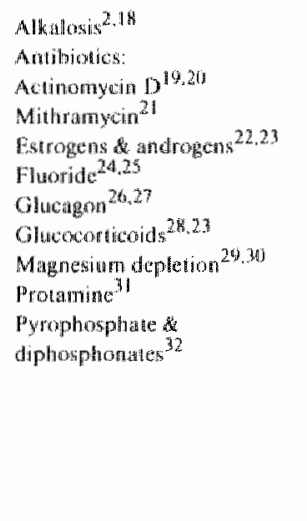 \\
\hline
\end{tabular}


The experiments described on the following pages were undertaken hoping that yet another factor could be added to the category "physiologic inhibitors of bone resorption"'.

\section{V.2. EXPERIMENTS}

\section{V.2.1. MATERIAL AND METHODS}

\section{Surgical procedures:}

Fasted male Holtzman rats weighing 100 gm were thyroparathyroidectomized 18-20 hours before the experiment. On the day of the experiment the animals were anesthetized with Urethane (ethyl carbamine, $0.07 \mathrm{ml} / \mathrm{gm} \mathrm{bwt}$ ) in two separate subcutaneous doses, 30 minutes apart. Thirty minutes after the second injection surgery was performed. The animals were kept on a heating pad throughout the experiment. A midabdominal incision was made and the aorta exposed and dissected free between the diaphragm and superior mesenteric artery. An 18 gauge needle was placed into the aorta with its tip opposite the orifice of the celiac axis. Ligation of the aorta cranially and caudally to the celiac axis. Ligation of the hepatic artery. An open $50 \mathrm{ml}$ pipet was brought into the lumen of the portal vein and its tip positioned near the orifice of the gastric vein. By placing ligatures cranially and caudally to this tip, gastric vein effluent could be selectively sampled. The anatomy of the stomach was left undisturbed and special care was taken to preserve the vagal nerve fibers. By connecting the aortic needle to a perfusion system, an artificial splenogastric circulation was instituted. Upper body and cerebral circulation was left undisturbed and kept the animals alive well beyond the duration of the perfusion experiment.

\section{The perfusion system:}

The following parts were used to build the perfusion system:

1. A reservoir holding Krebs-Henseleit solution to which mannitol $3 \%$ and dextrose $0.005 \mathrm{M}(0.9 \mathrm{~g} / 1)$ were added.

2. Travenol Roller pump for Travenol Coil Kidney Pump-Tank unit. Travenol Lab. Incl., U.A. 14.

3. Hot water bath, P.S. Precision Scientific Co., Chicago, cat. no. 66648.

4. Oxygenating cylinder, consisting of a lobulated glass cylinder aerated with a mixture of $\mathrm{O}_{2} 95 \%$ and $\mathrm{CO}_{2} 5 \%$.

5. Autoburette Abu 12, Radiometer, Copenhagen.

6. Titrator 11, Radiometer, Copenhagen.

7. pH meter 28 Radiometer, Copenhagen.

8. Baumanometer, W.A. Baum Co. Inc., New York.

9. Hone Flow distributor.

10. Roger Gilmont flow meter, cat. no. F1200, R. Gilmont Instruments Inc., New York.

11. Roller Pump, model RD 075.110, The Holter Co., Bridgeport, P.A.

12. Thermometer.

13. Final Filter Travenol, code $2 \mathrm{CO} 24 \mathrm{O}$, Travenol Lab. Inc., Deerfield, Illinois.

14. Harvard Infusion Pump. 
A diagram of the completed system is shown in Fig. 1.

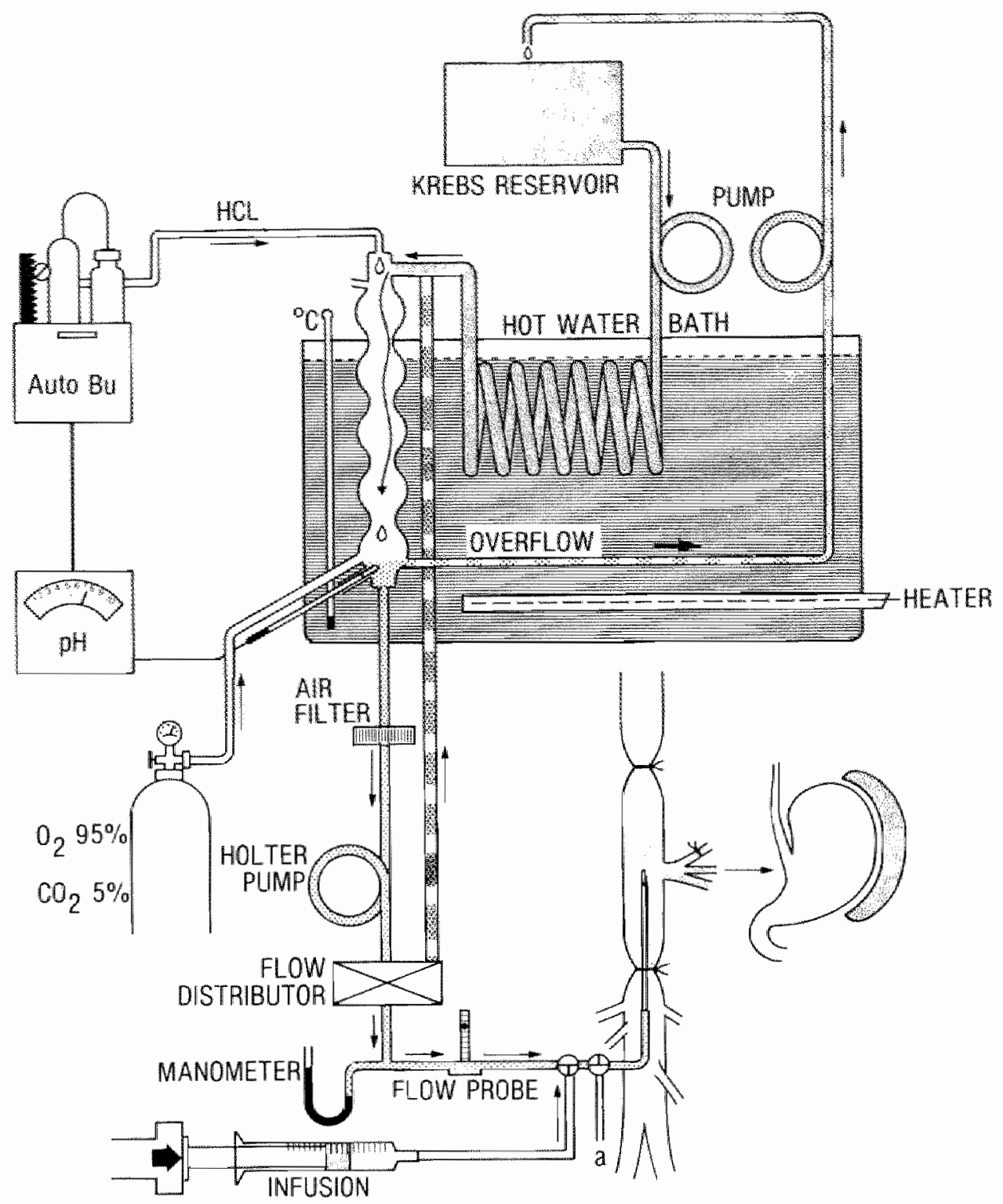

Figure V.1: System for arterio venous perfusion of the rat stomach and spleen. "a" = collecting site of "pre-animal" perfusate. 
After elaborate testing the system proved capable of maintaining a steady perfusion of the gastric vascular bed with complete control of flow, pressure, temperature, oxygenation and $\mathrm{pH}$. Flow varied between 0.5 and $2 \mathrm{ml}$ per minute with mean pressures of $80-110 \mathrm{~mm} \mathrm{Hg}$. Temperature, measured at a point just proximal to the aortic needle, was maintained at $37.5^{\circ} \mathrm{C} . \mathrm{PO}_{2}$ varied between 200 and $450 \mathrm{~mm} \mathrm{Hg}$ and $\mathrm{pH}$ was kept at 7.4 by continuous gassing with $\mathrm{O}_{2}$, $95 \%$, and $\mathrm{CO}_{2}, 5 \%$, and automatic titration of the perfusate with $0.01 \mathrm{M} \mathrm{HCl}$ in the collecting bowl at the bottom of the oxygenation cylinder.

Saline or pentagastrin were continuously added to the perfusate by means of a separate infusion pump, establishing concentrations calculated to approximate peak serum levels in $100 \mathrm{gm}$ rats injected with $25 \mu \mathrm{g}$ pentagastrin i.v. For example, with a perfusion rate of $1 \mathrm{cc}$ per minute, 25 divided by $7=3.5 \mu \mathrm{g}$ pentagastrin was infused per minute because it was assumed that a 100 gram rat has $7 \mathrm{ml}$ of blood (Ref. VI, 21).

The viability of the in vivo stomach preparation was tested in a pilot study in which gastric juice was collected from a canula draining the antrum through a duodenostomy and tested for the presence of hydrogen ions by the Oxford Titration method, using sodium hydroxide $0.4 \mathrm{M}$ as titrant and phenol red and pontamine blue as indicators. 4 rats were studied during infusion of saline and 5 during infusion of P.G. A peroral gastric tube was used to rinse out the stomach with $5 \mathrm{ml}$ of distilled water at the end of each sampling period. Sampling periods were chosen from minus 5 to zero minutes before the infusion was started and from zero to 5 minutes, 5 to 10 minutes and 10 to 15 minutes following the start of either saline or pentagastrin infusion.

In another pilot study the arterio-venous differences in $\mathrm{PO}_{2}$ were determined in perfusate samples taken from the perfusion system at a point just proximal to inflow into the aorta (Fig. I, lower section, point "a"), and from the portal pipet. Three perfusion studies were included and blood gas values determined at 5 and 30 minutes after the start of the perfusion. These values were compared with blood gas levels of arterial and venous blood samples taken from the abdominal aorta and portal vein of 2 intact rats under Urethane ${ }^{\circledR}$ anesthesia.

Finally, histological examination of the gastric wall. was performed on specimens taken from the junctional area between the parietal cell mass and the squamous cell area of non-perfused rats and of perfused rats, after 30 minutes of perfusion.

In the actual perfusion experiments samples were collected from the portal canula from -2 to 0 minutes ("0 minutes"), 1-3 minutes ("2 minutes"), 4-6 minutes ("5 minutes"), 9-11 minutes ("10 minutes") and 14-16 minutes ("15 minutes") after the start of saline or PG infusion. After determination of calcium and phosphate concentrations all samples were frozen and stored.

\section{The bone tissue culture:}

These studies were done in collaboration with Paula Stern of the Department of Pharmacology, Northwestern University, Chicago, Ill. The samples were added to a sensitive bone tissue culturing system to determine their effect on bone metabolism. The culture system is a modification of the system described 
by Raisz (18). Female, Sprague Dawley Rats (Holtzman) were injected with $200 \mathrm{Ci}$ of ${ }^{45} \mathrm{Ca} \mathrm{Cl}_{2}$ on the 17 th day of pregnancy. 24 hours later the rats were sacrificed, the embryos removed and each fetal radius and ulna excised an stored in a Petri dish containing ice-cold proteinfree modified B.G.J. medium (Grand Island Biological Company) buffered to pH 7.4 with $10 \mathrm{mM}$ T.E.S. (NTris- (hydroxymethyl) methyl-2-aminoethane sulfonic acid). This medium maintained a stable pH but could not be used for subsequent steps in the procedure since it has been found that T.E.S. and similar buffers inhibit bone resorption in vitro (23).

After dissection with a binocular dissecting microscope the bone explants, consisting of a thin tube of calcified bone matrix surrounding a core of calcified cartilage with discs of mature cartilage cells at each end and often showing a beginning of bone marrow formation, were washed three times with the medium and then precultured for $5-8$ hours at $37^{\circ} \mathrm{C}$ in an air atmosphere in proteinfree medium without T.E.S. in order to remove readily exchangeable ${ }^{45} \mathrm{Ca}$. The bones were placed on squares of millipore filter in small watch glasses, eight of which fitted into a $150 \mathrm{~mm}$ glass Petri dish. This filter was supported by a metal screen so cut that $0.5 \mathrm{ml}$ of medium filled the culture vessel to the surface of the screen. The cultures were maintained for 66 hours at $37^{\circ} \mathrm{C}$ in a medium buffered to $\mathrm{pH} 7.4$ with $\mathrm{NaHCO}_{3}$ and gassed with $5 \% \mathrm{CO}_{2}$ in air. Test solutions (gastric effluents) in 2 and $4 \%$ concentration were added. The effluents of three PG -, and two saline - stimulated perfusion studies were used for these experiments. As was described above, each perfusion study produced 5 effluent samples ("0 minutes", "2 minutes", etc.). Each effluent sample was mixed with the culture medium to form 2 or $4 \%$ solutions. Each different solution was used as the medium for 4 identical culturing experiments and the bone resorbing activity of each solution was expressed as the mean of the results of the four experiments. In addition, all studies using a $4 \%$ solution were repeated. As a control, both the culture medium alone and mixtures of the culture medium and the perfusate in 2 and $4 \%$ concentrations were tested for their bone resorbing activity four different times. Finally, in three experiments, $10^{-11} \mathrm{M} 1,25(\mathrm{OH})_{2} \mathrm{D}_{3}$, the active metabolite of vitamin $D$, was added to the medium which was then run in addition to the standard procedure.

At the end of incubation, the bones were examined at $16 \mathrm{x}$ magnification for evidence of resorption. These data were compared with the isotope data to confirm that the chemical measurements correlated with resorption. The bones were then extracted with $0.5 \mathrm{ml}$ of $0.1 \mathrm{~N} \mathrm{HCl} .{ }^{45} \mathrm{Ca}$ in samples of the culture medium and bone extracts was determined by liquid scintillation counting. Results are expressed as the percentage of the bone ${ }^{45} \mathrm{Ca}$ release into the medium:

$\%{ }^{45} \mathrm{Ca}$ release $=\frac{\text { medium }{ }^{45} \mathrm{Ca}}{\text { medium }{ }^{45} \mathrm{Ca}+\text { bone }{ }^{45} \mathrm{Ca}} \times 100$ 


\section{V.2.2. RESULTS}

\section{The Perfusion System:}

Table 2 shows the results of the pilot study on gastric acid secretion.

Table V.2: Acid secretion (in $\mu E q$ ) and secretory wolume (in ml) during arterio-venous perfu. sion of the stomach.

\begin{tabular}{|c|c|c|c|c|c|c|c|c|}
\hline \multicolumn{9}{|c|}{ PENTAGASTRIN } \\
\hline & \multicolumn{2}{|c|}{ minus $5-0$ min } & \multicolumn{2}{|c|}{$0-5 \min$} & \multicolumn{2}{|c|}{$5-10 \mathrm{~min}$} & \multicolumn{2}{|c|}{$10-15 \mathrm{~min}$} \\
\hline Rall no. & $\mu \mathrm{Eq}$ & $\begin{array}{c}\text { volume } \\
(\mathrm{ml})\end{array}$ & $\mu \mathrm{Eq}$ & $\begin{array}{l}\text { volume } \\
\text { (ml) }\end{array}$ & $\mu \mathrm{Eq}$ & $\begin{array}{l}\text { volume } \\
(\mathrm{ml})\end{array}$ & $\mu \mathrm{Eq}$ & $\begin{array}{c}\text { volume } \\
\text { (ml) }\end{array}$ \\
\hline 1. & 5.7 & 0.08 & 10.8 & 0.20 & 0.0 & 0.38 & 0.0 & 0.39 \\
\hline 2. & 6.2 & 0.09 & 16.2 & 0.22 & 4.8 & 0.32 & 0.0 & 0.45 \\
\hline 3. & 4.8 & 0.07 & 11.2 & 0.17 & 3.8 & 0.36 & 2.1 & 0.43 \\
\hline 4. & 5.0 & 0.08 & 12.4 & 0.23 & 3.6 & 0.30 & 0.7 & 0.41 \\
\hline 5. & 4.9 & 0.07 & 9.2 & 0.14 & 4.2 & 0.22 & 0.0 & 0.30 \\
\hline mean & 5.3 & 0.08 & 11.96 & 0.19 & 3.3 & 0.32 & 0.6 & 0.40 \\
\hline SEM & 0.27 & 0.01 & 1.18 & 0.02 & 0.89 & 0.03 & 0.41 & 0.03 \\
\hline \multicolumn{9}{|c|}{ SALINE } \\
\hline Rat no. & & & & & & & & \\
\hline $1^{1 *}$ & $\begin{array}{l}4.1 \\
3.6\end{array}$ & 0.15 & $\begin{array}{l}2.8 \\
4.1\end{array}$ & $\begin{array}{l}0.18 \\
0.16\end{array}$ & $\begin{array}{l}2.4 \\
12\end{array}$ & $\begin{array}{l}0.33 \\
029\end{array}$ & $\begin{array}{l}0.0 \\
2.0\end{array}$ & $\begin{array}{l}0.39 \\
038\end{array}$ \\
\hline 3. & 6.9 & 0.06 & 5.2 & 0.10 & 0.0 & 0.34 & $\begin{array}{c}2.0 \\
-.-\end{array}$ & 0.50 \\
\hline 4. & 4.8 & 0.11 & 4.9 & 0.13 & 0.5 & 0.28 & 0.0 & 0.41 \\
\hline mean & 5.0 & 0.09 & 4.25 & 0.14 & 1.03 & 0.31 & 0.67 & 0.39 \\
\hline SEM & 0.69 & 0.02 & 0.54 & 0.02 & 0.52 & 0.01 & 0.67 & 0.01 \\
\hline
\end{tabular}

Stimulation with pentagastrin ( 5 rats) or saline (4 rats). Values represent samples collected during successive episodes of 5 minutes.

Infusion of pentagastrin caused a twofold increase in total hydrogen ion content and volume during the first 5 minutes. From 5 to 10 minutes after the start of PG infusion total hydrogen ion content of the gastric juice decreased to below pre-stimulation levels but total volume was larger than before. After 10 minutes no hydrogen ions could be detected in most cases whereas the vollume of the gastric juice went on to increase still further. In the control animals no change in hydrogen ion secretion could be demonstrated after the start of saline infusion although the same "fading" phenomenon occurred in the course of the experiment as had been encountered in the PG group. Likewise, the total secretory volume increased progressively in the course of the experiment.

Bloodgas analysis across the stomachs of perfused rats and controls also seemed to confirm the viability of the perfused gastric tissue (Table 3). 
Table W.3: Blood gas analysis across the stomach in wact mats and across perfused ston machs in situ, after 5 and 30 mimutes of continuous perfusion.

\begin{tabular}{|c|c|c|c|c|}
\hline & & $\mathrm{pH}$ & $\mathrm{PCO}_{2}$ & $\mathrm{PO}_{2}$ \\
\hline \multicolumn{5}{|c|}{ NON PERFUSED (Blood) } \\
\hline \multirow{2}{*}{ RAT I } & Art & 7.32 & 37 & 139 \\
\hline & Ven & 7.26 & 50 & 60 \\
\hline \multirow{2}{*}{ RATII } & Art & 7.42 & 35 & 144 \\
\hline & Ven & 7.39 & 36 & 64 \\
\hline \multicolumn{5}{|c|}{ PERFUSED (Krebs Solution) } \\
\hline \multirow[t]{4}{*}{ RAT I } & Arts $_{s}$ & 7.36 & 27 & 450 \\
\hline & $\operatorname{Ven}_{5}$ & 7.32 & 36 & 230 \\
\hline & $\mathrm{Art}_{90}$ & 7.39 & 28 & 360 \\
\hline & $\operatorname{Ven}_{30}$ & 7.29 & 32 & 245 \\
\hline \multirow[t]{4}{*}{ RAT II } & $\mathrm{Art}_{5}$ & 7.56 & 24 & 355 \\
\hline & Vens & 7.38 & 33 & 198 \\
\hline & $\mathrm{Art}_{30}$ & 7.46 & 24 & 356 \\
\hline & $\operatorname{Ven}_{3 \beta}$ & 7.41 & 32 & 235 \\
\hline \multirow{4}{*}{ RAT III } & $\mathrm{Art}_{5}$ & 7.40 & 17 & 395 \\
\hline & $\mathrm{Ven}_{\mathrm{s}}$ & 7.23 & 21 & 225 \\
\hline & $\operatorname{Art}_{30}$ & 7.23 & 18 & 394 \\
\hline & $\operatorname{Ven}_{30}$ & 7.10 & 25 & 244 \\
\hline
\end{tabular}

Although $\mathrm{PO}_{2}$ values were considerably higher in the perfused animals, both groups showed comparable losses of $\mathrm{O}_{2}$ across the stomach after 5 minutes of perfusion. Furthermore, after 30 minutes of perfusion oxygen uptake occurred at the same rate as early on in the experiment.

After 5 to 10 minutes of perfusion, the stomachs became progressively swollen and glassy-looking as a result of diffusion of perfusate through the tissue layers of the gastric wall. Addition of mannitol $(3 \%)$ and dextrose $(0.9 \mathrm{~g} / \mathrm{L}) \mathrm{di}$ minished this problem by raising the osmolarity of the perfusate from 279 to $439 \mathrm{mosmol} / \mathrm{kg}$ (Table 4). Nevertheless, at the end of each perfusion study frank edema usually was present.

Table V.4: Comparison of glucose concentration, osmolarity and buffer capacity in standard Krebs-Henseleit solution and modified Krebs-Henseleit solutions.

$$
\begin{aligned}
& \text { Krebs-Henseleit Krebs-Henseleit Krebs-Henseleit units } \\
& \stackrel{+}{+} \underset{\text { dextrose }}{0.09 \mathrm{M}} \stackrel{+}{\text { dextrose } 0.09 \mathrm{M}} \\
& + \\
& \text { mannitol } 3 \%
\end{aligned}
$$

\begin{tabular}{lcccc} 
Glucose & - & 4.8 & 4.8 & $\mathrm{mmol} / \mathrm{L}$ \\
Osmolarity & 279 & 302 & 439 & $\mathrm{mosmol} / \mathrm{kg}$ \\
$\begin{array}{c}\text { Acid binding } \\
\text { capacity }\end{array}$ & 20 & 20 & 20 & $\mathrm{micro} \mathrm{osmol}$ \\
\hline
\end{tabular}


Although histological examination of the gastric wall confirmed the presence of this phenomenon, it may be concluded from Fig. 2 to 5 that, after thirty minutes of perfusion, gross anatomy of the tissues was preserved and the individual cells maintained a normal appearance.
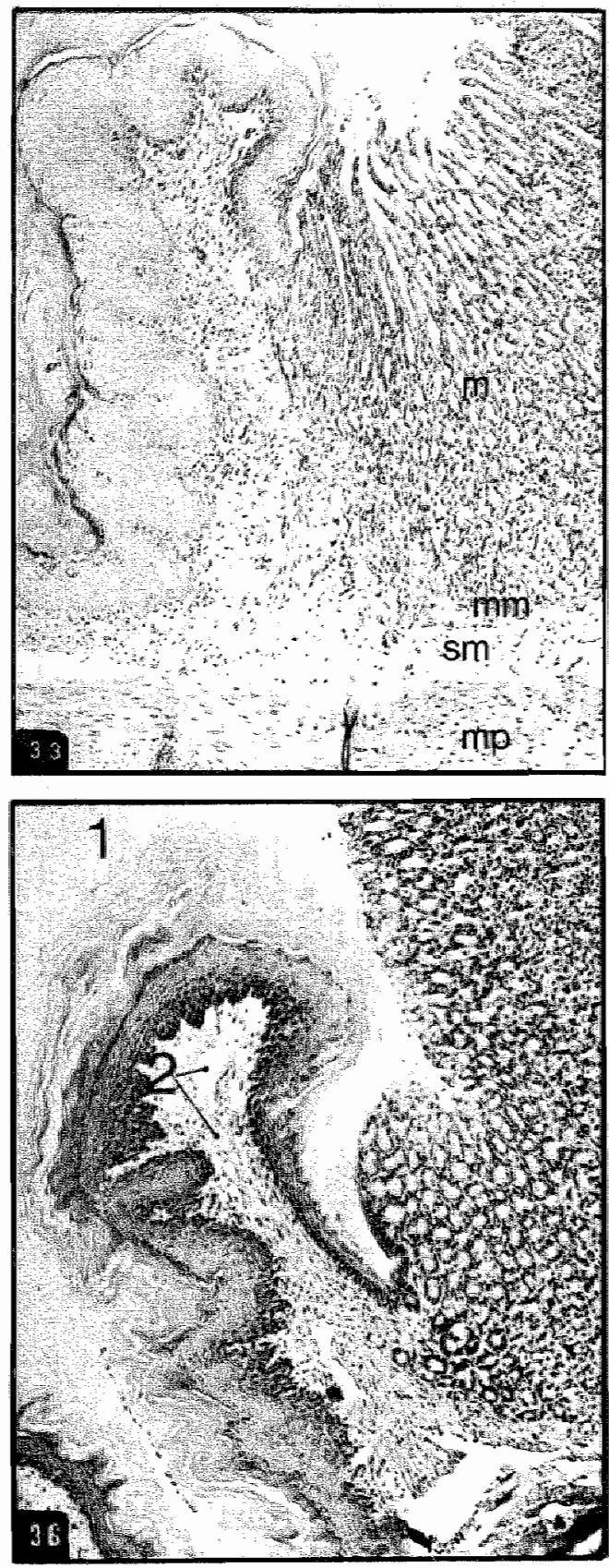

Figure V.2:

Transitional area of squamous cell $/$ parietal cell mass in the normal rat stomach (control).

$\mathrm{m}$ = mucosa of parietal cell mass;

$\mathrm{mm}=$ muscularis mucosae;

sm = submucosa;

$\mathrm{mp}=$ muscularis propria.

(Magnilication $\times 40$ ).
Figure V.3:

Transitional area of squamous cell/ parietal cell mass in the rat stomach affer 30 mimutes of perfusion (no pentagastin added).

1 gastric lumen;

2 enlarged submucosal vessells.

(Magnification $\mathrm{x} 40$ ). 

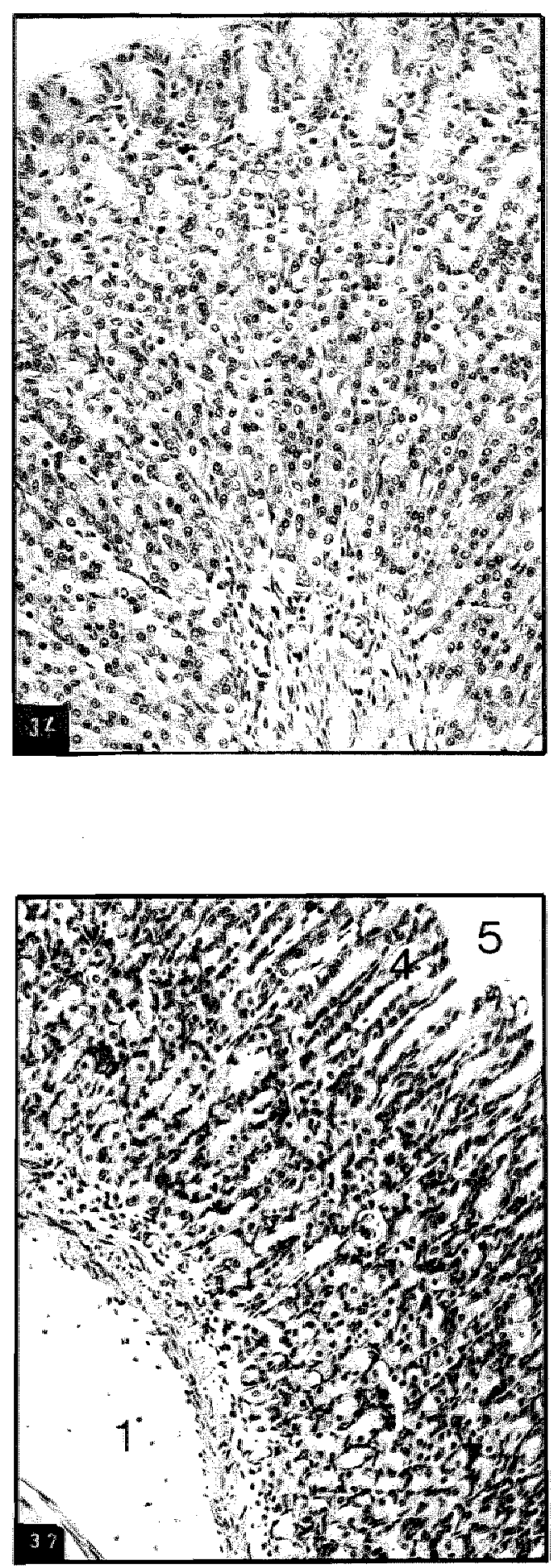

Figure V.4:

Fundic mucosa in normal rat, detail.

(Magnification x 250).
Figure V.5:

Fundic mucosa in perfinsed rat, detail.

1 submucosa;

2 muscularis mucosae;

3 mucosa:

4 pitglands, lined with parietal

(oxyntic) cells (darker) and zymogen (chief-) cells (lighter);

5 gastric lumen.

(Magnification $\times 250$ ). 
The results of these preliminary studies all seem to indicate that the perfusion system was capable of preserving form and function of the in situ perfused stomach for at least 5 to 10 minutes.

\section{The Bone Tissue Cultures:}

Culturing of the bone in standard culture medium resulted in release of approximately $20 \%$ of bone ${ }^{45} \mathrm{Ca}$ activity into the medium (Fig. 6-9, left lower section). As was to be expected, $1,25(\mathrm{OH})_{2}$ vitamin $\mathrm{D}_{3}$ enhanced bone resorption when added to the medium (Fig. 6,8 and 9, left upper section). Culturing with $2 \%$ or $4 \%$ solutions of the perfusate in standard culture medium resulted in mutually indistinguishable increases of bone resorption as compared to basal culture conditions, irrespective of the presence of either saline or pentagastrin in the perfusate. Even when bone resorption was increased by the addition of 1,25 $(\mathrm{OH})_{2}$ Vitamin $\mathrm{D}_{3}$, no clear effect became noticeable following incubation with 2 and $4 \%$ concentrations of the perfusate in the culture medium. Again, the presence of either saline or pentagastrin in these mixtures failed to effectuate any difference under those circumstances of enhanced bone resorption (Fig. 69 , left side).

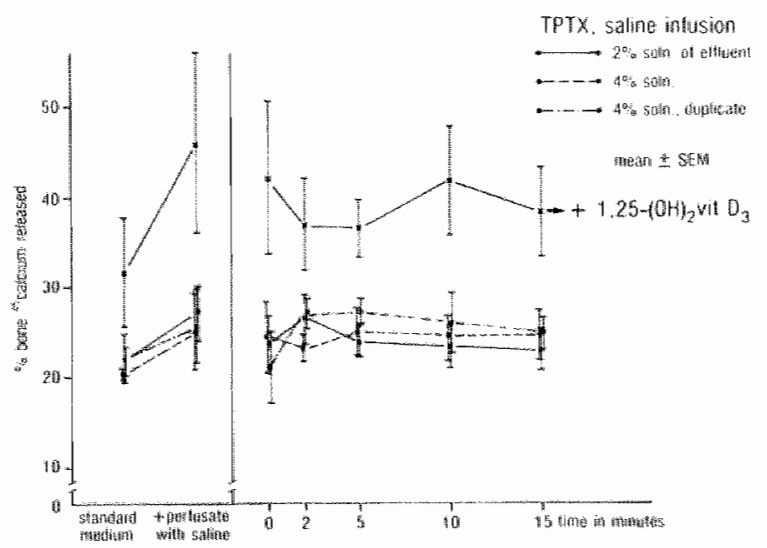

Figure V.6: The effect of gastric effuent on ${ }^{4}$ Ca release from bone explants in culture medium.

One rat was used in this study. Saline (control) was infused during the perfusion. On the left side the effect of the culture medium alone is compared with that of 2 and $4 \%$ concentrations of the Krebs-Henseleit solution in the culture medium. On the right side effluent samples, collected during 2 minutes at different time points after the start of saline infusion, were added to the medium in 2 and $4 \%$ concentrations. In one experiment, 1,25-dihydroxy vitamin $D_{3}, 10^{11} \mathrm{M}$, was added to the medium (upper half). Each value represents the mean \pm SEM of the results of four culture studies performed on the same sample.Student's t test. 


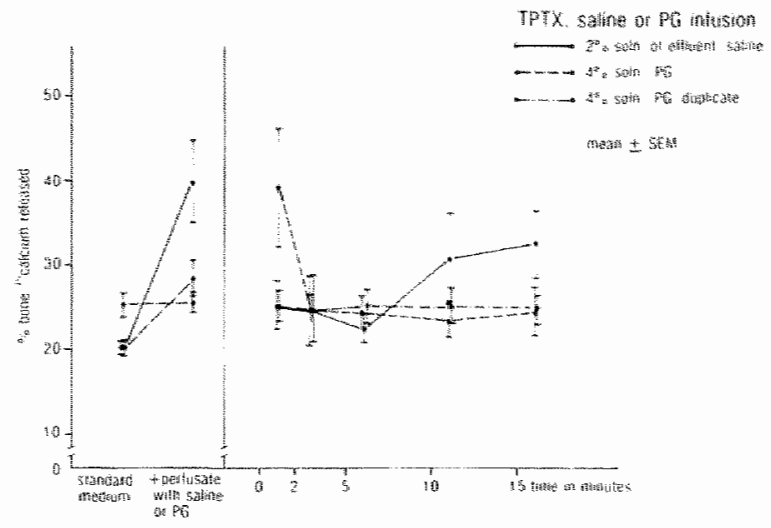

Figure V.7: The effect of gastric effuent on ${ }^{45}$ Ca release from bone explants in culture medium.

Two animals were used in this study. Saline was infused into one animal, PG into the other. On the left side the effect of the culture medium alone is compared with that of 2 and $4 \%$ concentrations of the Krebs-Henseleit solution in the culture medium. On the right side the effect of saline or pentagastrin stimulation of the stomach on the bone resorbing activity of the effluent samples was studied. Each value represents the mean \pm SEM of the results of four culture studies performed on the same effluent sample. Student's $t$ test.

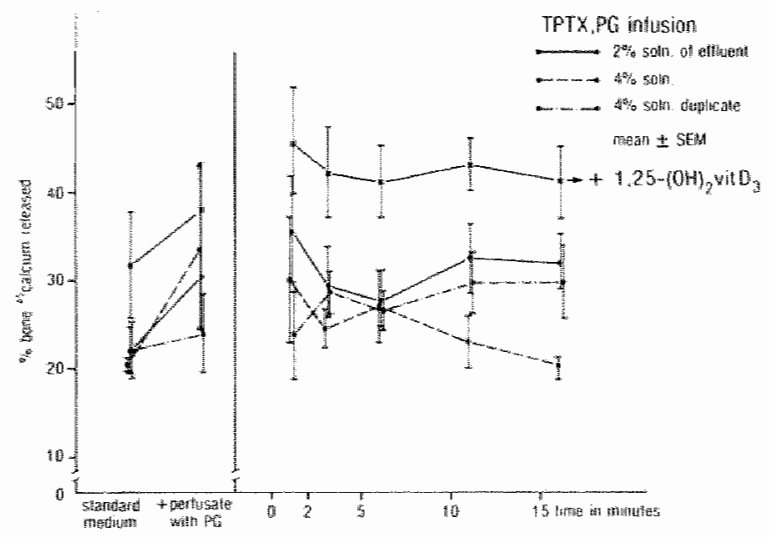

Figure V.8: The effect of gastric effluent on ${ }^{4}$ Ca release from bone explants in culture medium.

Pentagastrin stimulation was used during the gastric perfusion of this rat. On the left side the effect of the culture medium alone is compared with that of 2 and $4 \%$ concentrations of the Krebs-Henseleit solution in the culture medium. On the right side the effect of pentagastrin stimulation of the gastric tissue on the bone resorbing activity of the effluent samples was studied. In one experiment 1,25 -dihydroxy vitamin $D_{3}, 10^{11} \mathrm{M}$, was added to the medium (upper half). Each value represents the mean of the results of 4 culture studies performed on the same sample. Student's $t$ test. 


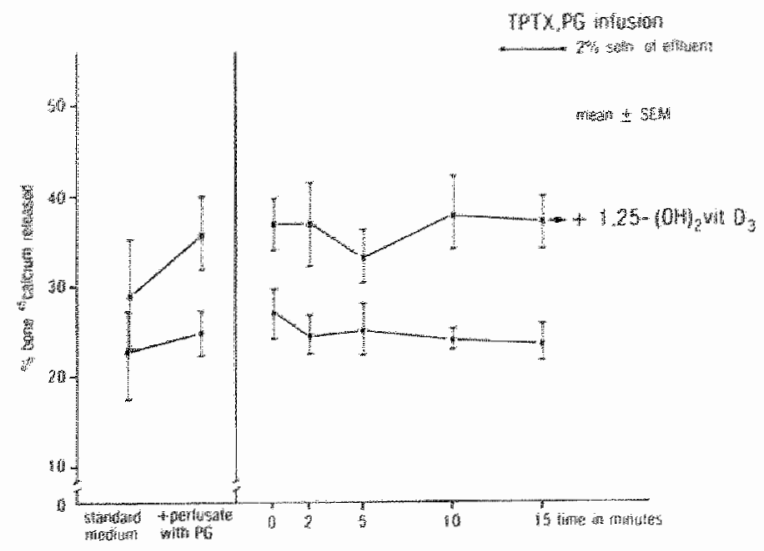

Figure V.9: The effect of gastric effuent on ${ }^{45}$ Ca release from bone explanis in culture medium.

Pentagastrin stimulation was used during the perfusion of this rat.

On the left side the effect of the culture medium alone is compared with that of a $2 \%$ solution of the Krebs-Henseleit solution in the culture medium. On the right side the effect of pentagastrin stimulation of the gastric tissue on the bone resorbing quality of the effluent samples was studied. The experiment was repeated with addition of 1,25 -dihydroxy vitamin $D_{3}$, $10^{-11} \mathrm{M}$, to the medium. Each value represents the mean of the results of 4 culture studies performed on the same sample. Student"s t test.

On the right side of Fig. 6 to 9 the effect of samples of the gastric effluent on bone resorption is shown. As can be seen, at no time point incubation of bone explants with mixtures of the medium and the gastric effluent resulted in any appreciable change of the bone resorptive process from basal values. Especially, no difference became visible between saline and PG-stimulated effluents, even not in the 2 or 5 minutes samples. Doubling the concentration of the gastric effluent from 2 to $4 \%$ did not alter these observations. Nor did the enhanced state of bone resorption, as effectuated by the addition of $1,25(\mathrm{OH})_{2}$ vitamin $\mathrm{D}_{3}$, disclose any inhibititive quality of the PG-stimulated effluent.

In other words, stimulation of the gastric tissue with high levels of pentagastrin did not seem to have resulted in the release of a substance capable of changing the rate of bone resorption.

\section{V.3. DISCUSSION}

As was stated before, the culturing of bone in a medium with venous effluent of the rat stomach was based upon the theoretical presence of cells in the parietal cell mass, capable of secreting a calcium lowering substance. During a revisional meeting of the original Wiesbaden classification (34) of the APUD series (Bologna, 1973) 6 different endocrine cell types were agreed upon to be located in the human stomach, based on the ultrastructural appearance of those cells: 
Enterochromaffin (EC), G, enterochromaffin-like (ECL), A-like (AL), D and Dl. Using either direct or indirect immunofluorescence procedures only the gastrin-producing G-cell could be identified by the available antisera. In a more recent publication (35) at least 3 different types were mentioned for the oxyntic cell area: ECL cells (argentophil), A-like (or X) cells and D cells, now specified as somatostatin cells. In the rat, the ECL and A-like cells seem to be special in that they produce and store histamine (36) but while these cells occupy $66 \%$ and $24 \%$ of the parietal endocrine cell mass respectively (37), their physiological functions or the nature of their assumed products remain totally unknown.

The bone tissue culturing system seemed an efficient way to try to demonstrate in vitro the presence of this hypothetical calcium lowering substance from the stomach, because all known serum calcium regulating factors influence, positively or negatively, the bone resorptive process.

Since the early experiments of Fell e.a. in 1926 (38) bone tissue cultures have become a generally accepted technique to study bone metabolism and its regulating factors. Different tissues, culture systems and media have been employed. Midshafts of fetal limbbones have always been used at the Department of Pharmacology of the Northwestern University, Chicago, Ill., because they retain good cellularity when maintained in culture for several days and respond consistently to various modifications in the milieu. The responses to hormones are greater when cartilage ends are removed and only the boneshaft is cultured (39). The non-protein components of the medium appear to affect not only general cell survival but also the direction of differentiation of the tissue. Calcium, phosphate, magnesium and hydrogen ions are the most critical; their concentrations in the medium were carefully monitored.

Although for some hormones proteins appear to be essential to become effective - for instance, both PTH (40) and CT (41) require serum for their effect on bone resorption - the presence of undefined protein constituents in media causes varied and somewhat unpredictable effects on the release of ${ }^{45} \mathrm{Ca}$ from cultured bone fragments (39). For this reason it was decided not to use serum in our experiments and blood was replaced by the modified Krebs-Henseleit solution.

The conditions in the perfusion model were chosen to be as close to normal physiology as possible. The stomach was left in situ completely, with great emphasis on vascularity and innervation. Flow rate was estimated from various reports in the literature. Sapirstein (42) with ${ }^{42} \mathrm{~K}$ and ${ }^{86} \mathrm{Rb}$, Bullard (43) employing indicator dilution methods and Blood e.a. (44) by the direct Fick method reported cardiac output values ranging from 205 to $230 \mathrm{ml} / \mathrm{kg} / \mathrm{min}$. Later, the use of radioactive microspheres was found to be more satisfactory and higher figures were presented by Malik e.a. (45), assessing cardiac output at 278 $\mathrm{ml} / \mathrm{kg} / \mathrm{min}$ in conscious unfasted rats. Measurements of regional distribution of cardiac output to the stomach with microspheres of varying diameter (15-50 $\mu \mathrm{m})$ resulted in flow rates ranging from 0.9 to $1.6 \%$ of cardiac output and to the spleen from 0.6 to $1.2 \%$ of cardiac output $(45,46,47)$. The effect of anesthesia on the distribution of cardiac output remains controversial but a clear increase in 
percentual gastric flow from 0.9 to $1.5 \%$ of cardiac output was reported by Sasaki e.a. (46) with the use of intravenous Pentabarbital. Based upon these findings the physiologic gastrosplenic flow in our 100 gram, anesthetized rats was estimated to range from $0.45-1.26 \mathrm{ml} / \mathrm{min}$. Physiological systemic pressures of $120 \mathrm{~mm} \mathrm{Hg}(45,48)$ could not be maintained unless flow-rates were increased to above reasonable limits. Instead, systemic pressures of 80 to $100 \mathrm{~mm}$ $\mathrm{Hg}$ were established by regulating flow rates between $0.5 \mathrm{ml}$ to $2 \mathrm{ml}$ per minute, which was thought to be acceptable.

The acid secretory process of the stomach is absolutely dependent on the presence of oxygen (49) because it is directly coupled to the mitochondria of the parietal cell. In the rat the mitochondria occupy about one third of the cytoplasm of the parietal cell, the highest figure reported for any mammalian cell (50). High $\mathrm{PO}_{2}$ values were established by circulating the perfusate through the oxygenation cylinder.

After its passage through the stomach a large drop in oxygen tension was measured in the perfusate, on the one hand indicative of the viability of the perfused tissues, and on the other of the poor oxygen binding capacity of the Krebs solution. Gassing the modified Krebs solution with $\mathrm{O}_{2}, 95 \%$, and $\mathrm{CO}_{2}$, $5 \%$, resulted in a fall of $\mathrm{pH}$ to $7.5 \pm 0.5$. Further control to $\mathrm{pH} 7.4$ was achieved by continuous automatic titration, resulting in very stable experimental conditions.

The oxygen loss across the stomach, the increase in titratable acidity of the gastric juice and the histological integrity of the perfused gastric wall that were found in the pilot studies all seem to indicate that the perfusion system was

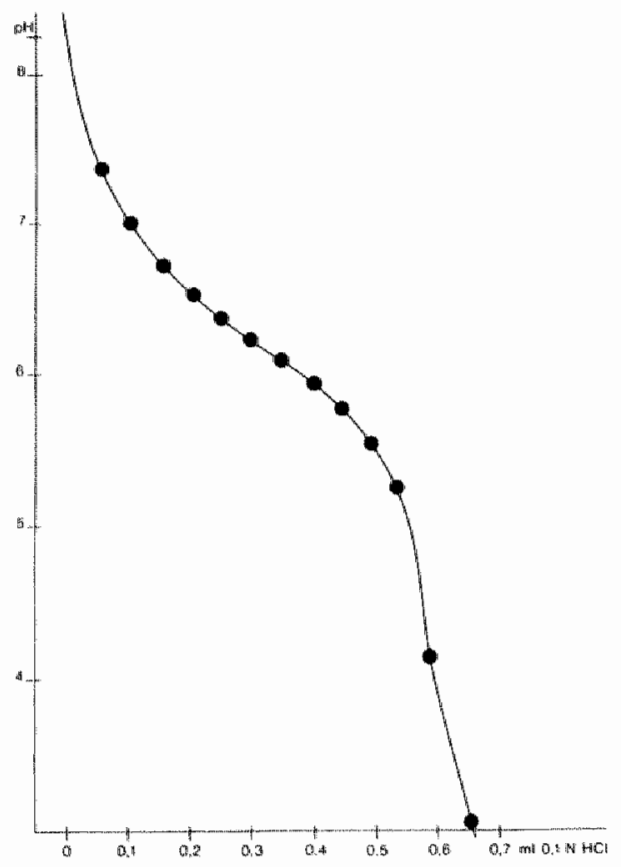

Figure V.10: Titration curve of $3 \mathrm{ml}$ of the modified Krebs-Henseleit solution. At the start of the titration experiment the solution was gassed with a mixture of $\mathrm{CO}_{2}$, $4 \%, \mathrm{O}_{2}, 12 \%$ and $\mathrm{N}, 84 \%$ for 30 minutes. Optimal buffering capacity was demonstrated between pH $6.8-5.5$. 
succesful in maintaining stable circulatory conditions for at least 10 minutes.

How then, is the early disappearance of titratable acid from the gastric juice to be explained? As can be seen in Table 2, there was a progressive increase in total volume of gastric secretion during perfusion. Clearly this was caused by diffusion of perfusate through the wall into the gastric lumen as otherwise evidenced by the progressive edema. In a separate titration experiment (Fig. 10), the modified Krebs-Henseleit solution had good buffering properties in a range of $\mathrm{pH} 6.8$ to 5.5 .

Therefore, each ml of the solution must be considered capable of neutralizing $18-20 \mu \mathrm{Eq}$ of $\mathrm{HCl}$ under those conditions (Table 4). In the physiologic range buffering was insignificant. If on diffusing into the gastric lumen the perfusate encountered small amounts of gastric acid $(\mathrm{HCl})$ it would quickly reach the optimal buffering range. Thus, a maximum of 7 to $8 \mu \mathrm{Eq}$ of acid may have been neutrallized in the 10 and 15 minutes samples respectively, assuming that most of the gastric juice in those periods was formed by trans-membranous diffusion of perfusate. Secondly, the progressive edema of the gastric wall may have interfered with the acid secretory process. The fair histological appearance of the gastric tissue after 30 minutes of perfusion, or the undiminished oxygen uptake do not favor this view, however. A third possibility is offered by the mechanism of fading (tachyphylaxis). This phenomenon is defined as a diminishing biological response to a constant stimulus (51). The exact nature of this escape phenomenon is not known but it is thought that receptor kinetics or loss of receptor sites play a rolle. The high concentrations of PG that were used in our experiments may have accelerated such response.

If it is assumed then, that the stomach was functioning normally during the first five to ten minutes after the start of the perfusion, would there be time enough for the release of the hypothetical hypocalcemic amine or peptide? It appears so, because target cells are known to react almost immediately to a specific stimulus. This was nicely demonstrated in the experiment where peak levels of iCT were measured at two minutes after injection of $\mathrm{PG}$ into intact rats (Chapter IV). Also, in normal human beings and in patients with medullary $\mathrm{Ca}$ of the thyroid gland, peak serum calcitonin levels are reached by 2.5 minutes after intravenous administration of pentagastrin $(52,53)$. In addition, acid secretion, to which the release of the hypocalcemic agent is linked, starts well within five minutes after the intravenous administration of pentagastrin, as was shown earlier in this chapter.

Taking all of the above into account, it appears justified to say that the first two effluent samples collected after the start of the PG infusion, and maybe the third sample as well, were potential carriers of the calcium lowering agent.

Nevertheless, all samples failed to induce any reproducable change in the in $\mathrm{vi}$ tro bone resorptive process.

There is no reason to doubt the validity of the bone tissue culture procedures since this method has been recognized as a sensitive indicator of bone accretion and resorption in vitro and, in our experiments, a normal stimulation of bone resorption was observed after addition of vitamin $D_{3}$ to the medium. Since it is unlikely that a calcium regulating agent would not involve the body's 
most important regulator of calcium homeostasis, the bone, it seems reasonable to state that the hypocalcemia following pentagastrin administration to the rat is not caused by the release of a hypocalcemic substance from the stomach.

\section{V.4. CONCLUSION}

A perfusion system, perfusing the rat in situ stomach with a protein free solution was capable of maintaining the secretory function of the gastric mucosa during at least 10 minutes. Stimulation of the stomach by pentagastrin did not result in the isolation of a factor capable of influencing bone resorption in a well controlled, sensitive bone tissue culture system.

The hypocalcemia following i.v. administration of pentagastrin is mediated by the stomach but it seems not to be caused by the release of a hormone from this organ.

\section{V.5. REFERENCES}

1. Raisz, L.G. (1970): Physiologic and pharmacologic regulation of bone resorption. N. Engl. J. Med. 282, p. 909.

2. Barzel, U.S. and Jowsey, J. (1969): The effects of chronic acid and alkali administration on bone turnover in adult rats. Clin. Sci. 36, p. 517.

3. Hausmann, E. and Raisz, L.G. (1970): Endotoxins: stimulation of bone resorption in tissue culture. Science 168, p. 862.

4. Kaplan, E.L., Tager, H.S., Klementschitsch, P. and Lagocki, R. (1978): C.E.P.: The calcium elevating peptide from the pancreas. Scand. J. Gastroenterol. 13, Suppl. 49. p. 96.

5. Stern, P.H. (1969): Stimulation of bone resorption by oleic acid in vitro. Pharmacologist 11, p. 239.

6. Goldhaber, P. (1965): Heparin enhancement of factors stimulating bone resorption in tissue culture. Science 147, p. 407.

7. Griffith, G.C., Nichols, G. Jr., Asher, J.D. and Flanagan, B. (1965): Heparin osteoporosis. JAMA 193, p. 91

8. Goldhaber, P. (1958): The effect of hyperoxia on bone resorption in tissue culture. Arch. Path. (Chicago) 66, p. 635.

9. Goldhaber, P. (1965): Bone resorption factors, co-factors and giant vacuole osteoclasts in tissue culture. In: The parathyroid glands: ultrastructure, secretion and function. Ed. by Gaillard, P.J., Talmage, R.V. and Bundy, A.M., p. 153. Chicago: Chicago University Press, 1965.

10. Dietrich, J.W., Goodson, J.M. and Raisz, L.G. (1975): Stimulation of bone resorption by various prostaglandins in organ culture. Prostaglandins 10, p. 231.

11. Tashiian, A.H. Jr., Voelkel, E.F., Levine, C. and Goldhaber, P. (1972): Evidence that the bone resorption stimulating factor produced by mouse fibrosarcoma cells is prostaglandin $\mathrm{E}_{2}$. J. Exp. Med. 136, p. 1329.

12. Stern, P.H. and Raisz, L.G. (1967): An analysis of the role of serum in parathyroid hormone-induced bone resorption in tissue culture. Exp. Cell Res. 46, p. 106.

13. Fell, H.B. (1969): Role of biological membranes in some skeletal reactions. Ann. Rheum. Dis. 28, p. 213. 
14. Vaes, G. (1969): Lysosomes and the cellular physiology of bone resorption. In: Frontiers of biology, vol. 14. Lysosomes in biology and pathology. Ed. by Dingle, J.T. and Fell, H.B., Amsterdam, North-Holland Publishing Company, p. 217. 1969.

15. Burkhart, J.M. and Jowsey, J. (1967): Parathyroid and thyroid hormones in the development of immobilization osteoporosis. Endocrinology 81, p. 1053.

16. Raisz, L.G. (1976): Direct stimulation of bone resorption by thyroid homones. J. Clin. Invest. 58 , p. 529.

17. Reynolds, J.J. (1968): Inhibition by calcitonin of bone resorption induced in witro by vitamin A. Proc. R. Soc. Ser. B 170, p. 61.

18. Raisz, L.G. (1965): Bone resorption in tissue culture: factors influencing the response to parathyroid hormone. J. Clin. Invest. 44, p. 103.

19. Tashiian, A.H. Jr. (1965): Homeostasis of plasma calcium: effects of actinomycin D, parathyroidectomy and thyrocalcitonin. Endocrinology 77, p. 375 .

20. Raisz, L.G. (1965): Inhibition by actinomycin D of bone resorption induced by parathyroid hormone or vitamin A. Proc. Soc. Exp. Biol. Med. 119, p. 614.

21. Ryan, W.G., Schwartz, T.B. and Perlia, C.P. (1969): Effect of mithramycin on Paget's disease of bone. Ann. Intern. Med. 70, p. 549.

22. Riggs, B.L., Jowsey, J., Kelly, P.J., Jones, J.D. and Maher, F.T. (1969): Effect of sex hormones on bone in primary osteoporosis. J. Clin. Invest. 48, p. 1065.

23. Stern, P.H. (1969): Inhibition by steroids of parathyroid hormone-induced $45 \mathrm{Ca}$ release from embryonic rat bone in vitro. J. Pharmacol. Exp. Ther. 168, p. 211.

24. Faccini, J.M. (1967): Inhibition of bone resorption in the rabbit by fluoride. Nature (London) 214, p. 1269.

25. Goldhaber, P. (1967): The inhibition of bone resorption in tissue culture by nontoxic concentrations of sodium fluoride. Israel J. Med. Sci. 3, p. 617.

26. Birge, S.J. and Alvioli, L.V. (1969): Glucagon-induced hypocalcemia in man. J. Clin. Endocrinol. 29, p. 213.

27. Stern, P.H. and Bell, N.H. (1968): On the mechanism by which glucagon produces hypocalcemia. Pharmacologist 10, p. 201.

28. Jowsey, J. and Simons., G.W. (1968): Normocalcemia in relation to cortisone secretion. Nature (Londion) 217, p. 1277.

29. Estep, H., Shaw, W.A., Watlington, C., Hobe, R., Holland, W. and Tucker, St.G. (1969): Hypocalcemia due to hypomagnesemia and reversible parathyroid hormone unresponsiveness. J. Clin. Endocrinol. 29 , p. 842.

30. Raisz, L. G. and Niemann, I. (1969): Effect of phosphate, calcium and magnesium on bone resorption and hormonal responses in tissue culture. Endocrinology 85 , p. 446 .

31. Johnston, C.C.Jr. and Smith, D.M. (1970): Protamine - an inhibitor of bone resorption. Clin. Res 18, p. 53.

32. Russell, R.G.G., Bisaz, S, and Fleisch, H. (1969): Pyrophosphate and Diphosphonates in calcium metabolism and their possible role in renall failure. Arch. Intern. med. (Chicago) 124, p. 571 .

33. Maghoub, A and Stern, P.H. (1974): Use of amine buffers for in witro studies of bone resorption. In vitro 9, p. 311 .

34. Creutzfeldt, W., Gregory, R.A., Grossman, M.I. and Pearse, A.G.E. (1970): Origin, chemistry, physiology and pathophysiology of the gastro-intestinal hormones. Schattauer Verlag, Stuttgart.

35. Hakanson., R., Alumets, J., Ekelund, M., Hedenbro, I., Liedberg, G., Loren, I., Sundler, F. and Vallgren, S. (1973): Stimulation of gastric acid secretion. Scand. J. Gastroenterol. suppl. 19.

36. Hakanson, R. and Owman, Ch. (1967): concomittant histochemical demonstration of histamine and catecholamines in the enterochromaffin-like cell of gastric mucosa. Life Sci. Oxford 6, p. 759. 
37. Hakanson, R, Larsson, L.I., Liedberg, G., Oscarson, J., Sundler, F. and Vang J. (1976): Effects of antrectomy or porta-caval shunting on the histamine-storing endocrine-like cell in oxyntic mucosa of rat stomach. A fluorescence histochemical electron microscopic and chemical study. J. Physiol. 259, p. 785.

38. Strangeways, T.S.P. and Fell, H.B. (1926, 1927): Experimental studies on the differentiation of embryonic tissues growing in vivo and in vitro. The development of the undifferentiated limb bud (a) when subcutaneously grafted in to the post embryonic chick and (b) when cultivated in vitro. Proc. R. Soc. Lond. Ser. B99, p. 340 .

39. Stern, P.H. and Raisz, L.G. (1979): Organ culture of bone. In: Skeletal Research. Academic Press Inc, 1979.

40. Stern, P.H. and Raisz, L.G. (1967): An analysis of the role of serum in parathyroid hormone-induced bone resorption in tissue culture. Exp. Cell Res. 46, p. 106.

41. Gozarin, L., Bellwinkel, S. and Ziegler, R. (1973): Effects of serum on the calcitonim-dependent bone resorption in vitro. Endocrinol. Exp. 7, p. 129.

42. Sapirstein, L.A. (1958): Regional blood flow by fractional distribution of indicators. Am. J. Physiol. 193, p. 161.

43. Bullard, R.W. and Adolph, E.F. (1956): Maintenance of arterial pressure and cardiac output in the hypothermic rat. Fed. Proc. 15 , p. 28.

44. Blood, F.R., Smith, D.L. and D'Amour, F.E. (1950): Cardiac output in rat at normal and at high altitudes and its relationship to gas embolism. Am. J. Plhysiol. 163, p. 268 .

45. Malik, A.B., Kaplan, J.E. and Saba, T.M. (1976): Reference sample method for cardiac output and regional blood flow determinations in the rat. J. Appl. Physiol. 40, p. 472 .

46. Sasaki, Y. and Wagner, H.N. Jr. (1971): Measurement of the distribution of cardiac output in unanesthetized rats. J. Appl. Physiol. 30, p. 879.

47. Rakus-an, K. and Blahitka, J. (1974): Cardiac output distribution in rats measured by injection of radioactive microspheres via cardiac puncture. Can. J. Physiol. Pharmacol. 52, p. 230.

48. Takács, L., Kállay, K. and Skolnik, J.H. (1962): Effect of tourniquet shock and acute hemorrhage on the circulation of various organs in the rat. Circ. Res. 10, p. 753.

49. Berglindh, Th., Helander, H. and Sachs, G. (1979): Secretion at the parietal cell levell - a look at rabbit gastric glands. Scand. J. Gastroenterol. 14, p. 55.

50. Helander, H.F. (1976): Stereological changes in rat parietal cells after vagotomy and antrectomy. Gastroenterology 71, p. 1010.

51. Edkins, J.S. (1906): The chemical mechanism of gastric secretion. J. Physiol. 34, p. 133.

52. Sizemore, G.W., Go, V.L.W. (1975): Stimulation tests for diagnosis of medullary thyroid carcinoma. Mayo Clin. Proc. 50, p. 53.

53. Deftos, L.J., Roos, B.A., Knecht, G.L., Lee, J.C., Pavlinac, D., Bone, H.G. and Parthemore, J.G. (1978): Calcitonin secretion. In: Endocrinology of calcium metabolism, p. 134. Ed. by Copp, D.H. and Talmage, R.V., Amsterdam, Excerpta MediCa, 1978, W 3 Ex. 89, nr. 421 . 
Chapter VI

WHERE DOES CALCIUM GO WHEN HYPOCALCEMIA OCCURS?

\section{VI.1. INTRODUCTION}

Although numerous controversies remain to be solved, the results that were presented in previous chapters seem to indicate that pentagastrin and other gastro-intestinal peptides and amines play a role in normal calcium homeostasis. Together with calcitonin gastro-intestinal hormones may be part of a gut$\mathrm{C}$-cell axis in the physiologic regulation of calcium homeostasis. However, from the results presented here it has become clear that CT is not an essential part of the mechanism through which these agents lower serum calcium concentration in the rat. It is a challenging question whether gut hormones involved in the acid secretory process act as primary regulators of post-prandial hypercalcemia, for it is well known that hypercalcemia can induce hypergastrinemia $(1,2,3)$. This question will be dealt with later on.

Attention will be focused now on the question of by what mechanism acid secretagogues lower serum calcium concentration. Close inspection of the known biological actions of (penta-) gastrin may lead to the identification of the mechanisms and tissues that are instrumental in the hypocalcemia. The best known physiological action of gastrin on the gastro-intestinal tract is, of course, the increase of gastric hydrochloric acid secretion $(4,5,6)$. Stimulation of pancreatic enzyme secretion (7), pepsin secretion, stimulation of gastric mucosal blood flow and its trophic action on parietal cells and Brunner's glands $(8,9)$ may be other physiologic processes that follow the elevation of serum gastrin levels because they occur at the minimal dose needed to stimulate acid secretion (10). Other effects of gastrin include the stimulation of bile secretion and a change of bile composition (11), stimulaton of water and electrolyte secretion from the stomach, pancreas and small intestines (12) and several more actions on gastro-intestinal dynamic (13) and hormonal $(14,15,16)$ systems.

This information helps us to list the possible pathways that calcium may take after administration of pentagastrin.

1. Calcium may be excreted by the gastric mucosa into the gastric juice as part of the acid secretory process.

2. Calcium may enter the gastric wall to act as second messenger for hydrochloric acid production.

3. A gastric factor may be responsible for the migration of calcium from the plasma into bone, the blood cells, any other tissue or for its excretion in bile, urine or the gastro-intestinal lumen. 
4. Finally, a gastric factor may be responsible for a decrease of calcium efflux from bone in to the extracellular space without influencing bone accretion resulting in an acute deficit in the serum.

Several experiments were designed to explore the above possibilities.

Firstly, in pylorus-ligated rats, total calcium and gastric acidity were determined in gastric juice after injection with PG or saline and the relationship between gastric calcium secretion and PG stimulation was examined.

Secondly, portal and systemic calcium concentrations were determined simultaneously after administration of $\mathrm{PG}$ to investigate the uptake of calcium by the stomach. An arterio-venous gradient across the stomach might occur if calcium were excreted into the gastric juice or incorporated in the gastric wall. Unfortunately, a true A-V difference was hard to achieve in the rat and a compromise was made by measuring jugular vein and portal vein blood.

Finally, several studies with tracer calcium, ${ }^{45} \mathrm{Ca}$ or ${ }^{47} \mathrm{Ca}$, were performed to: - measure the possible calcium shift from the extracellular space into the gastric wall and,

- to study serum calcium kinetics in order to understand the direction of calcium movement after PG administration in relation to the bone.

\section{V1.2. EXPERIMENTS}

\section{VI.2.1. CALCIUM SECRETION INTO THE GASTRIC JUICE}

\section{vi.2.1.1. Material and Methods}

Forty two $90-100 \mathrm{mg}$ rats were fasted for 24 hours. Ether anesthesia was given. Following ligation of the pylorus with the technique described by Shay (17), the rats were injected with either saline $(n=23)$ or $P G, 25 \mu g(n=19)$, each in a volume of $0.2 \mathrm{ml}$. Serum Calcium was performed on venous blood collected at 0

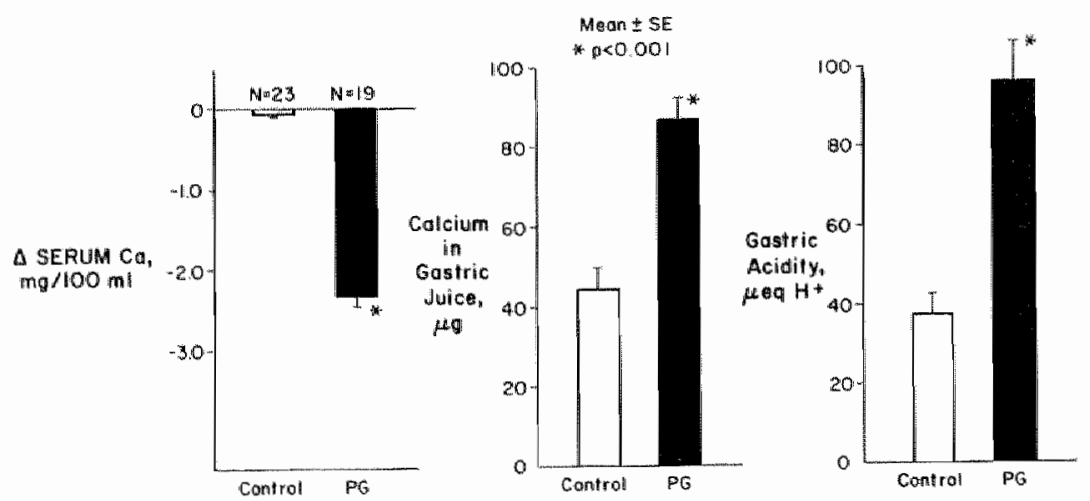

Figure VI.l: Effect of pentagastrin, $25 \mu \mathrm{g}$ or physiologic saline on serum calcium, gasiric calcium and gastric acidity, 30 minutes after $i . v$. injection in pylorus-ligated rats. 
and 30 minutes after injection. Total calcium and gastric acidity were determined in gastric juice after removal of the stomach with the Oxford Titration Method. Statistical significance was determined using Student's t test.

\section{V1.2.1.2. Results}

The results are summarized in Fig. 1.

The mean serum Ca fell more than $2.2 \mathrm{mg} / 100 \mathrm{ml}$ at 30 minutes following administration of $P G(p<0.001)$, clearly different from the effect seen in the control animals. Gastric acidity increased markedly, as expected: approximately $60 \mu \mathrm{Eq} \mathrm{H} \mathrm{H}^{+}$ions were secreted in excess of basal secretion of $38 \mu \mathrm{Eq}$ per 30 minutes as measured in the control group $(p<0.001)$. Calcium in the gastric juice also increased significantly following $P G$ administration. $P G$ stimulated animals secreted $87 \mu \mathrm{g} \mathrm{Ca}$ into the gastric juice and controls $44 \mu \mathrm{g}$, an increase of $98 \%$ in 30 minutes. Although this looks promising, one can see in fig. 2 that there is no direct linear relationship between the calcium in the gastric juice and serum calcium concentration in either the PG- or saline- treated animals.

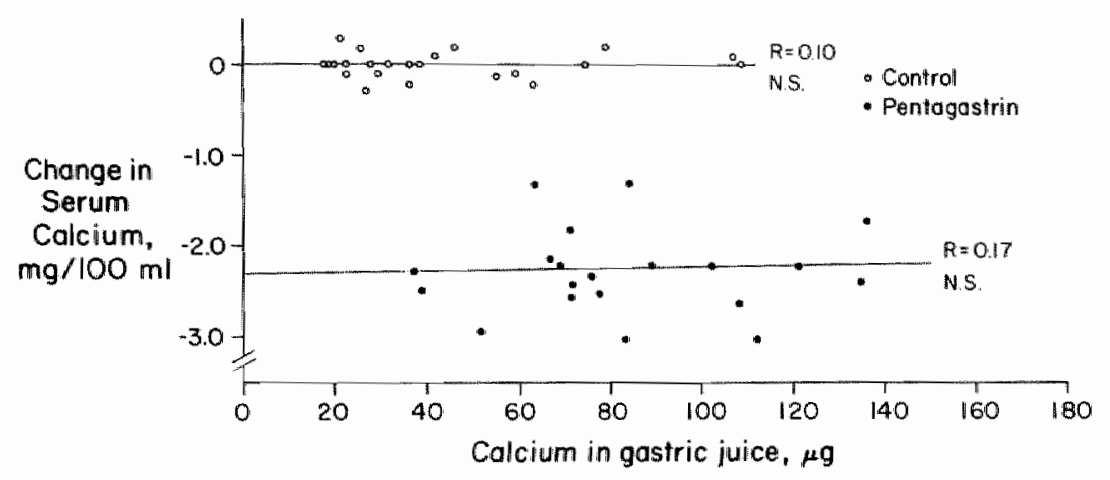

Figure VI.2: Relationship between change of serum calcium and calcium secreted in gastric juice, 30 minures after iv. injection of gastrin or control, in pylorus-ligated rats.

Furthermore, despite a large output of calcium in the gastric juice of some of the saline treated animals (controls) there was no change in the serum calcium. concentration.

V1.2.2. CALCIUM IN THE GASTRIC WALL: A GRADIENT ACROSS THE STOMACH?

\section{vi.2.2.1. Material and Methods}

Forty 70-80 gm rats were fasted for 18-20 hours and randomly divided into 5 groups of rats. Pentagastrin, $25 \mu \mathrm{g}$, was given i.v. At 0, 5, 10, 20 and 30 minutes after the injection bloodsamples were drawn from a different group of rats at each consecutive time point. Blood from the jugular vein was taken to represent pre-gastric blood and portal samples were considered representative for gastric 
vein effluent. Care was taken to draw the two samples as closely together in time as possible (always within one minute). During sampling the animals were under ether anesthesia. Total serum calcium was measured and statistical significance of the observed changes determined with Student's $t$ test.

\section{VI.2.2.2. Results}

No difference in serum calcium levels could be determined across the stomach (Fig. 3).

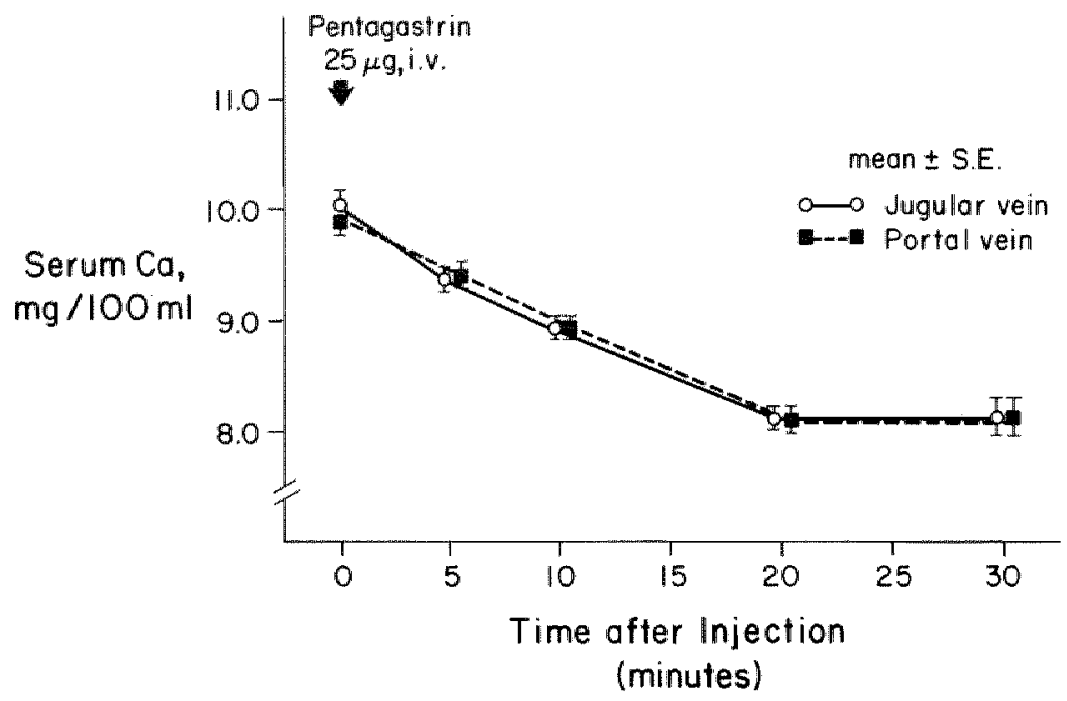

Figure VI.3: Comparison of serum calcium concentration in systemic vs. portal circulation. 8 rats/group.

PG injection was followed by a rapid fall of serum calcium, reaching a maximum of $1.8 \mathrm{mg} / 100 \mathrm{ml}$ at 20 minutes post injection, but "twin" samples remained statistically equal at all time points. Thus, no gradient could be demonstrated. However, the limitations of this experimental model are recognized since peripheral blood was used instead of blood from the gastric artery, and portal blood instead of blood from the gastric vein.

\section{VI.2.3. STUDIES WITH TRACER CALICUM}

\section{VI.2.3.1. Material and Methods}

\section{Experiment 3.A:}

Four male Holtzman rats, weighing $\rrbracket 00-120$ gm were fasted for 18-20 hours and injected with $50 \mu \mathrm{Ci}^{45} \mathrm{Ca}\left(\mathrm{T}^{1 / 2} \mathrm{l} / \mathrm{d} \mathrm{d}\right)$ into the jugular vein under ether anesthesia. Blood samples, 0.4 or $0.3 \mathrm{ml}$ were drawn 6 and 15 minutes, $1,2,4$, $12,24,30$ and 48 hours later. Serum ${ }^{45} \mathrm{Ca}$ was counted in a liquid scintillation 
counter (Tracor Analytic, Model 1185; 2 inch crystal; efficiency $88 \%$ ) and after correction for decay and the loss of counts by the withdrawal of samples, the percent decrease ${ }^{45} \mathrm{Ca}$ per minute was calculated for each individual period between samples. The activity measured at the start of each period was taken as $100 \%$ for that period.

\section{Experiment 3.B:}

Male Holtzman rats, 30 days old and weighing $80-100 \mathrm{gm}$ were fasted for $18-20$ hours. They were randomly assigned to 3 groups of 12 or 16 animals. All surgery, blood samples and injections were done under ether anesthesia. The first group was sham-operated by exposure of the parathyroid-thyroid complex (12 rats), the second group was thyroparathyroidectomized (TPTX) (12 rats) and the third group underwent gastrectomy (GX) as described previously (16 rats). One hour following these procedures the jugular vein was surgically exposed and $2.6 \mu \mathrm{Ci}^{47} \mathrm{CaCl}_{2}\left(\mathrm{~T}^{1 / 2} 4.53 \mathrm{~d}\right)$ injected. The ${ }^{47}$ calcium solution was given in a volume of $0.3 \mathrm{ml}$ and was buffered with $1.5 \mathrm{~N} \mathrm{NaOH}$ to $\mathrm{pH} 7.5$. Thirty and sixty minutes later, blood samples were drawn $(0.6$ and $0.5 \mathrm{ml}$, respectively). Immediately following the drawing of the second sample either saline or $\mathrm{PG}, 25$ $\mu \mathrm{g}(0.2 \mathrm{ml})$ was given as an intravenous bolus to groups 1 and 2 . The GX rats were injected with saline or $\mathrm{PG} 30$ minutes after ${ }^{47} \mathrm{Ca}$ was given. Thirty minutes after injection of the test solution the last blood sample was drawn from the abdominal aorta, the animals exsanguinated quickly and the stomachs harvested from the non-gastrectomized animals. After removal of their squamous part the stomachs were washed with saline, dried and spun at $2000 \mathrm{r} / \mathrm{min}$ for $30 \mathrm{~min}-$ utes to obtain isoform shapes for counting of radioactivity in a gamma counter. Serum calcium was determined with the Oxford titration method using calchrome $10 \mathrm{~B}$ as indicator. Serum ${ }^{47} \mathrm{Ca}$ activity was measured by gamma counting. All counts were corrected for background activity and decay. ${ }^{47} \mathrm{Ca}$ specific activity was calculated using the formula:

S.A. $=\frac{{ }^{47} \mathrm{Ca}, \% \text { of administered dose }}{\text { serum Ca, } \mathrm{mg} / 100 \mathrm{ml}}$

Statistical significance was determined with the two sample Student's $t$ test for corresponding observations.

\section{Experiment 3.C:}

14 sham-operated and 20 TPTX rats were used. $25 \mu \mathrm{Ci}^{47} \mathrm{CaCl}_{2}$ per rat was injected 32 and 24 hours respectively before injection of either pentagastrin or saline. Blood samples were drawn just before ( 0 minutes) and 30 minutes after $\mathrm{PG}, 50 \mu \mathrm{g}(0.3 \mathrm{ml})$ or physiological saline $(0.3 \mathrm{ml})$ administration. Stomachs were removed immediately following the last blood sample and exsanguination. Otherwise experimental animals and conditions were identical to those in experiment 3.B.

\section{Experiment 3.D:}

Three groups of 16 rats were used. Half of each group underwent TPTX, the other half a sham-operation (exposure of the thyroid-parathyroid complex). 
Two hours after surgery ${ }^{87} \mathrm{CaCl}_{2}, 3 \mu \mathrm{Ci}$ and albumen bound ${ }^{125} \mathrm{I}, 36 \mu \mathrm{Ci}$ were given to each animal using separate syringes for each isotope. 60 minutes later either saline $0.2 \mathrm{ml}$, porcine calcitonin, $5 \mathrm{mU}$ or pentagastrin, $25 \mu \mathrm{g}$ were administered intravenously. 30 minutes later the abdominal aorta was opened, exsanguinating the animals, and the stomachs taken out. In the $\mathrm{PG}$ group ${ }^{47} \mathrm{Ca}$ counts were multiplied by the fraction of ${ }^{125} I$ counts in the saline group and the PG group,

$\frac{{ }^{125} \mathrm{I}_{\text {8aline }}}{{ }^{125} \mathrm{I}_{\mathrm{PG}}}$, and in the calcitonin group by $\frac{{ }^{125} \mathrm{I}_{\mathrm{saline}}}{{ }^{125} \mathrm{I}_{\mathrm{Cr}}}$

Albumin bound ${ }^{123} I$ was employed to function as a marker of gastric intramural blood wolume because it was assumed that $\mathrm{PG}$ or $\mathrm{Ct}$ would not change the serum albumin concentration, making it possible to correct for any drug-induced change in vascularization of the gastric wall, which would, of course, influence the ${ }^{47} \mathrm{Ca}$ counts.

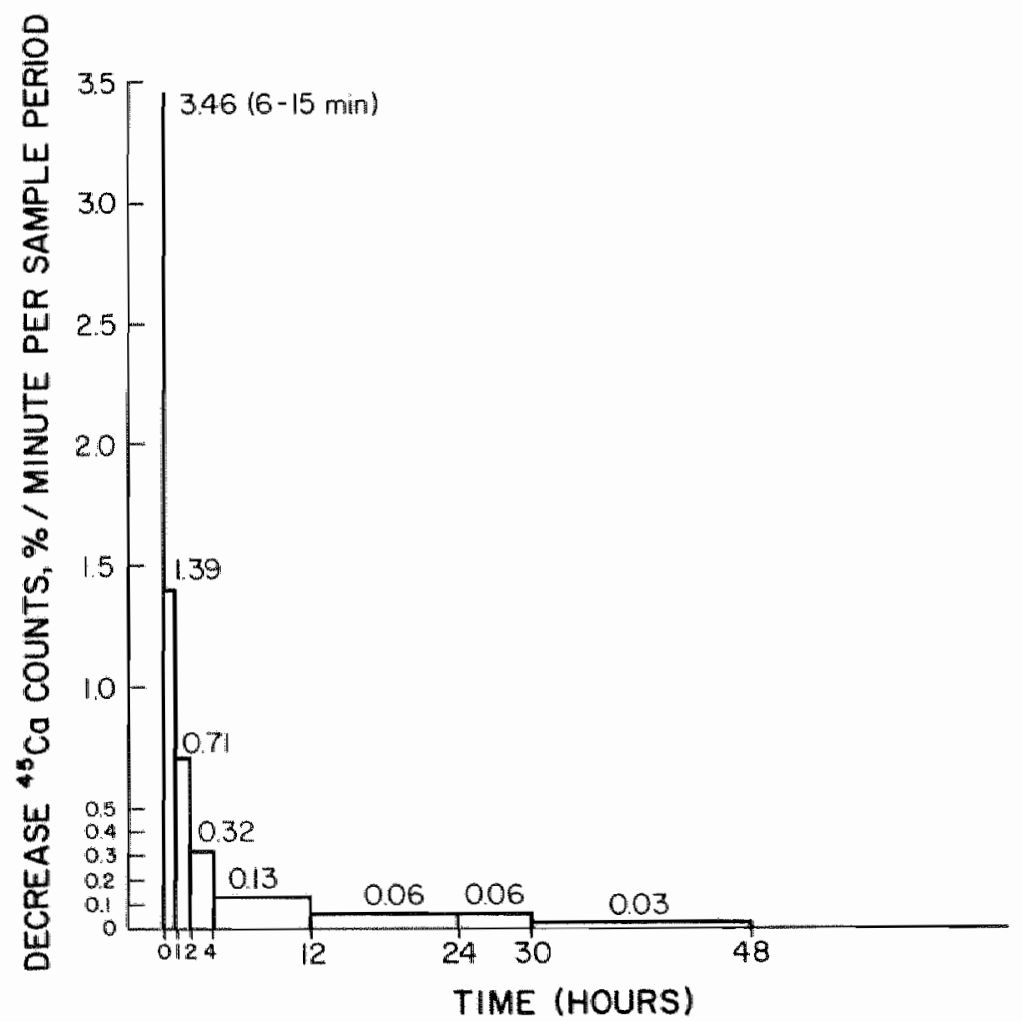

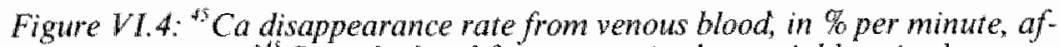
ter i.v. injection of ${ }^{45} \mathrm{C}$, calculated for consecutive but variable episodes. 


\section{V1.2.3.2. Results}

The biologic disappearance rate of radiocalcium (Exp. 3.A).

In experiment 3.A a striking fall of serum activity was measured during the first minutes after injection of ${ }^{45} \mathrm{Ca}$. From the 6 th to the 15 th minute a mean fall of 3.465 percent of the original activity (at 6 minutes) per minute was calculated but the disappearance rate quickly slowed down in the next few hours, stabilizing after 12 hours to $0.06-0.03 \%$ per minute (Fig. 4).

${ }^{45} \mathrm{Ca}$ incorporation into the stomach wall (Exp. 3.B, C and D).

Influx of calcium into the stomach wall was not significantly influenced by pentagastrin administration. In the acute experiment (exp. 3.B) the mean activity of the glandular stomach of the intact animals was $2.8 \% \pm 0.12$ (SEM) and $2.9 \% \pm 0.04$ (SEM) of the administered dose in the saline- and PG-injected groups respectively. For the stomachs of the TPTX rats $2.3 \% \pm 0.20$ (SEM) and $3.0 \% \pm 0.28$ (SEM) of the administered dose was measured in the control group and the PG group respectively (Fig. 5).

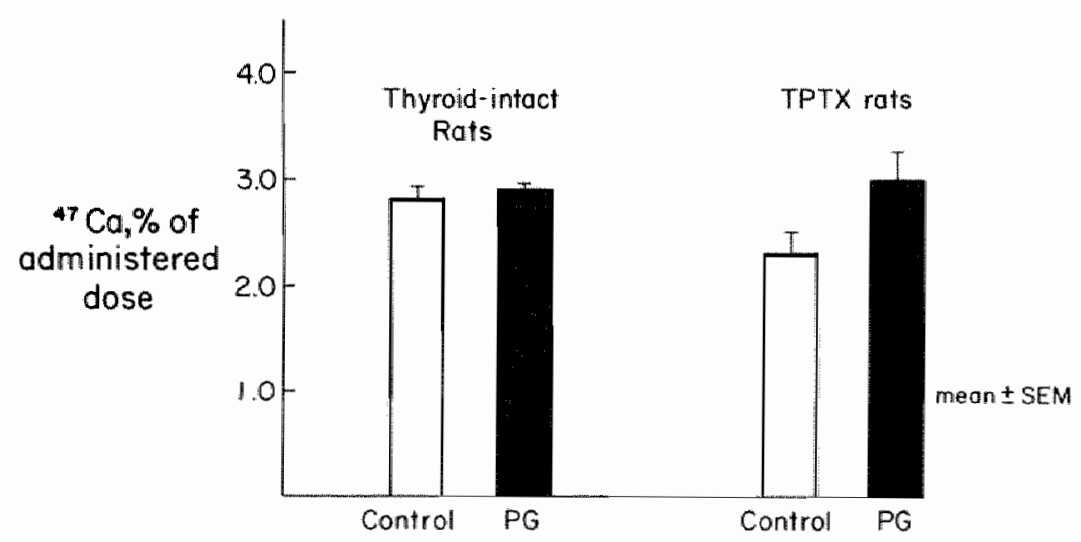

Figure VI.5: Effect of pentagastrin, 25 ug on ${ }^{47}$ Ca incorporation into the stom. ach wall, 90 minutes after i.v. administration of ${ }^{47} \mathrm{Ca}, 2.6 \mu \mathrm{Ci}, 30$ mimutes after i.v. injection of gastrin, $25 \mu \mathrm{g}$ or control in thyroid-intact and thyroparathy. raidectomized rats.

Each bar represents the mean \pm SEM of groups of 6 rats.

Differences between controls and PG injected rats were not statistically significant.

Similar results were obtained if more time had elapsed since the administration of radiocalcium. In experiment 3.C stomachs of intact rats were harvested and counted 32 hours after administration of the tracer and 30 minutes after either PG or saline. The mean activity for the control group was $0.036 \% \pm 0.001$ (SEM) of the administered dose and for the PG group it was $0.041 \% \pm 0.003$ 
(SEM). The difference was not significant. The stomachs of the TPTX rats in this experiment were removed and counted 24 hours after radiocalcium administration. Mean activities were $0.054 \% \pm 0.008$ (SEM) and $0.054 \% \pm 0.012$ (SEM) of the administered dose for the saline- and $\mathrm{PG}$-treated rats respectivily (N.S.) (Fig. 6).

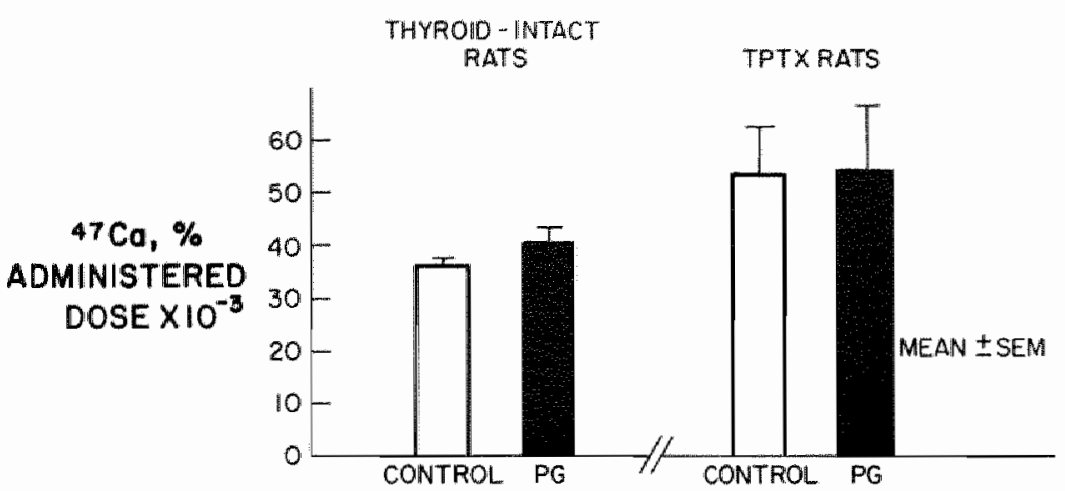

Figure VI.6: Effect of pentagastrin, $50 \mathrm{\mu g}$ on "Ca incarporation into the stomach wall of thyroid-intact and thyroparathyroidectomized rats, 32 and 24 hours respectively after administration of ${ }^{77} \mathrm{Ca}, 25 \mu \mathrm{Ci}$, i.v.

Each bar represents the mean \pm SEM of a group of 7 (control) or 10 rats (TPTX).

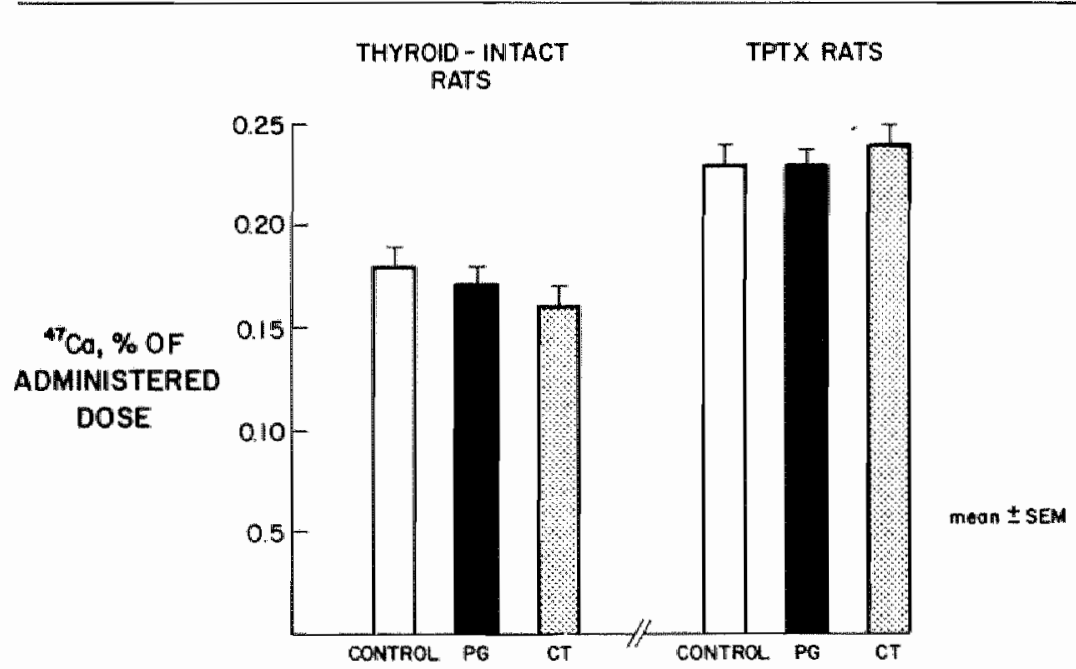

Figure V1.7: "Ca incorporation into the stomach wall of thyroid-intact and thyroparathyroidectomized rats 90 minutes after i.v. administration of ${ }^{47} \mathrm{Ca}$ and ${ }^{5} \mathrm{I}$, 30 minutes after gastrin $25 \mu \mathrm{g}$, calcitonin $5 \mathrm{mU}$ or physiological sa. line i.v.

Each bar represents the mean \pm SEM of a group of 8 rats. ${ }^{47} \mathrm{Ca}$ values were calculated after correction of the differences in blood content of the gastric vascular bed with the use of $1^{125}$ labeling. 
Correction for difference in blood content of the stomach walls by labeling with ${ }^{125} I$ did not influence these results because no statistically significant differences were measured in the stomachs in this experiment (exp. 3.D): intact saline, $0.176 \% \pm 0.011$ (SEM); intact $-\mathrm{PG}, 0.173 \% \pm 0.013$ (SEM); intact CT, $0.162 \% \pm 0.012$ (SEM) and TPTX - saline, $0.205 \% \pm 0.013$ (SEM); TPTX - PG, $0.196 \% \pm 0.008$ (SEM) and TPTX - CT, $0.214 \% \pm 0.007$ (SEM) (Fig. 7). As can be seen, $\mathrm{CT}$ administration did not influence calcium influx into the stomach wall either.

\section{Serum calcium kinetics (Exp. 3.B and C):}

In the acute experiment (exp. 3.B) $\mathrm{PG}$ administration to intact rats resulted in a clear drop of serum Ca concentration 30 minutes later $(2.8 \mathrm{mg} / 100 \mathrm{ml}, \mathrm{p}<$ 0.001 ) and no change was observed in the control group (Fig. 8A). However, serum ${ }^{47} \mathrm{Ca}$ activity did not differ from control values (Fig. 8B). Consequently, specific activity (S.A.), 30 minutes after $\mathrm{PG}$ injection was raised in comparison with the saline controls $(\mathrm{p}<0.05)$ (Fig. 8C).

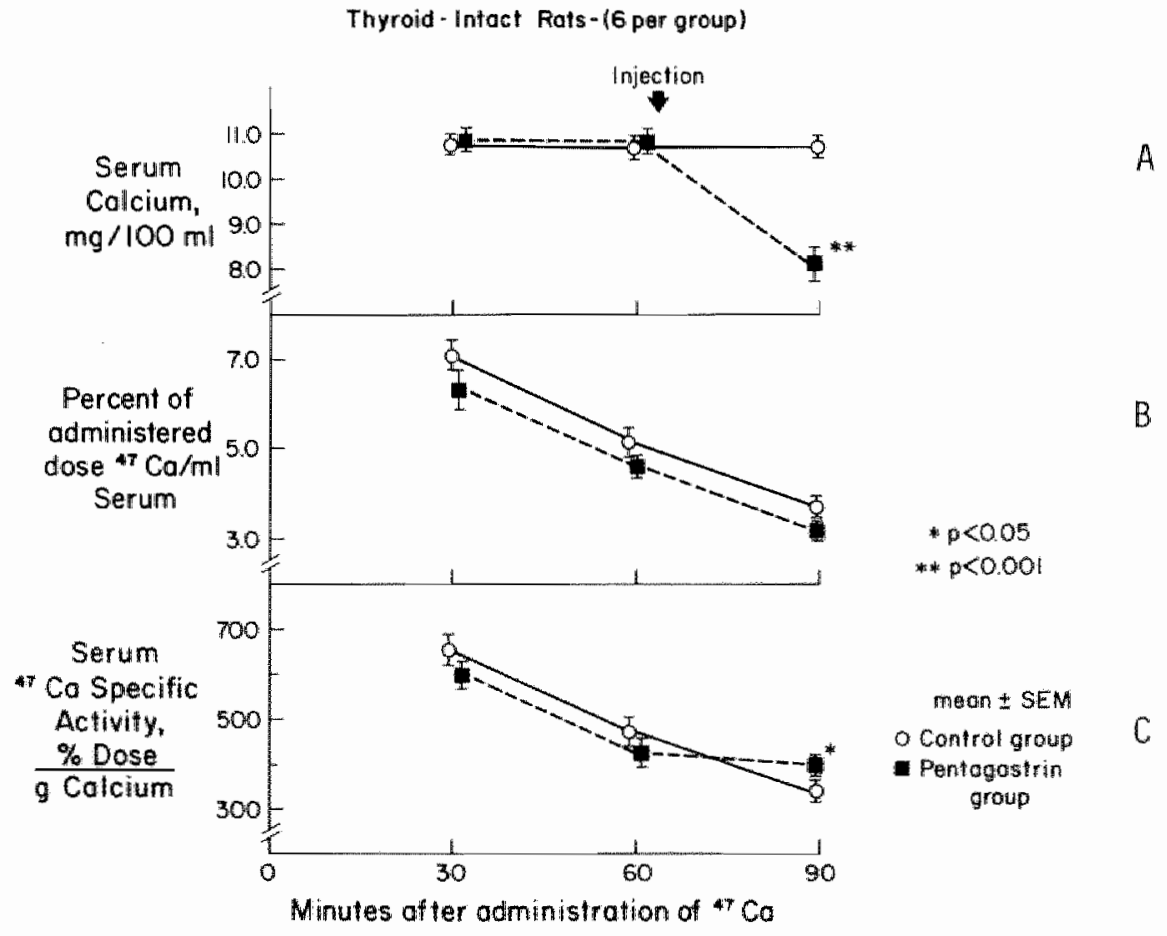

Figure V1.8: Effect of pentagastrin, $25 \mu \mathrm{g}$, i.v. or control on serum calcium and $7 \mathrm{Ca}$ kinedics in thyroid-intact rals.

Similar results were obtained in the TPTX animals. Serum calcium fell 1.8 $\mathrm{mg} / 100 \mathrm{ml}(\mathrm{p}<0.001)$ at 30 minutes after PG administration while no fall occurred in the controls (Fig. 9A). Serum radioactivity decreased at equal rates in the two groups before and after injection of either saline or PG (Fig. 9B). Con- 
sequently, S.A. was significantly increased at the time of maximal hypocalcemia $(\mathrm{p}<0.05)$ (Fig. $9 \mathrm{C}$ ).

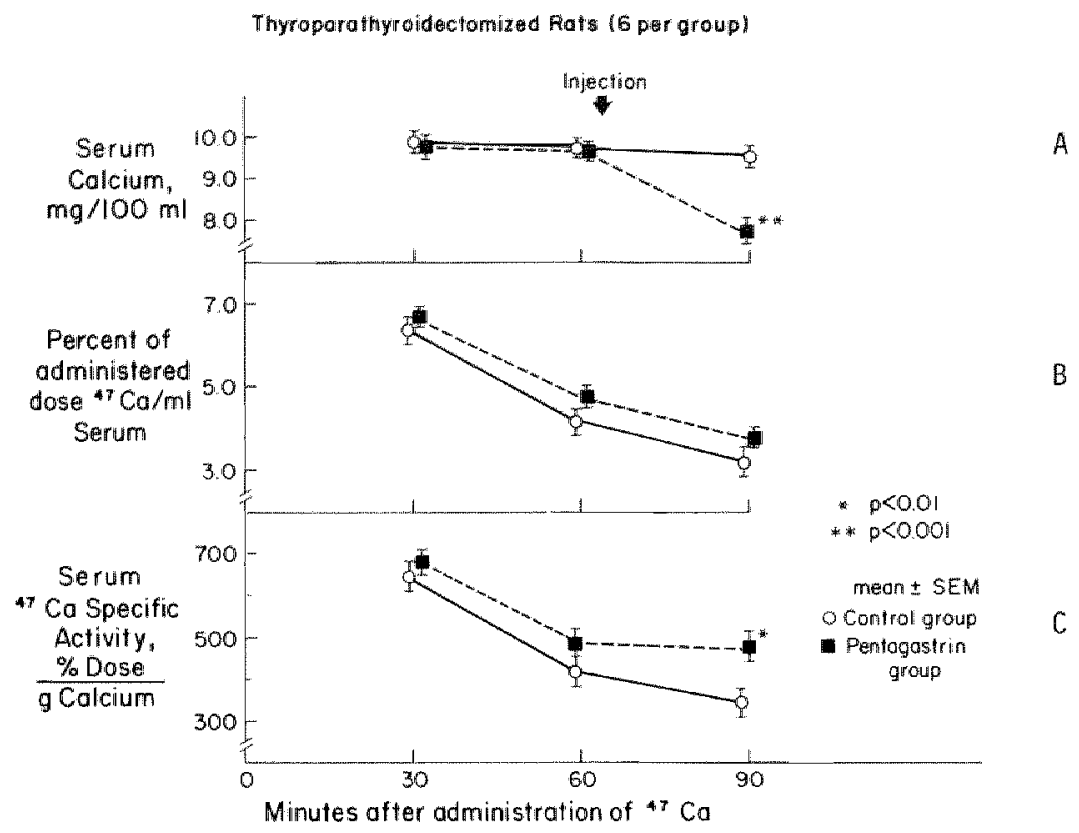

Figure VI.9: Effect of pentagastrin, $25 \mu g, i . v$. or physiological saline on serum calcium and ${ }^{\text {th }}$ Ca kinetics in thyroparathyroidectomized rats.

In the GX, thyroid-intact rats no differences between the controls and the $\mathrm{PG}$ group were measured: serum calcium in the control group changed from 10.8 $\mathrm{mg} / 100 \mathrm{ml}$ to $10.7 \mathrm{mg} / 100 \mathrm{ml}$ at 30 minutes after injection (N.S.) and in the PG group serum calcium changed from $10.7 \mathrm{mg} / 100 \mathrm{ml}$ to $10.6 \mathrm{mg} / 100 \mathrm{ml}$ (N.S.) (Fig. 10A). Serum ${ }^{47} \mathrm{Ca}$ values showed parallel changes in both groups (Fig. 10B) and therefore, S.A. in the GX group was not affected (Fig. 10C). 


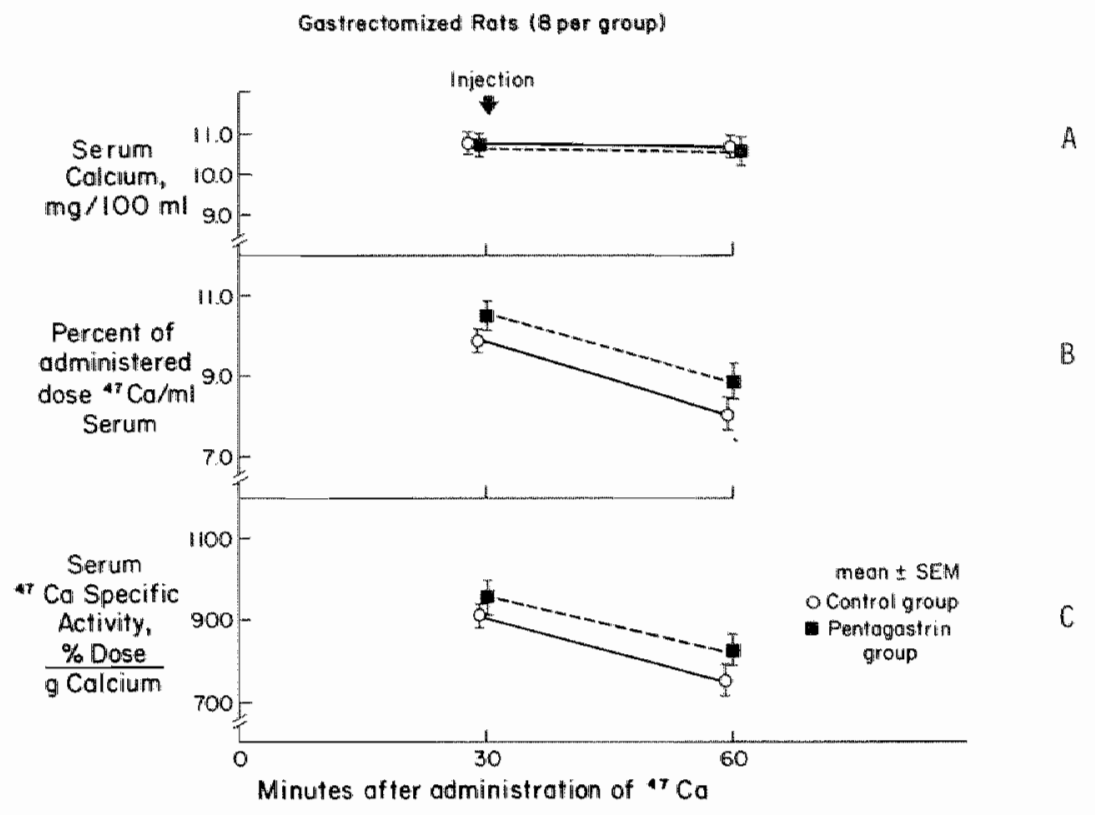

Figure VI.10: Effect of pentagastrin, $25 \mu \mathrm{g}$, i.v. or physiological saline on serum calcium and ${ }^{47}$ Ca kinetics in gastrectomized rats.

In the subacute study (exp. 3.C) a more modest but nevertheless significant fall in serum calcium was caused by $\mathrm{PG}$ administration. At 30 minutes after PG injection serum calcium fell $0.7 \mathrm{mg} / 100 \mathrm{ml}(\mathrm{p}<0.001)$ both in the intact group and in the TPTX group (Fig. 11A and 12A). There was no GX group in this experiment. Serum ${ }^{4} \mathrm{Ca}$ activity was not affected by $\mathrm{PG}$ administration in either group (Fig. 11B and 12B). This time, only in the TPTX rats S.A. was significantly raised by $\mathrm{PG}$ administration (Fig, $12 \mathrm{C}$ ). In the intact animals a rise was calculated but statistical significance was not reached (Fig. $1 \mathrm{JC}$ ). 


\section{(7 RATS PER GROUP)}

INTACT RATS

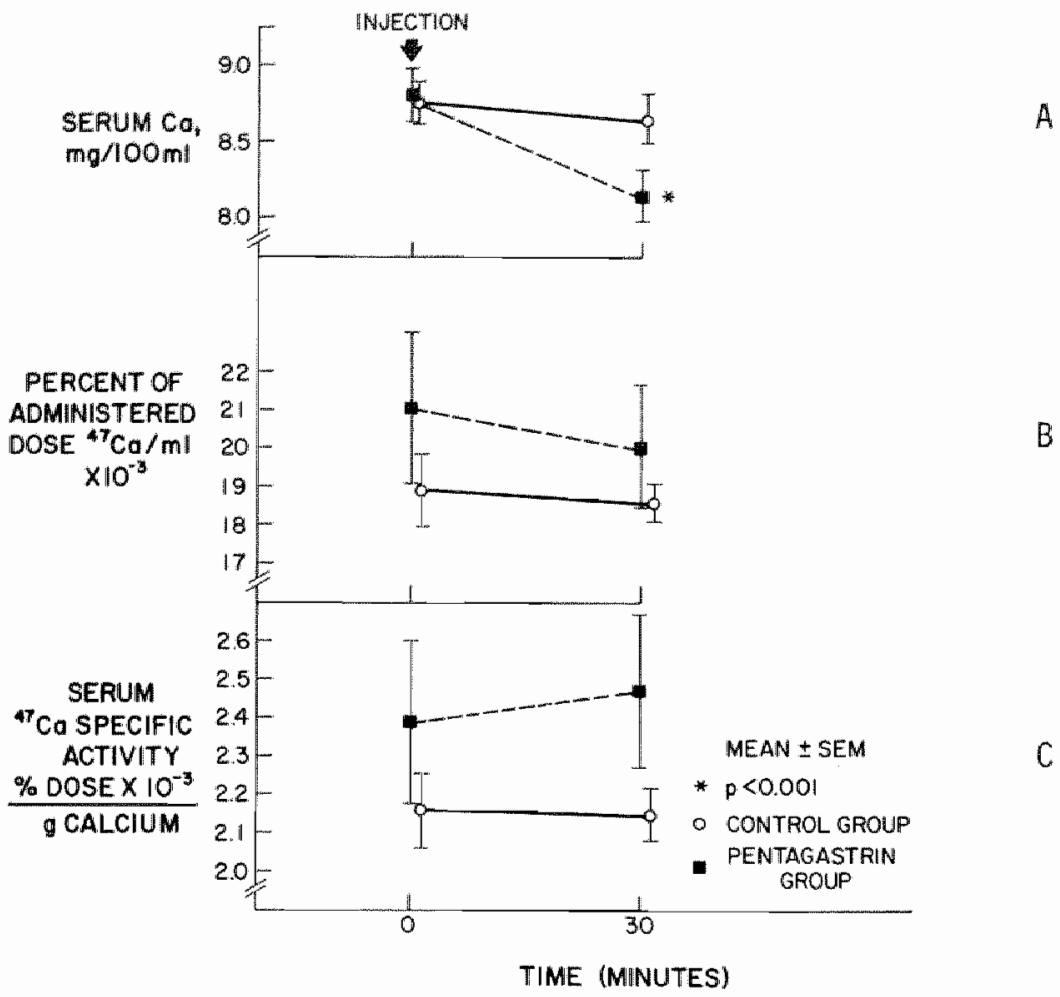

Figure VI. 11: Effect of pentagastrin, $50 \mu \mathrm{g}, i_{.}$.. or physiological saline on serum calcium and ${ }^{77} \mathrm{Ca}$ kinetics in intact rats, 32 hours aftre $i$. $v$. administration of ${ }^{4} \mathrm{Ca}, 25 \mu \mathrm{Ci}$. 


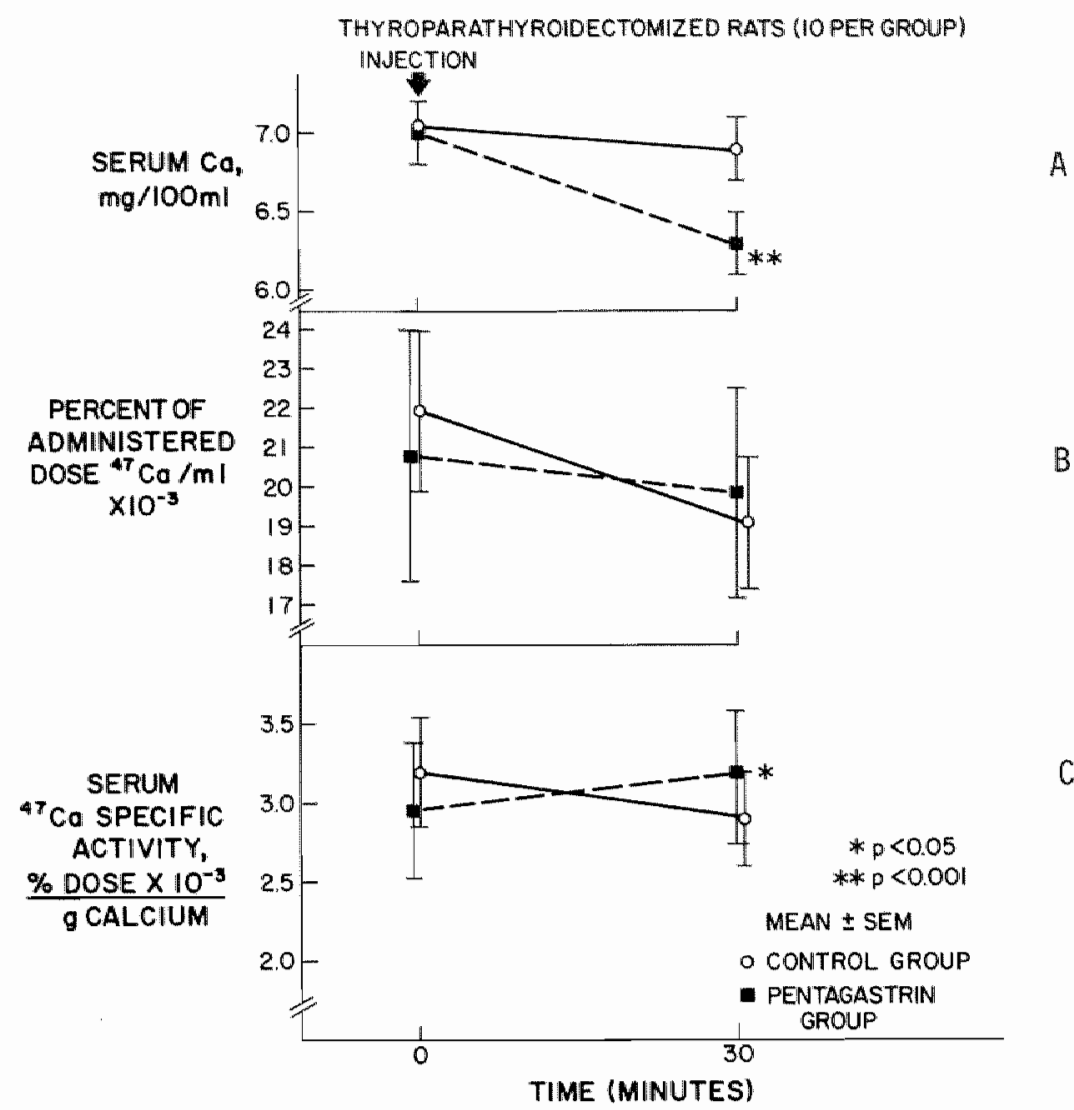

Figure VI.12: Effect of pentagastrin, $50 \mu \mathrm{g}, \mathrm{i.v}$. or physiological saline on senum calcium and ${ }^{47}$ Ca kinetics in thyroparathyroidectomized rats, 24 hours afier $t . v$ administration of $\mathrm{Ca}, 25 \mu \mathrm{Ci}$. 


\section{VI3. DISCUSSION}

Because the hypocalcemia caused by several gastro-intestinal hormones appears to be related to their acid secretory action it seemed reasonable to have a closer look at the biological potentials of (penta-) gastrin.

The exact mechanism that causes the calcium fall has not yet been identified but much has become clear about the tissues and reactions involved. Although others (18) have found inhibiting effects of gastrin on $\mathrm{Ca}$ absorption from the gut in pigs, this mechanism does not seem to play a role in the hypocalcemia of $\mathrm{PG}$ in the rat, for removal of the small and large bowel did not change this reaction (19). Neither can renal excretion explain the gastrin-induced hypocalcemia because urinary calcium output was not changed during hypocalcemia after pentagastrin administration (20) nor did acute bilateral nephrectomy prevent or diminish hypocalcemia 30 minutes after $P G$ administration (19). Although gastrin has been reported to stimulate bile secretion and change bile composition in dogs (11), calcium excretion in bile of rats was not increased by intraperitoneal gastrin administration (20).

Calcium excretion in the gastric juice seems to be responsible for a fraction of the hypocalcemia only. After in traperitoneal PG administration gastric calcium secretion was increased by $57 \%$ in one hour, but the absolute increase was limited to $8 \mu \mathrm{g} / \mathrm{hr} / 100 \mathrm{gm}$ rat only, far too little to explain the observed fall of serum calcium concentration (20). In our study of gastric secretion PG-induced calcium secretion amounted to $43 \mu \mathrm{g}$ in 30 minutes in excess of control values but no linear relationship could be demonstrated between calcium secretion and the change in serum calcium concentration. In other words it was not demonstrated that the increase in gastric calcium secretion had anything to do with the loss of calcium from the serum. Theoretically, $43 \mu \mathrm{g}$ Ca would account for only a small portion of the calcium loss from the extracellular fluid compartment if one assumes that in a young animal the EFC takes up a little under one third of total body weight. This means that in our experiment, using $100 \mathrm{gram}$ rats, approximately one third of $2.2 \mathrm{mg}=700 \mu \mathrm{g}$ calcium was lost from the EFC. Even if one, inappropiately, would assume that the calcium was lost exclusively from the serum ( $\pm 7 \%$ of the total body weight (21)) only one third of the observed loss would be accounted for.

It has been recognised that the calcium ion plays a central role in regulating the secretion and permeability characteristics of gastric mucosa as well as other epithelial tissue $(22,25)$ but our actual understanding of the effects of calcium in gastric mucosa is rudimentary. Data from in vitro frog mucosa models show that gastric secretory stimulation may be due to a dual effect of the calcium ion: first, a membrane-entry process; and second, a c-AMP dependent release of $\mathrm{Ca}^{++}$from storage sites (26). This suggests that calcium ion entry is involved in hormonal stimulation of acid secretion. Therefore it is reasonable to assume that at least part of the calcium loss from the extracellular fluid compartment can be ascribed to the entry of the ion into the parietal cell mass, setting off hydrochloric acid production after the pentagastrin stimulus. However, in above experiments no such pathway for calcium was demonstrated. Firstly, no A-V 
gradient across the stomach was found. Measuring of $A-V$ differences is a well accepted method for quantitating tissue metabolism (27,28); the Fick-principle, first proposed as a means for measuring blood flow, can be used to measure any single metabolite if experimental conditions are kept stable (29). Secondly, no radio-calcium influx into the stomach wall was found 30 minutes after $\mathrm{PG}$ administration. Correction for a small (but statistically not significant) rise in blood content of the gastric tissue after $\mathrm{PG}$ administration by means of blood labeling with ${ }^{125} I$ (exp. 3.D), did not challenge this outcome. Maybe experimental conditions could be refined even further, but more likely, only minute quantities of calcium are involved in the acid secretory process the secretion of which have no measurable effect on total serum calcium concentration.

It is well-known that in man after an i.v. injection of labeled calcium most of the tracer will quickly leave the intravascular space and eventually partly be taken up by the skeleton. This is a rapid process for it has been calculated that after entering the circulation every fourth atom leaves the blood every minute (30) and 1 hour after injection more than $60 \%$ of an injected dose of radiocalcium will have disappeared from the blood (31). In adult man the rapidly exchangeable bone area makes up less than $0.5 \%$ of the total skeletal calcium and most of the bone pool is unavailable for direct exchange with circulating calcium. The latter can be incorporated in this part of the skeleton only by formation of new bone salts. The rapidly exchangeable $\mathrm{Ca}$ pool can be found in specific areas, particularly in the epiphyseal and periosteal regions of long bones (32). There, depending on physical processes such as the solubility of $\mathrm{Ca}$ phosphates and by simple chemical exchange, an equilibrium is maintained between the fluid compartments and those portions of bone with which the fluid is in most direct contact. With increasing time following injection, the activity in the exchangeable area drops in parallel with that of the soft tissue compartment and around the tenth day almost half of the tracer will have been excreted, while almost half will be located in the slowly exchangeable bone mineral (30). Once incorporated, it will act as stable $\mathrm{Ca}$ and participate in the modeling and remodeling process. It seems reasonable to assume that during the first 24 hours only a minor part of the tracer will be incorporated in the stable bone fraction $(30,33,35)$. Therefore in man only the late fase of the disappearance curve of radiocalcium, i.e. after 24 hours, is thought to be representative for stable bone metabolism.

The rat appears to have a radiocalcium distribution similar to that described above, but a faster rate of disappearance from plasma. Parsons states that after 10 minutes already $50 \%$ of an injected dose of ${ }^{45} \mathrm{Ca}$ has entered the rat bone (36). His data should be compared with the above mentioned human data with caution because they were based upon an assumptive distribution, and counting was done on long bones, the scapulae and the tail only. The long bones having the largest exchangeable area, as we have seen, are not representative for the whole skeleton. On the other hand, in another study it was demonstrated that in the rat $60 \%$ of the radioactivity had entered the skeleton within 2 hours following its administration and an additional $10 \%$ by 5 hours. In this experiment the whole skeleton was included (31). 
The disappearance curve that we computed (Fig. 4) confirms the extremely fast disappearance from the serum of an injected dose of tracer calcium in our rat model, stabilizing after 8-18 hours. It also shows that it would have been difficult to detect an increase in the efflux of calcium from the plasma after pentagastrin administration, since a disappearance rate of the isotope of $30 \%$ in 30 minutes can be calculated during the first kinetic studies. Specific Activity (S.A.), the fraction of the measured radioactivity of an element (\% admin. dose) and the serum concentration of its cold isotope, has been utilized as a convenient tool to measure movement of that element between body spaces and has been applied extensively to the study of bone metabolism $(33,34,37,38)$. The present experiments were based on this concept and in particular on a sophisticated study by O'Riordan and Aurbach on the mode of action of calcitonin in the rat (31). In their studies Specific Activity was central in demonstrating the direction of movement of ${ }^{45} \mathrm{Ca}$ and ${ }^{40} \mathrm{Ca}$ between different body pools, whose existence had been postulated by means of a computerized model system. The principle of S.A. is applicable to our studies on calcium homeostasis in the following way: when total serum calcium concentration falls in response to the administration of a hypocalcemic agent, this may either be explained by its disappearance from or its failure to enter the intravascular space. If calcium were to leave the plasma the measured radioactivity per $\mathrm{ml}$ serum would fall in the same proportion as total serum calcium and S.A. remain unchanged. If, on the other hand, calcium were to enter the plasma from a yet unlabeled tissue pool at a slower rate after the injection of $\mathrm{PG}$, there would be a relative increase in the specific activity of radiocalcium compared to controls. Only under those conditions the fraction between serum ${ }^{47}$ and ${ }^{40} \mathrm{Ca}$ will become positive.

From experiment 3.B it therefore appears that the action of $\mathrm{PG}$ inhibits calcium release from bone because S.A. was significantly higher in this group than in control animals, both in the intact and TPTX experiments. Gastrectomy abolished this effect.

It is interesting to note that at a later time point after injection of tracer calcium (Exp. 3.C) S.A. in the TPTX animals was likewise found to be significantly higher after pentagastrin than in controls. At the time of the experiment the calculated biological disappearance rate only amounted to $1.8 \%$ in 30 minutes, situating the experiment in a fase of the disappearance curve which substantially represents a slowly exchangeable bone pool. The absence of a significant change in S.A. in the intact group may be ascribed to the fact that at the time of pentagastrin injection the bone calcium pool in these animals is already in equilibrium with ${ }^{47} \mathrm{Ca}$. Moreover, the smallness of the fall in stable calcium that was found in this experiment may have been of influence. Also, the greater deviation of the data due to the individual variation of the disappearance rates may have obscured the effect. 


\section{VI.4. CONCLUSIONS:}

Not every possible pathway of calcium was investigated in this chapter. In particular, bone metabolism was not studied directly. It is generally assumed, however, that such kinetic studies as were used reflect bone metabolism almost uniquely. Therefore, several conclusions may be reached from these experiments:

1. The hypocalcemia following PG injection is only partially due to calcium secretion into the gastric juice.

2. The hypocalcemia following pentagastrin (and CT) administration is not caused by calcium influx into the gastric wall.

3. Pentagastrin acts through the inhibition of calcium influx into plasma, probably by a decrease of calcium efflux from bone.

4. The decrease of this calcium efflux from bone is abolished by removal of the stomach.

5. Calcitonin release from the thyroid gland does not contribute to this inhibition.

\section{VI.5. REFERENCES:}

1. Barreras, R.F. and Donaldson, R.M. Jr. (1967): Effects of induced hypercalcemia on human gastric secretion. Gastroenterology 52, p. 670.

2. Smallwood, R.A. (1967): The effect of intravenous calcium administration on gastric secretion of acid and pepsin in man. Gut 8, p. 592.

3. Kaplan, E.L., Hill, B.J., Canterbury, J.M., Reiss, E. and Peskin, G.W. (1972): Calcium induced gastric hypersecretion: Lack of effect of endogenous parathyroid hormone. J. Surg. Res. 12, p. 229.

4. Konturek, S.J., Wysocki, A. and Oleksy, J. (1968): Effect of medical and surgical vagotomy on gastric response to graded doses of pentagastrin and histamine. Gastroenterology 54, p. 392.

5. Johnson, L.R. (1973): Effect of gastric mucosal acidification on the action of pepsigogues. Am. J. Physiol. 225, p. 1411.

6. Gibson, R., Hirschowitz, B.I. and Hutchinson, G. (1974): Actions of metiamide, an $\mathrm{H}_{2}$-histamine receptor antagonist, on gastric $\mathrm{H}^{+}$and pepsin secretion in dogs. Gastroenterology 67, p. 93.

7. Valenquela, J.E.,Walsh, J.H. and Isenberg, J. (1976): Elject of gastrin on pancreatic enzyme secretion and galbladder emptying in man. Gastroenterology 71, p. 409.

8. Walsh, J.H. and Grossman, M.I. (1975): Gastrin (first of two parts). N. Engl. J. Med. 292, p. 1324.

9. Friesen, S.R. (1978): Introductory concepts of clinical endocrinology. In: Surgical endocrinology: clinical syndromes. Lippincot Cie., p. 10.

10. Wesdorp, R.I.C. (1977): Studies on gastrin. Doctoral thesis, p. 10.

11. Kaminsky, D.L., Rose, R.C. and Nahrwold, D.L. (1973): Effect of pentagastrin on canine bile flow. Gastroenterology 64, p. 630.

12. Johnson, L.R., Lichtenberger, L.M., Copeland, E.M., Dudrick, S.I and Castro, G.A. (1972): Actions of gastrin on gastro-intestinal structure and function. Gas. troenterology 68, p. 1184.

13. Castell, D.O and Harris, L.D. (1970): Hormonal control of gastro-esophageal sphincter strenght. N. Engl. J. Med. 282, p. 884.

14. Care, A.D., Bates, R.F.L., Swaminathan, R. and Ganguli, P.C. (1971): The role of gastrim as a calcitonin secretagogue. J. Endocrinol. 51 , p. 735 . 
15. Rehfeld, J.F. (1972): Gastrointestinal hormones and insulin secretion. Scand. J. Gastroenterol. 7, p. 289.

16. Said, S.I and Makhlouf, G.M. (1974): Vasoactiwe Intestinal Peptide: Spectrum of biological activity. In: Endocrinology of the gut, ed. by Chey and Brooks, publ. by Charles B. Slack Inc., p. 83.

17. Shay, H., Sun, D.C.H. and Gruenstein, M. (1954): A quantitive method for measuring spontaneous gastric secretion in the rat. Gastroenterology 26, p. 906.

18. Swaminathan, R. (1974): The inhibitory effect of pentagastrin on intestinal calcium absorption. J. Physiol. Lon. 238 , p. 75.

19. Schulak, J.A and Kaplan, E.L. (1975): The importance of the stomach in gastrin-induced hypocalcemia in the rat. Endocrinology 96, p. 1217.

20. Krisnamra, $N$. and Limlomwongse, L. (1978): The influence of gastrin on plasma calcium, bile and gastric calcium secretion. Proc. Soc. Exp. Biol. Med. 158, p. 40.

21. Cartland, G.F. and Koch, C. (1928): A micromodification of the Keith-Rowntree plasma-dye method for the estimation of blood volume in the rat. Am. J. Physiol. 85, p. 540 .

22. Curran, P.F. and Gill, J.R. Jr. (1962): The effect of calcium on sodium transport by frog skin. J. Gen. Physiol. 45, p. 631.

23. Forte, J.G, and Nauss, A.H. (1963): Effects of calcium removal on bullfrog gastric mucosa. Am. J. Physiol. 205, p. 631.

24. Sedar, W. and Forte, J.G. (1964): Effects of calcium depletion on the junctional complex between oxyntic cells of gastric glands. J. Cell. Biol. 22, p. 173.

25. Tidall, C.S. (1964): Mg and Ca as regulators of intestinal permeability. Am. J. Physiol. 206, p. 243.

26. Jacobson, A., Schwarz, M. and Rehm, W.S. (1965): Effects of calcium removal from bathing media on frog stomach. Am. J. Physiol. 209 , p. 134.

27. Singh, M., Lin, C. and Post, M. (1975): Calcitonin inhibition of bone cell metabolism in vivo: an experimental study in dogs. Endocrinology 96, p. 1468.

28. Rodin, G.A., Liberman, U.A., Paran, M. and Ambar, M. (1967): Lack of physiochemical equilibrium between blood and bone calcium in isolated perfused dog limb. Israel J. Med. Sci. 3, p. 702.

29. Zierler, K.L. (1961): Theory of the use of arterio-venous concentration differences for measuring metabolism in steady and non-steady status. J. Clin. Invest. 40, p. 2111.

30. Bauer, G.C. (1965): Diagnosis of bone disease. In: Nuclear Med., ed. by W.H. Bland, p. 461 .

31. O'Riordan, J.L.H. and Aurbach, G.D. (1968): Mode of action of thyrocalcitonin. Endocrinology 82, p. 377.

32. Comar, C.L. (1956): Radioisotopes in biology and agriculture. McGraw-Hill, N.Y., p. 324.

33. Talmage, R.V. and Elliot, J.R. (1958): Removal of calcium from bone as influenced by the parathyroids. Endocrinology 62, p. 717 .

34. Hirsch, P.E. (1967): Thyrocalcitonin inhibition of bone resorption induced by parathyroid extract in thyroparathyroidectomized rats. Endocrinology 80, p. 539.

35. Milhaud, G., Perault, A.M. and Moukhtar, M.S. (1965): Etude du mécanisme de l'action hypocalcémiante de la thyrocalcitonine. C.R. Acad. Sci. (Paris) 261, p. 813.

36. Parsons, J.A. and Robinson, C.J. (1968): Calcium shift into bone causing transient hypocalcemia after injection of parathyroid hormone. In: Parathyroid hormone and thyrocalcitonin, ed. by Talmage, R.V., Bélanger, L.F., Excerpta Medica, Amsterdam, p. 329.

37. Heaney, R.P. and Whedon, G.D. (1958): Radiocalcium studies on bone formation rate in human metabolic bone disease. J. Clin. Endocrinol. Metab. 18, p. 1246.

38. Heaney, R.P. (1963): Evaluation and interpretation of calcium-kinetic data in man. Clin. Orthop. 31, p. 153. 


\section{Chapter VII}

\section{THE ALKALINE TIDE}

\section{VII.1. INTRODUCTION}

In all of the experiments presented thus far the importance of the (proximal) stomach as a mediator of the hypocalcemia following administration of acid secretagogues has remained undisputed. It was demonstrated that the hypocalcemia is not the result of a shift of calcium ions from the plasma into the gastric wall and may only partly be explained by the secretion of calcium ions into the gastric lumen at the time of acid secretion. Furthermore, it is unlikely that the hypocalcemic mechanism is the result of the release of calcitonin from the thyroid gland or from the stomach. Finally, the presence of another peptide or amine from the stomach which could lower the serum calcium concentration could not be demonstrated.

Since the stomach is necessary for the hypocalcemia to occur, attention will be focused on the metabolic consequences of pentagastrin administration in relation to its inhibitory effect on calcium release from bone.

From the work of Terepka (unpublished data) Neuman (1) concluded that every 23 minutes, all calcium ions in the entire human extracellular fluid compartment (E.F.C.) enter and leave the skeleton. Therefore, disturbances of this calcium flux, even if only ol short duration, will have immediate and profound impact on serum calcium concentration. Thus, although calcium balance ultimately is determined by intestinal inflow and renal outflow, on a moment to moment basis regulation takes place by the balance of fluxes to and from the skeleton. How then, might the stomach influence bone metabolism?

In in vitro experiments in which calvaria taken from 3-4 days-old chicks (with periosteal and endosteal membranes intact) were kept in a medium with $\mathrm{pH}$ under rigid control, Neuman found that $\mathrm{pH}$ was the primary determinant of the final calcium levels in the medium (1). Later, other factors, termed mineral solubilizers, supposedly produced by the bone cells, were suggested by him to play a dominant role (2). Many others have also pointed out the dependency of the calcium flux on $\mathrm{pH}$ in the fluid surrounding the bone mineral surface, both in vitro $(3,4,5,6)$ and in vivo $(7,8,9)$. In all of those experiments the concentration of calcium, either in the medium or in the serum, was inversely proportional to $\mathrm{pH}$. Interestingly, gastric acid secretion is known to be accompanied by a hydrogen ion shift in which hydrogen ions move into the oxyntic cells and, in exchange, bicarbonate ions appear in the circulation, elevating the blood $\mathrm{pH}$.

The exact biochemical and electrical events leading to the secretion of hy- 
drochloric acid are not fully understood. In an excellent review, Sachs e.a. (1978) clarify many of the immensely complex details concerning regulation of acid secretion, metabolism and ion transport of the gastric mucosa, with emphasis on $\mathrm{H}^{+}$transport (10). It is suggested that stimulation of secretion may result in fusion of cytoplasmatic tubulovesicular membranes (holding receptor sites) with the inverted apical parietal cell membrane, followed by eversion, forming the characteristic microvillus appearance of this surface of the secreting cell. Some form of second messenger (the first messenger being the stimulus, like pentagastrin) is likely to control this process. Calcium ion and cyclic AMP both may exert this function with calcium ions required for fusion and cAMP - dependent phosphorylation regulating the affinity of the $\mathrm{Ca}^{++}$sites. It also has been reported that cylic guanosine monophosphate (c-GMP) is increased by pentagastrin stimulation in man $(11,12)$. Furthermore, prostaglandins and thromboxanes may be important in modifying the gastric secretory response (10). In addition, the oxyntic cell contains at least three different kinds of ATP-ases. One of those appears to be a specialised gastric ATP-ase that, in contrast to other $\mathrm{H}^{+}$transport ATP-ases, is not clearly electrogenic and possibly catalyzes an electroneutral $\mathrm{H}^{+}: \mathrm{K}^{+}$exchange across the vesicle membrane. The electrolytes potassium, sodium and bicarbonate are required for secretion of the hydrogen ion. The concentration of hydrogen ion is about 3 million times greater in gastric juice than in blood or tissue. Although the origin of the ion is not altogether clear, it can be thought of as resulting from the hydrolysis of water. In the presence of carbonic anhydrase, the hydroxyl reacts with carbon dioxide to produce bicarbonate. Leaving the basal portion of the cell, the bicarbonate enters the venous effluent. Thus, during gastric-acid secretion, bicarbonate production of the oxyntic cell increases the venous $\mathrm{pH}$; this phenomenon is referred to as the "alkaline tide" $(13,14,15,16)$.

The experiments presented in this chapter were designed to evaluate wether or not the alkaline tide occurred in our rat model and to assess its magnitude and metabolic consequences. In doing so, the following questions will be addressed:

1. Is there an alkaline tide following i.v. administration of pentagastrin in the rat?

2. If so, does it precede or coincide with the fall in serum calcium concentration?

3. Is the magnitude of such a hydrogen ion shift in agreement with the quantity of PG-induced acid secretion?

4. Can a comparable fall of serum calcium concentration be reproduced by an intravenous injection of base equivalent to the acid secreted into the gastric lumen?

5. And, finally, if the secretory response to pentagastrin were to be minimized by establishing a state of maximal acid secretion at the time of pentagastrin administration, e.g. by feeding, would hypocalcemia indeed fail to occur? 


\section{VII.2. EXPERIMENTS}

\section{VI1.2.1. MATERIAL AND METHODS}

\section{Experiment No. 1:}

14 male Holtzman rats weighing 70-90 grams were fasted for 18 hours. Urethaneß anesthesia $(0.25 \mathrm{~g} / \mathrm{ml}$ distilled water), $0.007 \mathrm{ml} \times$ body weight in grams, was administered in two doses separated by 30 minutes into two different subcutaneous areas. During the experiment the rats were kept on a heating pad. 30 minutes after the second injection with Urethane 7 rats were given pentagastrin, $25 \mu \mathrm{g}(0.2 \mathrm{ml})$ as a bolus into a surgically exposed jugular vein and 7 rats received saline, $0.2 \mathrm{ml}$. Venous blood samples of $0.3 \mathrm{ml}$ each were drawn into a glass syringe from a size $\mathrm{p}$ - 10 polyvinyl catheter positioned in a femoral vein at $0,15,30$ and 60 minutes after the administration of pentagastrin or saline. Venous $\mathrm{pH}$ was determined immediately following sampling. Each sample was investigated twice on a Corning pH meter, model 10 , that was re-calibrated between samples. $\mathrm{pH}$ values are described in terms of the actual $\mathrm{H}^{+}$ion concentration in nanoequivalents (or nanomoles) per liter (17). The respiratory rate of the animals was counted after Urethane@ administration and just prior to the drawing of each blood sample. Statistical analyses were performed using Student's t test.

\section{Experiment No. 2:}

The experimental conditions in this experiment matched those of experiment No. 1 except that this time only two venous blood samples were taken from each animal: at 0 and 15 minutes ( 14 PG rats and 10 saline rats), 0 and 30 minutes ( $11 \mathrm{PG}$ rats and 9 saline rats) or 0 and 60 minutes ( 9 PG rats and 8 saline rats) after injection of the test solution respectively.

\section{Experiment No. 3:}

8 fasted male Holtzman rats, weighing 80 grams were anesthetized with Urethane@ as described under experiment No. 1. 30 minutes after the second Urethane injection either pentagastrin, $25 \mu \mathrm{g}$ or saline were injected as a bolus of $0.2 \mathrm{ml}$ into a jugular vein. There were 4 rats for each test solution. At 0 and 30 minutes after administration of $P G$ or saline, arterial blood samples $(0.7 \mathrm{ml}$ each) were drawn from a size $\mathrm{p}$-10 polyvinyl catheter secured in a femoral artery $\mathrm{H}^{+}$ion concentration and total serum calcium concentration were determined in duplicate samples.

\section{Experiment No. 4:}

24 rats, weighing 80 grams, were prepared in the same manner as the animals in the preceding experiments. Size p-10 catheters were surgically inserted into a femoral artery and vein. The femoral vein catheter was connected to a pumpdriven syringe infusing sodium bicarbonate, 60,120 or $600 \mu \mathrm{Eq}$, or saline, 15 or $60 \mu \mathrm{Eq}$ over 30 minutes. At 0 and 30 minutes arterial samples were taken from the femoral artery and $\mathrm{pH}$ values determined immediately. Each sample was investigated twice.

Experiment No. 5:

36 male Holtzman rats were fasted for 18 hours. Ether anesthesia was given. In 
between injections and blood sampling procedures the animals were allowed to wake up. The animals were randomly assigned to 6 groups of 6 rats. Pentagastrin, $25 \mu \mathrm{g}$ or sodium bicarbonate, 60 or $120 \mu \mathrm{Eq}$ was given as a bolus into a surgically exposed jugular vein. $60 \mu \mathrm{Eq}$ was decided upon because this corresponded to the increase in gastric acidity which we could measure in the rat stomach during the first 30 minutes after administration of pentagastrin, $25 \mu \mathrm{g}$, our standard stimulus. The control group for the pentagastrin-treated rats received physiologic saline in the same volume $(0.2 \mathrm{ml})$. The other controls received equivalent amounts of sodium as sodium chloride. Venous blood samples were taken from the opposite jugular vein at 0,15 and 30 minutes after administration of the test solution. Total serum calcium levels were determined.

\section{Experiment No. 6:}

8 male Holtzman rats, $80-100$ gm of weight, were anesthetized with Urethane after an 18 hour fast. Through a midabdominal incision the stomach and pyloric channel were exposed. A duodenotomy was performed and a cannula (inner diameter $3 \mathrm{~mm}$ ) introduced into the antrum. Through a temporary nasogastric tube the gastric contents were washed out with saline until the stomach was completely empty. With the use of a dissecting microscope, size p-10 polyvinyl catheters were fitted into the femoral artery and vein. Physiologic saline, $0.4 \mathrm{ml}$ in 30 minutes was infused into the venous line with a Harvard infusion pump. After 30 minutes saline was replaced by pentagastrin, $50 \mu \mathrm{g}$ in 30 minutes. Then, saline infusion was re-started at $0.4 \mathrm{ml} / 30$ minutes and continued until completion of the experiment. Blood samples, 0.6 or $0.4 \mathrm{ml}$ each, were collected from the arterial line before and at 30,60 and 90 minutes following the start of the infusion. Arterial $\mathrm{pH}$ and total serum calcium concentration were determined. Gastric juice was sampled during periods of 30 minutes and gastric acidity, expressed as hydrogen ions, $\mu \mathrm{Eq} / 30$ minutes, was measured with the Oxford Titration method.

Due to the extent of surgery and blood sample size, only limited blood sampling could be performed in these small animais. Ultimately, five consecutive rats were utilized for analysis.

\section{Experiment No. 7:}

60 male Holtzman rats, weighing 100 grams were randomly assigned to 4 experimental groups of 10 or 20 rats. Half of each group was fasted for 18 hours, the other half had free access to food and water until the experiment was started. Ether anesthesia was administered and pentagastrin, $12.5 \mu \mathrm{g}$ (20 rats), $25 \mu \mathrm{g}$ (20 rats) or $50 \mu \mathrm{g}(10$ rats) injected into a surgically exposed jugular vein. One group ( 10 rats) served as control and received $\mathrm{NaCl}, 0.2 \mathrm{ml}$, intravenously. Thirty minutes later serum calcium values were determined.

\section{V11.2.2. RESULTS}

Experiment No. 1:Throughout the experiment the animals were in a stable condition and respiratory frequency and depth remained unchanged. Venous hydrogen ion concentration decreased $3.0 \mathrm{nEq} / \mathrm{L} \pm 0.4 \mathrm{SEM}$ at 15 minutes and $3.8 \mathrm{nEq} / \mathrm{L} \pm 0.2 \mathrm{~S}$.E.M. at 30 minutes after administration of pentagastrin 
(both $p<0.001$ ). This change was no longer significant 60 minutes after injection of PG. Saline administration did not affect venous hydrogen ion concentration (Fig. 1).

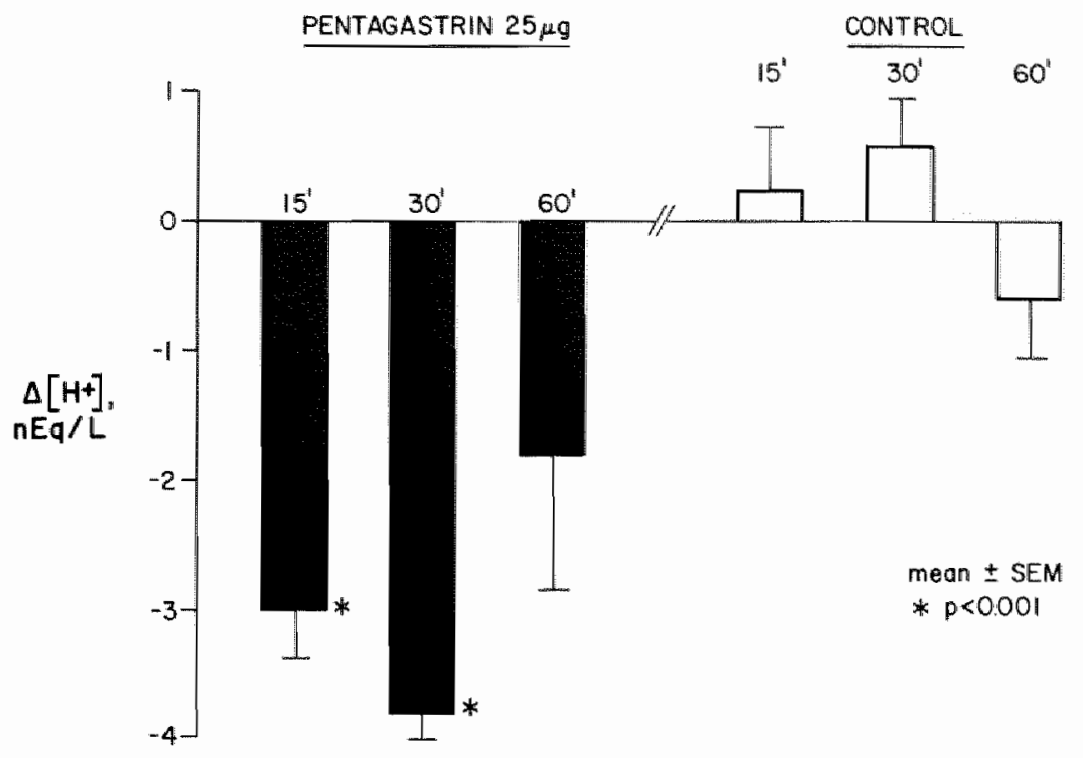

Figure VII.1: Change of venous hydrogen ion concentration $\left.\left(\Delta / H^{+}\right]\right), 15,30$ and 60 minutes after pentagastrin, $25 \mu \mathrm{g}$ or saline i.w.

Values represent the mean $\pm S E M$ for experimental groups of 7 rats each.

Student's t test.

\section{Experiment No. 2:}

Cumulative blood loss from repeated blood sampling did not play a role because similar results were obtained when only two samples per animal were taken (Fig. 2).

\section{Experiment No. 3:}

The hydrogen ion shift was demonstrated in arterial blood as well. $\mathrm{H}^{+}$ion concentration decreased $4.8 \mathrm{nEq} / \mathrm{L} \pm 1.2 \mathrm{SEM}$ in 30 minutes following an i.v. bolus injection of $\mathrm{PG}(\mathrm{p}<0.02)$ and no change was observed after saline injection (Fig. 3). Coincidently, serum calcium concentration decreased $2.0 \mathrm{mg} / 100$ $\mathrm{ml} \pm 0.3 \mathrm{SEM}$ at 30 minutes after $\mathrm{PG}$ administration $(\mathrm{p}<0.005)$ while saline did not influence serum calcium concentration.

\section{Experiment No. 4:}

Continuous infusion of sodium bicarbonate, 60 or $120 \mu \mathrm{Eq}$ in 30 minutes, created a comparable hydrogen ion deficit in arterial samples. Although a stronger reaction was measured after infusion of $120 \mathrm{\mu Eq}$, the difference between the effect of 60 or $120 \mu \mathrm{Eq}$ sodium bicarbonate was statistically not significant. Infusion of $600 \mu \mathrm{Eq}$ sodium bicarbonate in 30 minutes caused a huge decrease of 
hydrogen ion concentration in the blood (Fig. 4). Infusion of 15 or $60 \mu \mathrm{Eq}$ sodium chloride in 30 minutes did not result in a significant shift.

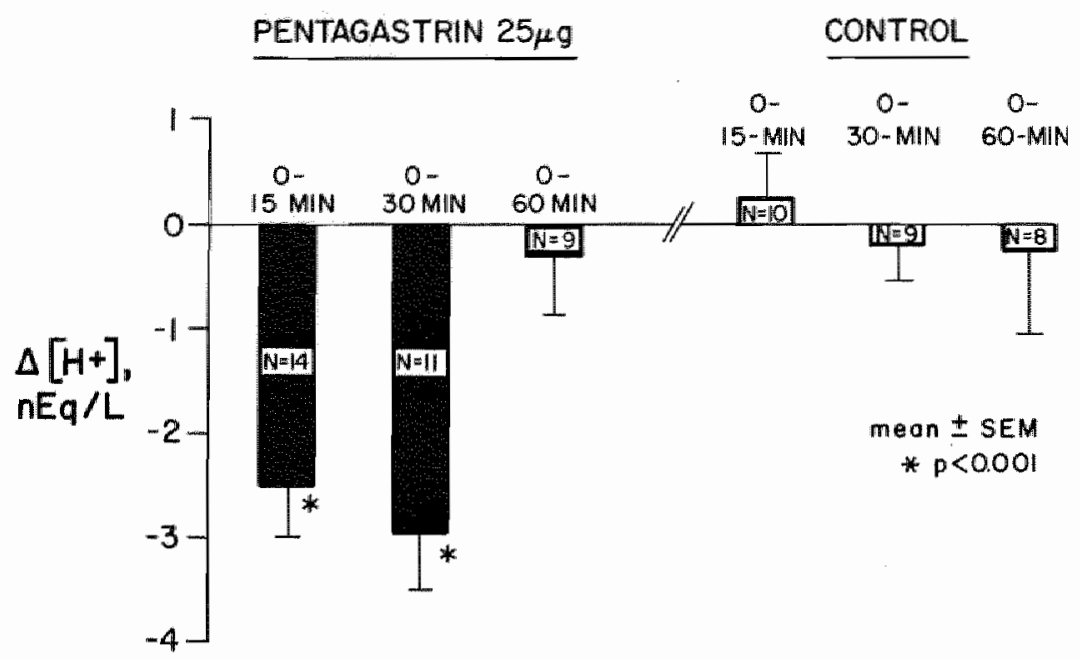

Figure VII.2: Change of venous hydrogen ian concentration $\left(\Delta\left[\mathrm{H}^{+}\right]\right)$after pentagastrin, $25 \mu \mathrm{g}$ or saline i.x.

Each bar represents a different group of rats. Values represent the mean \pm SEM. Student's t test.

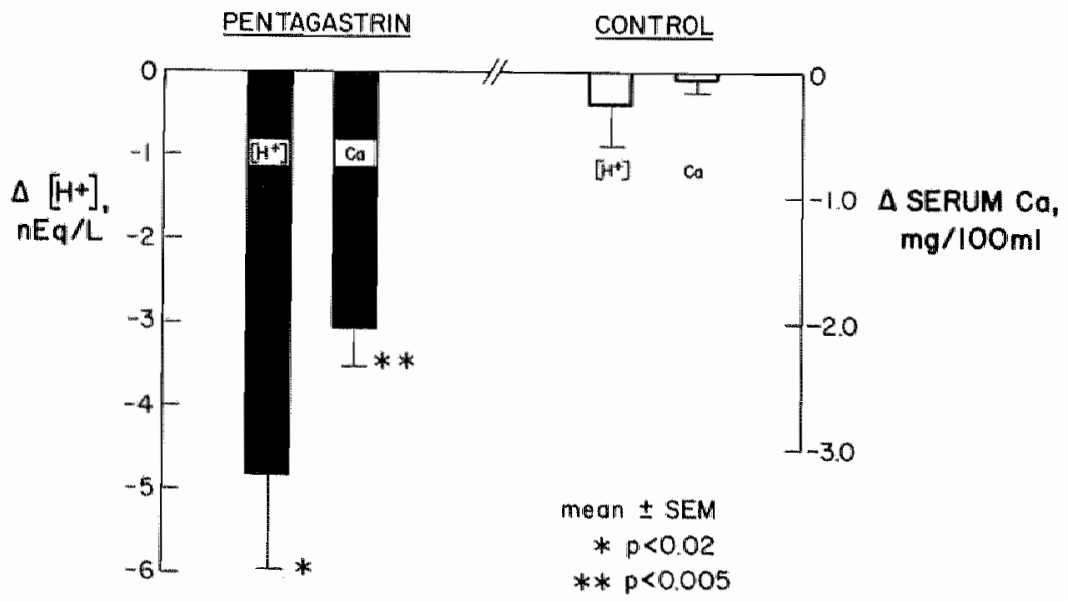

Figure VII.3: Changes of hydrogen ion concentration $\left(\Delta\left[H^{+}\right]\right)$and serum calcium concentration ( $\Delta$ serum $\mathrm{Ca}$ ) in arterial blood, 30 minutes after bolus i.v. injecrion of pentagastrin, $25 \mu \mathrm{g}$ or saline.

Values represent the mean \pm SEM for experimental groups of 4 rats each.

Statistical analysis was carried out using Student's $t$ test. 


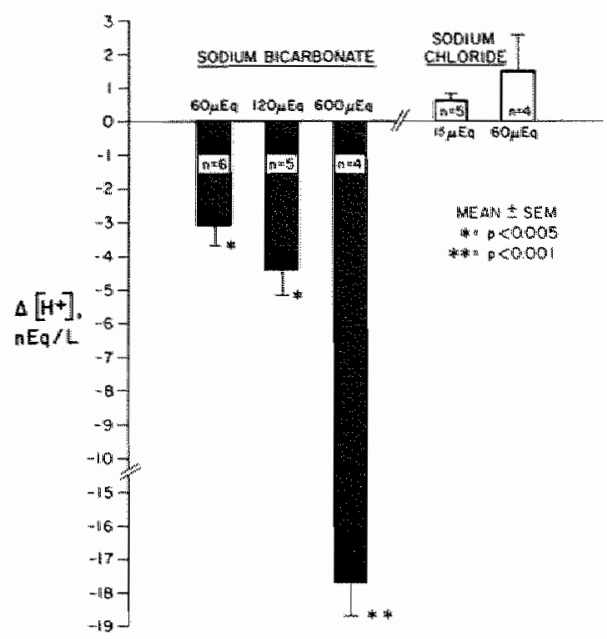

Figure VII.4: Effect of 30 minutes continuous intravenous infusion of sodium bicarbonate or sodium chloride on arterial hydrogen ion concentration $\left(\Delta\left[H^{+}\right]\right)$.

Values represent the mean \pm SEM for groups of varying size. Student's $t$ test.

\section{Experiment No. 5:}

Comparison between i.v. bolus injection of $\mathrm{PG}, 25 \mu \mathrm{g}$ and sodium bicarbonate, 60 and $120 \mu \mathrm{Eq}$ and their equivalent controls resulted in several interesting observations. Serum calcium concentration decreased $1 \mathrm{mg} / 100 \mathrm{ml}$ and 1.1 $\mathrm{mg} / 100 \mathrm{ml}$ at 15 and 30 minutes after $\mathrm{PG}$ administration respectively. Both reactions were statistically different from saline controls (fig. 5). Administration of sodium bicarbonate, $60 \mu \mathrm{Eq}$ was followed by small but statistically significant falls of serum calcium concentration 15 and 30 minutes later but only at 15 minutes this change was significantly different from control (Fig. $5, \mathrm{p}<$ $0.05)$. The observed changes were statistically different from those measured following PG administration (Table 1). Administration of sodium bicarbonate, $120 \mu \mathrm{Eq}$ was followed by decreases of serum calcium concentration at 15 and 30 minutes not different from those following PG administration (Table 1). Both reactions were different from controls (Fig. 5).

\section{Experiment No. 6:}

Simultaneous determination of serum calcium concentration, hydrogen ion concentration in the blood and gastric acid production beautifully demonstrated the time sequence of the events taking place after infusion of pentagastrin in 5 rats. After 30 minutes of $P G$ infusion a discrete but statistically significant decrease of hydrogen ion concentration was measured $(3 \mathrm{nEq} / \mathrm{L}, \mathrm{p}<0.02)$. At the same time serum calcium fell to its lowest concentration while gastric acid production more than doubled (Fig. 6). 30 minutes after reinstitution of saline infusion serum calcium almost returned to basal values and gastric acid secre- 
tion fell to a level significantly below basal secretory rate $(\mathrm{p}<0.001)$. Hydrogen ion concentration was not measured at this point because sample size was kept small to prevent exsanguination.

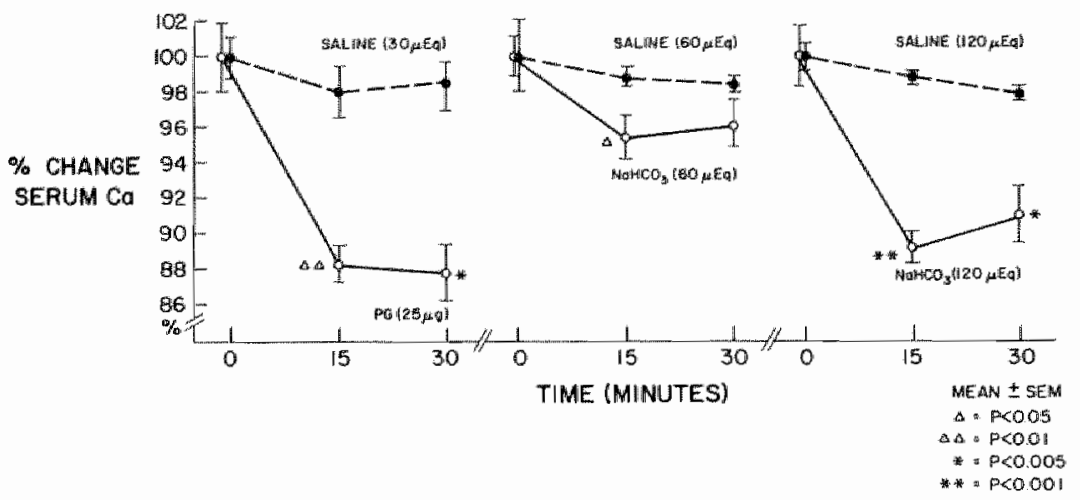

Figure VII.5: Changes (percent of basal value) of serwin calcium concentration ( $\Delta$ serum $C a)$, 15 and 30 minutes afier injection of pentagastrin, sodium bicarbonate or control (sodium chloridé).

Each value (mean \pm SEM) was compared with its saline control, Student's t test.

Table VII.I: Comparing the changes of serum calcium concentration after injection of pentagastrin, sodium bicarbonate or sodium chloride.

\begin{tabular}{|c|c|c|c|}
\hline Corresponding values & 1 & $\begin{array}{l}\text { Degree of } \\
\text { Freedom }(F)\end{array}$ & $\mathrm{p}<$ \\
\hline PG-Saline $30 \mu \mathrm{Eg}$ at 15 minutes & 3.55 & 9.7 & 0.01 \\
\hline PG-Saline $30 \mu q$ at 30 minutes & 4.12 & 10.0 & 0.005 \\
\hline $\mathrm{NaHCO} 360 \mu \mathrm{q}-$ Saline $60 \mu \mathrm{q}$ at 15 minutes & 2.63 & 6.6 & 0.05 \\
\hline $\mathrm{NaHCO} 30 \mathrm{\mu q}$-Saline $60 \mu \mathrm{q}$ at 30 minutes & 1.65 & 6.0 & N.S. \\
\hline NaHCO3 $120 \mu q-$ Saline $120 \mu \mathrm{q}$ at 15 minutes & 10.36 & 7.3 & 0.001 \\
\hline NaHCO3 $120 \mu \mathrm{q}$-Saline $120 \mu \mathrm{q}$ at 30 minutes & 4.52 & 5.8 & 0.005 \\
\hline $\mathrm{PG}-\mathrm{NaHCO} 360 \mathrm{\mu q}$ at 15 minutes & 2.71 & 8.6 & 0.025 \\
\hline $\mathrm{PG}-\mathrm{NaHCO} 360 \mu \mathrm{q}$ at 30 minutes & 3.33 & 9.6 & 0.01 \\
\hline $\mathrm{PG}-\mathrm{NaHCO} 3120 \mu \mathrm{g}$ at 15 minutes & 0.08 & 6.9 & N.S. \\
\hline $\mathrm{PG}-\mathrm{NaHCO} 3120 \mathrm{\mu q}$ at 30 minutes & 1.08 & 9.7 & $\mathrm{~N}, \mathrm{~S}$ \\
\hline
\end{tabular}

Statistical significance between corresponding values was determined with the two sample Student's t test. The unpooled (Welch) S.E. of differences was used. 


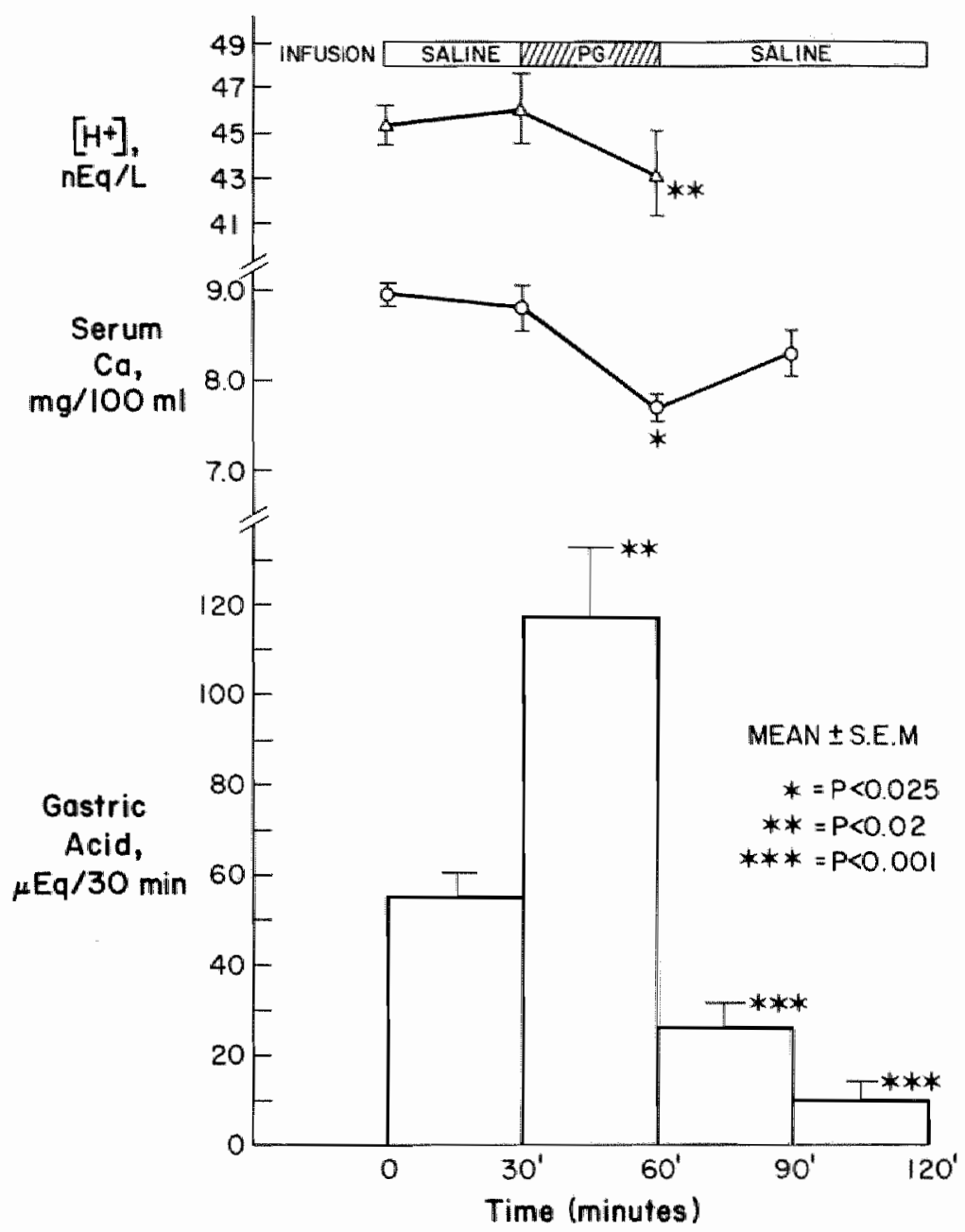

Figure VII.6: Effect of pentagastrin ( $P G, 50 \mu \mathrm{g}$ ) or saline infusion on arterial hydrogen ion concentration $\left(\left[H^{+}\right]\right)$, serum calcium concentration and gastric acid secretion in 5 anesthetized rais.

Values represent the mean \pm SEM. Asterixes indicate values that were statistically different from basal values. Student's $t$ test.

\section{Experiment No. 7 :}

As expected, pentagastrin administration resulted in a significant fall of serum calcium concentration in all fasted animals 30 minutes after injection. Falls of $0.66 \pm 0.06 \mathrm{mg} / 100 \mathrm{ml}($ mean $\pm \mathrm{SEM}), 0.83 \pm 0.16 \mathrm{mg} / 100 \mathrm{ml}$ and $1.18 \pm$ $0.16 \mathrm{mg} / 100 \mathrm{ml}$ were measured following increasing doses of pentagastrin (Fig. 7). However, no change in serum calcium levels was seen in the fed animals despite $\mathrm{PG}$ injection. $\mathrm{NaCl}$ administration resulted in no change in serum calcium concentration in either group. 


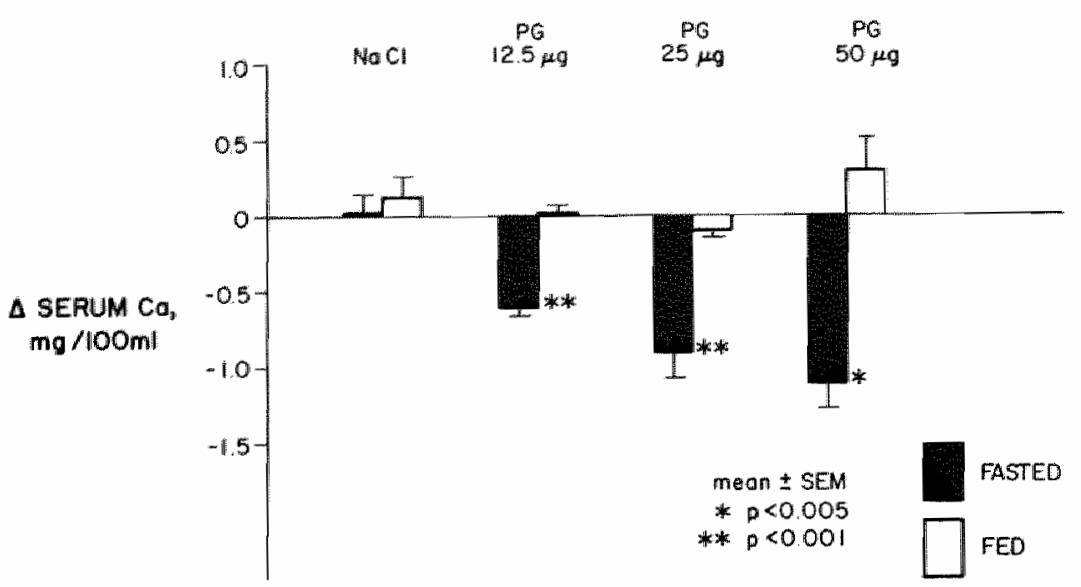

Figure VII.7: Changes in serum calcium concentration 30 mimutes after penlagastrin administration to fasted or fed rats.

Control group, 10 rats; $12.5 \mu \mathrm{g} P G, 20$ rats; $25 \mu \mathrm{g} \mathrm{PG}, 20$ rats and $50 \mu \mathrm{g}$ $\mathrm{PG}, 10$ rats. Each value represents the mean $\pm \mathrm{SEM}$. Student's $t$ test.

\section{VII.3. DISCUSSION}

Both ionized and total calcium have been demonstrated experimentally to be dependent upon the hydrogen ion concentration of blood $(18,19,20,21,22,23)$. Plasma calicum ion concentration decreases with an increase in $\mathrm{pH}$ irrespective of the type of acid-base disorder and, conversely, increases with a decrease in $\mathrm{pH}$. Total calcium levels in plasma show generally similar, but quantitatively smaller alterations to those of calcium ion activity. On the basis of in vitro studies, Moore in 1970 (24) concluded that a rise in blood pH in vivo increases plasma protein binding of ionized calcium and lowers blood ionized calcium concentration. Hughes e.a. (25) calculated that half the fall of ionized calcium could be accounted for by increased protein binding, under conditions of constant levels of serum protein, the other half by complex-formation of (soluble) calcium bicarbonate.

However, the fall of total calcium can not be explained by these electrochemical events and it has to be assumed that calcium is driven from or kept from entering the circulation by a rise in $\mathrm{pH}$. Studies on bone metabolism indicate that the latter possibility i.e. inhibition of bone resorption by alkalosis is the physiologic mechanism $(3,4,5,6,7,8,9)$. As previously postulated as an explanation for the results of the isotope kinetic studies (chapter VI), inhibition of bone resorption may underlie the hypocalcemia that follows administration of acid secretagogues also. Understandably, the analogy of these two mechanisms has led us to suspect that acid secretion and bone metabolism are linked through this shift of hydrogen and bicarbonate ions.

The hypothesis that the metabolic changes that accompany gastric acid secretion play a role in the regulation of calcium homeostasis has not been sug- 
gested before. The results of the experiments reported here, seem to confirm this hypothesis. It offers an elegant explanation for the hypocalcemia in the experiments described before and opens an intruiging, new view on postprandial calcium regulation.

The rwe questions that were listed in the introductory section of this chapter can all be answered affirmatively.

1. There was a small alkaline tide following PG administration, that was equally well demonstrable in venous as in arterial blood. The results were not compromised by repeated blood sampling or by the development of respiratory alkalosis.

2. Next, the question conceming cause - relationship was addressed. Assuming that the bicarbonate ion is fomed on a one to one basis and synchronous with the formation of the hydrogen ion, one would expect the alkaline tide to occur in parallel with the secretion of hydrochloric acid. Acid secretion following stimulation with pentagastrin in the rat abruptly doubles during the first 10 minutes and triples during the second 10 minute period. During the next 20 minutes this high acid output is maintained but then gradually diminishes, returning to basal levels around 60 minutes after stimulation (26). Therefore, one has to assume that the greatest increase of alkalinity occurs during the first twenty minutes after injection also, well in time to be followed by the maximum deerease of serum calcium concentration at 15 and 30 minutes. In the experiments this assumption was confirmed by the demonstration of a clear rise of alkalinity at 15 and 30 minutes after stimulation of acid secretion, while at 60 minutes hydrogen ion concentration was not different from basal values.

3. Continuous infusion of bicarbonate was employed in an attempt to approximate the alkaline tide of acid secretion. The finding of a shift in the hydrogen ion concentration comparable to that observed after stimulation with pentagastrin seems to indicate, firstly, that the migration of bicarbonate ions takes place at the suggested rate and, secondly, that the amount of bicarbonate ions that enters the circulation may be derived directly from the quantity of acid secreted into the stomach.

Although those findings are not conclusive by themselves they answer the third question from the introductory section of this chapter affirmatively. Besides, because basal hydrogen ion concentrations were variable, they suggest that the fall in serum calcium is a function of the change in blood $\mathrm{pH}$ and not of the hydrogen ion concentration per se.

4. Further support for the hypothesis concerning the calcitropic effect of the alkaline tide was sought by exogenous creation of an alkaline tide. There is no doubt that convincing evidence was provided by the results of this experiment. The administration of both 60 and 120 micro equivalents of sodium bicarbonate caused a fall in serum calcium that was significantly greater than in controls. Sodium bicarbonate $60 \mu \mathrm{Eq}$, was not sufficient, however, to parallel the serum calcium reaction to $\mathrm{PG}, 25 \mu \mathrm{g}$. On the other hand, the effect of $120 \mu \mathrm{Eq}$ was almost identical to that of pentagastrin, both at 15 and 30 minutes following administration.

From earlier experiments (Chapter VI) it was demonstrated in the rat mod- 
el that PG administration increases acid secretion by approximately $60 \mu \mathrm{Eq}$ during the first thirty minutes. This figure was reached using the Shay preparation and the same result was obtained using an open-drainage procedure (experiment No. 6 in this chapter). For practical purposes it was assumed that during those first 30 minutes after stimulation of acid secretion an equivalent amount of bicarbonate was being released in to the circulation. This calculation leaves us with a discrepancy because twice that amount was needed to produce the expected hypocalcemia. It should be remembered that while $60 \mu \mathrm{Eq}$ of acid were recovered, this may underestimate the amount of total acid secretion. For instance, the phenomenon of back-diffusion of hydrogen ions from the gastric lumen into the mucosa $(27,28)$ was not taken into account but may have acted to decrease the amount of acid that was recovered from the gastric juice. Also, saliva from the esophagus must be held responsible for neutralizing some of the gastric acid. Furthermore, test groups were small and it is possible that injection of less than 120 micro equivalents (but more than 60) would have given an equally good reaction. Another factor might be the acute injection of the base creating an unphysiologic peak-concentration early on in the experiment, limiting the effect on calcium release from bone. In addition, it is convenient to recall the occurrence of the small increase of gastric calcium secretion that accompanies stimulated acid secretion, as was previously demonstrated (Chapter VI). Although no significant correlation between this increased rate of calcium secretion and the fall in total serum calcium could be established, perhaps this flux of calicum might supplement the hypocalcemia caused by the inhibition of bone resorption.

5. Finally, feeding completely abolished the hypocalcemic effect of pentagastrin injection, presumably because acid secretion had been maximally stimulated by feeding, prohibiting any further release of hydrochloric acid in response to the administration of acid secretagogues. This again supports the hypothesis that it is the alkaline tide accompanying acid secretion that is responsible for the observed transient hypocalcemia.

\section{VII.4. CONCLUSION}

In conclusion, it seems justified to state that the hypocalcemia that follows the administration of acid secretagogues in the rat is chiefly caused by a decrease of the hydrogen ion concentration in the fluid surrounding the bone mineral compartment, inducing an abrupt inhibition of bone resorption. Increased secretion of calcium into the gastric juice may contribute to the hypocalcemia.

The question arises whether these events may constitute the dominant mechanism through which postprandial hypercalcemia is prevented the rat. This intruiging possibility will be discussed in the next chapter. 


\section{VII.5. REFERENCES}

1. Neuman, W.F., Bareham, B.J. (1975): Evidence for the presence of secondary calcium phosphate in bone and its stabilization by acid production. Calcif. Tissue Res. 18, p. 161 .

2. Brommage, R., Neuman, M.W. and Neuman, W.F. (1978): Aerobic glycolysis, ion fluxes and the bone membrane. in: Endocrinology of calicum metabolism. Ex 89, 421, p. 79, 1978, ed. by Copp, D.H. and Talmage, R.V., Amsterdam, Excerpta Medica W3.

3. Schartum, S. and Nicols, G. (1962): Concerning pH gradients between the extracellular compartment and filuids bathing the bone mineral surface and their relation to callcium ion distribution. J. Clin. Invest. 41 , p. 1163.

4. Raisz, L.G. (1965): Bone resorption in tissue culture. Factors influencing the response to parathyroid hormone. J. Clin. Invest. 44, p. 103.

5. Stern, P.H. (1971): Albumin - induced resorption of fetal rat bone in vitro. Calcif. Tissue Res. 7, p. 67.

6. Martin, K.J., Freitag, J.J., Bellorin-Font, E., Conrades, M.B., Klahr, S. and Slatopolsky, E. (1980): The effect of acute acidosis on the uptake of parathyroid hormone and the production of adenosine $3^{\prime}, 5^{\prime \prime}$-monophosphate by isolated perfused bone. Endocrinology 160 , p. 1607.

7. Lemann, J. Jr., Litzow, J.R and Lennon, E.J. (1966): The effects of chronic acid loads in normal man: further evidence for participation of bone mineral in the defence against metabolic acidosis. J. Clin. Invest. 45, p. 1608.

8. Barzel, U.S. and Jowsey, J. (1969): The effects of chronic acid and alkali administration on bone turnover in adult rats. Clin. Sci. 36, p. 517.

9. Burnell., J.M. (1971): Changes in bone sodium and carbonate in metabolic acidosis and alkalosis in the dog. J. Clin. Invest. 50, p. 327.

10. Sachs, G., Spenney, J.G. and Lewin, M. (1978): H* Transport: Regulation and mechanism in gastric mucosa and membrane vesicles. Physiol. Rev. 58, p. 106.

11. Goldberg, N.D., O'Dea, R.F. and Haddox, M.K. (1973): Cyclic GMP. Adv. Cyclic Nucleotide Res. 3, p. 155.

12. Goldberg, N.D., Haddox, M.K., Nicol, S.E., Glass, D.B., Sanford, C.H., Kuehl, F.A. and Estensen, R. (1975): Biological regulation through opposing influences of cyclic GMP and cyclic AMP, the yin-yang hypothesis. Adv. Cyclic Nucleotide Res. 5, p. 307.

13. Davies, R.E. (1948): Hydrochloric acid production by isolated gastric mucosa. Biochem. J. 42, p. 609.

14. Davies, R.E. (1951): Mechanism of acid secretion by stomach. Gastroentetology 76 , p. 78 .

15. Rune, S.J. (1965): The metabolic alkalosis following aspiration of gastric acid secretion. Scan. J. Clin. Lab. Invest. 17, p. 305.

16. Rune, S.J. (1966): Comparison of the rates of gastric acid secretion in man after ingestion of food and after maximal stimulation with histamine. GUT 7, p. 344.

17. Goldberger, E. (1975): The principles of acid-base chemistry and physiology. In: Water, electrolyte and acid-base syndromes, p. 151, ed. by Lea and Febiger, Philadelphia, fifth edition.

18. Moore, E.W. (1969): Studies with ion-exchange calcium electrodes in biological fluids: Some applications in biomedical research and clinical medicine. In: Ion selective electrodes. Washington, D.C. National Bureau of Standards Publication 314 , p. 215 , ed. by Durst, $\mathbb{R} . A$.

19. Irvin, G.L. III, Gittes, R.F. and Gibbs, M.F. (1966): Influence of acid-base distur* bances on total plasma calcium and evidence for a homeostatic role of thyrocalcitonin. Am. J. Surg. 164, p. 1073.

20. Kaplan, E.L., Hill, B.J., Locke, S. and Peskin, G.W. (1971): Acid-base balance and parathyroid function: metabolic alkalosis and hyperparathyroidism. Surgery 70 , p. 198. 
21. Holfken, B., Parkinson, D.K., Storms, P. and Radde, I.C. (1971): Effects of alterations of blood pH on calcium jon activity in rat plasma. Clin. Orthop and Related Res. 78 , p. 30.

22. Montellar, M.E. and Tuttle, E.P. (1964): Effects of alkalosis on plasma concentration and urinary excretion of inorganic phosphate in man. J. Clin. Invest. 43, p. 138.

23. Lemann, J. Jr., Litzow, J.R. and Lennon, E.J. (1967): Studies on the mechanism by which chronic metabolic acidosis augments urinary calcium excretion in man. $J$. Clin. Invest. 46, p. 1318.

24. Moore, EW. (1970): Ionized calcium in normal serum, ultrafiltrates, and whole blood determined by ion-exchange electrodes. J. Clin. Invest. 41, p. 318.

25. Hughes, W., Cohen, S., Arvan, D. and Seamonds, B. (1977): the effect of the alkaline tide on serum - ionized calcium concentration in man. Digestion 15, p. 175.

26. Barrett, A.M. (1966): Specific stimulation of gastric acid secretion by a pentapeptide derivative of gastrin. J. Pharm. Pharmac. 18, p. 633.

27. Teorell, T. (1934): Ionic diffusion as a cause of the variations in gastric juice acidity. Scand. Arch. Physiol. 71, p. 33.

28. Teorell, T. (1935): "Duodenal regurgitation" versus "electrolyte diffusion" in the gastric juice. Acta Med. Scand. 85, p. 518. 
Chapter VIII

\section{A PHYSIOLOGIC ROLE?*}

\section{VIII.1. INTRODUCTION}

It is of interest to see how our findings apply to normal physiology and can be made to fit a general concept of serum calcium regulation. Intuitively one would expect that following a meal containing calcium the serum calcium level would rise due to the gastrointestinal absorption of this ion. However, a number of investigators ( $1-5)$ have reported that rats maintained on a regular feeding and activity conditioning schedule show a fluctuation in serum calcium concentration according to a circadian rhythm with an amplitude of 5-10\%, starting their fall in calcium concentration 4 hours before the onset of feeding and not recovering from the lowest attained level until several hours after the dark-fed period had begun. These changes did not occur in non-conditioned rats. The same conditioned response was reported for ionized calcium (6). Thus, the opposite appears to be true. This fall in serum calcium was once thought to be a manifestation of the PTH-calcitonin homeostatic axis. However, with the discovery that some G.I. peptide hormones, especially those which are gastric acid secretagogues have effects on serum calcium levels the simple notion that PTH and CT exclusively control serum calcium levels is no longer held. In order to clarify the physiologic role of the stomach in serum calcium homeostasis several studies were undertaken.

1. First, the effectiveness of orally administered metiamide, an $\mathrm{H}_{2}$-receptor antagonist, to suppress pentagastrin-stimulated acid secretion was studied in non-conditioned rats.

2. Next, the effect of a regulated feeding and light-dark schedule on serum calcium levels in rats was studied and,

3. The effect of metiamide on serum calcium levels during this regulated feeding period was examined.

* Parts of this chapter were presented at the 13th annual meeting of the Association for Academic Surgery, Great Gorge, New Jersey, November 11-14, 1979. 


\section{VIII.2. EXPERIMENTS}

\section{WIII.1. MATERIAL AND METHODS}

\section{Experiment No. 1:}

Non-conditioned male Holtzman rats, 100-125 grams of weight, were randomly assigned to 4 groups of 8 rats and fasted for 24 hours. Following ligation of the pylorus through a mid-abdominal incision group one received $0.4 \mathrm{ml}$ physiologic saline i.v.; group two, three and four received pentagastrin, $50 \mu \mathrm{g}$, intravenously. Thirty minutes later blood samples for total serum calcium determination were drawn and the animals sacrificed. After ligation of the esophagus the stomachs were removed and gastric acidity determined by the Oxford Titration method. Furthermore, group three and four received $1 \mathrm{ml}$ physiologic saline (control) and $10 \mathrm{mg}$ metiamide dissolved in $1 \mathrm{ml}$ deionized water ( $\mathrm{pH}$ adjusted to 7.5 ) respectively through a nasogastric tube, two hours prior to pyloric ligation and pentagastrin injection. Student's t test was applied for statistical analysis.

\section{Experiment No. 2:}

Fifty male Holtzman rats (10 per cage) were adapted to a regular feeding schedule in which food was available for 9 hours and withheld for 15; tap water was available ad libitum. The "dark" period corresponded to the fed period, and the times of feeding and fasting remained constant \pm 5 minutes. The food was standard Tevdek rat chow (Ca $2 \%$, Phosphorus $0.9 \%$ ). The rats were acclimated to this schedule for 21 days before blood samples for Ca determinations were drawn by tail bleeding. At this point the rats had reached an average weight of 150 to 175 grams. The period studied in detail was from -4 hours to +2 hours with time 0 representing the onset of feeding and darkness. No rat was bled more than once during a single day with 10 rats (a single cage) representing each time point ( -4 hours, -2 hours, $0,+1$ hour, +2 hours). Between trials, conditioning was maintained with a minimum of 3 days between experiments. To ensure that the rats were not being conditioned to our presence, the cages were rotated between trials, thereby, an individual rat was bled at a different time point in each experiment. After determination of the pattern of serum calcium concentration, the experiment was repeated with the addition of metiamide administration. Metiamide was dissolved in deionized water utilizing small amounts of $0.1 \mathrm{M} \mathrm{HCl}$ to aid in dissolution and then titrating back to $\mathrm{pH} 7.5$ with $0.1 \mathrm{M} \mathrm{NaOH}$, to a concentration of $3 \mathrm{mg}$ per cc. This was administered to the animals in their water bottles during the light-unfed period for 6 hours prior to the onset of the experiment. On this regimen there was no difference in the amount of fluid ingested in that time period and the total dose of metiamide per rat was found to be between $5-10 \mathrm{mg}$. Total serum calcium was measured with all 50 samples from a single trial run on the same day. The same experiment was repeated with the same rats as they had grown heavier, 275-300 gm. 


\section{Experiment No. 1:}

The preliminary studies in non-conditioned rats confirmed that pentagastrin is a gastric acid stimulator. A four-fold increase in gastric acid secretion followed the injection of $50 \mu \mathrm{g}$ both in groups two and three (Fig. 1, p $<0.001$ ).

Orally administered metiamide completely blocked gastric acid secretion in group four when given two hours prior to pyloric ligation and pentagastrin injection. As can be seen (Fig. 1, right side) serum calcium concentration fell. significantly 30 minutes after pentagastrin administration in these non-conditioned animals except when metiamide had been given before.
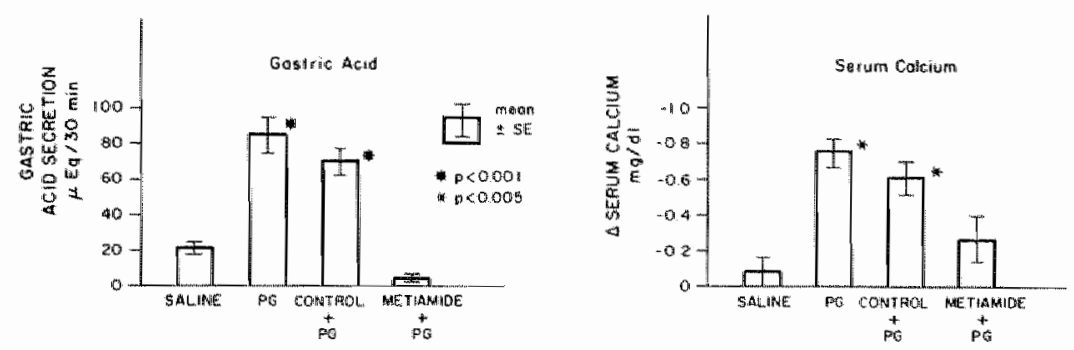

Figure VIII.1: Effect of oral metiamide on pentagastrin $(P G)$-induced gastric acid secretion and hypocalcemia in non-conditioned rats.

Each bar represents the mean \pm SEM for experimental groups of 8 rats.

Statistical significance was determined using Student's t test.

\section{Experiment No. 2:}

In conditioned rats serum calcium fell in the 4 hour period prior to feeding and hypocalcemia was maintained at least 2 hours into the regular feeding period (Fig. 2).

When this experiment was repeated, there was a fall as great as $15 \%$ in young rats, 175-200 grams, (Fig. 3), and in older rats, 275-300 grams, there was a fall of $10 \%$ (Fig. 4).

Each was statistically significant at the $p<0.005$ level. After ingestion of metiamide, the fall in serum calcium which had occurred both before and after feed ing was completely inhibited in both age groups. 


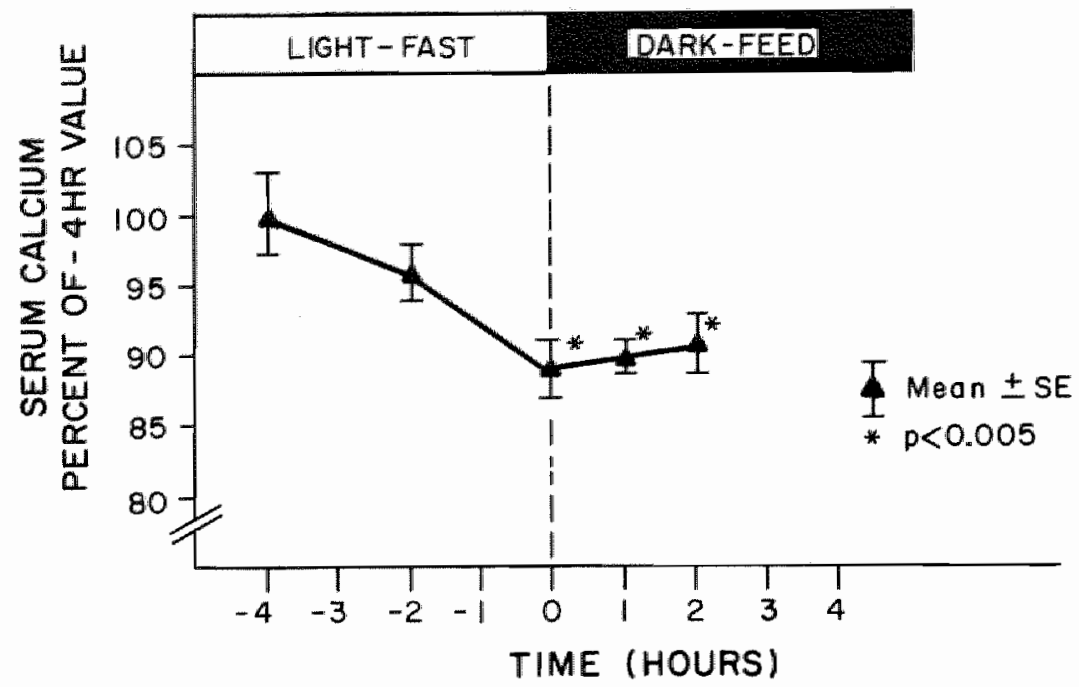

Figure VIII.2: Effect of conditioning on serum calcium levels in the rat.

Each point represents the mean \pm SEM of groups of 10 rats. Statistical significance was determined using Student's t test.

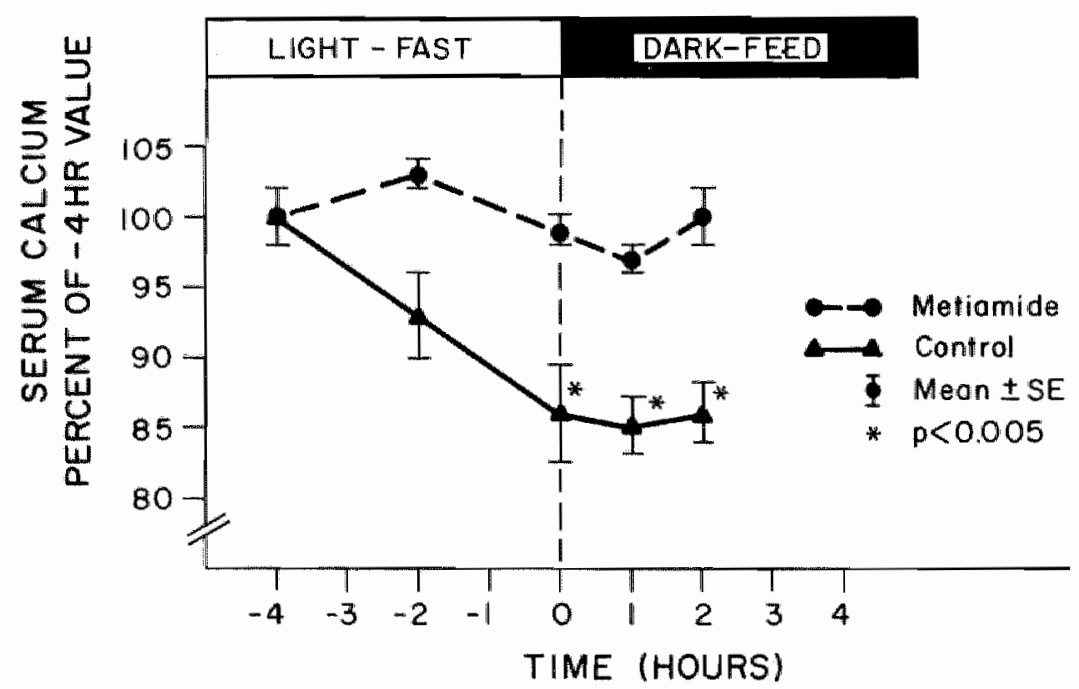

Figure VIII.3: Effect of oral metiamide on serum calcitm concentration in conditioned rats, $150-175$ grams of weight.

Each point represents the mean \pm SEM for experimental groups of 10 rats (1 cage). Statistical significance was determined using Student's t test. 


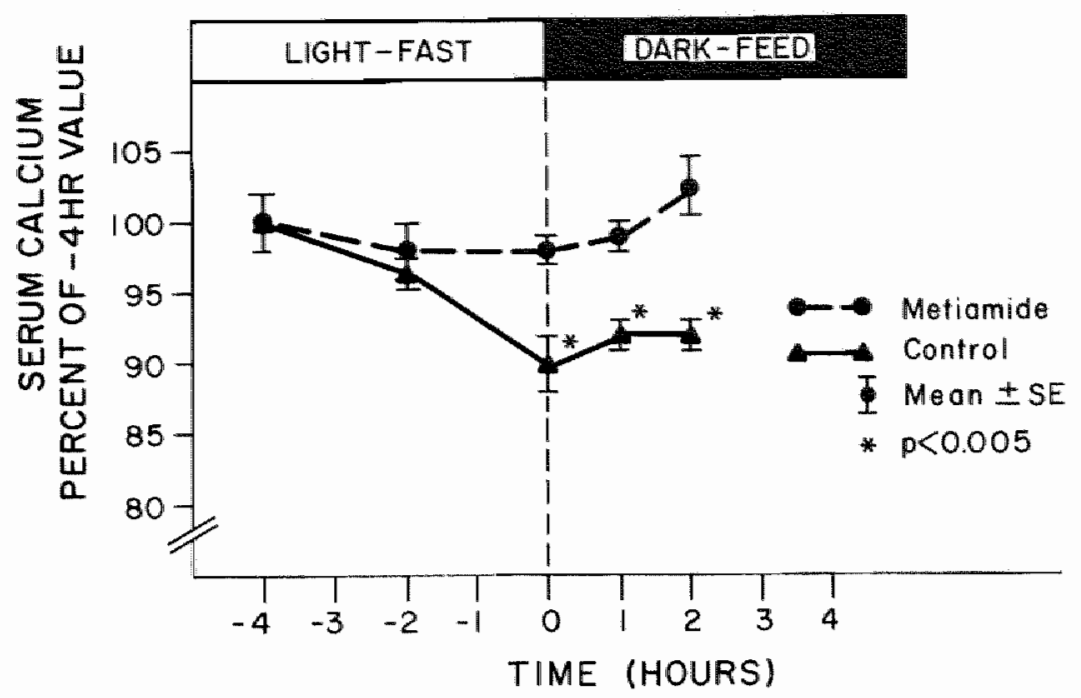

Figure VIII.4: Effect of oral metiamide on serum calcium concentration in conditioned rats, 275-300 grams of weight.

Each point represents the mean \pm SEM for experimental groups of 10 rats (1 cage). Statistical significance was determined using Student's t test.

\section{VIII.3. DISCUSSION}

Since the concept of a "fixeté du milieu interieur" was introduced by Claude Bernard in the nineteenth century, the understanding of the regulation of the calcium level in body fluids, once thought to be a classic example of a physiologic constant, has gradually but dramatically developed from a purely static to a dynamic system in which the calcium ion is subject to a complex system of subtly interrelated physiological regulators.

The notion of a fixed serum calcium level soon had to be reconsidered after the discovery that PTH, calcitonin and vitamin D metabolites each were strongly involved in serum calcium metabolism. Although the exact mechanism by which these hormones interact to regulate serum calcium concentration is constantly undergoing further examination, the "negative feedback" principle has proved to be important.

More recently, the existence of a rhythmic fluctuation in serum calcium concentration was reported (2). In rats conditioned to a regulated feeding schedule these authors found evidence for a physiologic role of calcitonin in controlling serum levels of calcium and phosphate during the period of normal food intake, but the significance of calcitonin remains controversial. Rhythmicity was a new concept for serum calcium regulation and was quickly confirmed. Talmage, Roycroft e.a. (4) also conditioned young rats for three weeks. 
to a 12 hour fed-fast regimen. They focussed on the period beginning 4 hours prior to feeding and observed a serum calcium fall of approximately $5 \%$ during this 4 hour period. The calcium remained low for several more hours whether or not the animals were fed at time " 0 ". In addition they demonstrated in this study that calcium response was not related to the light-dark cycle since varying this condition did not influence the patterns of response. Surprisingly, however, in a follow-up study (5) they also found that serum levels of both gastrin and calcitonin were irresponsive to the existing serum calcium levels but related to eating since a marked increase in both peptides only started after food had become available at the time when serum calcium was at it's lowest concentration, while no change in the secreton of these peptides occurred when food was withheld (Fig. 5).

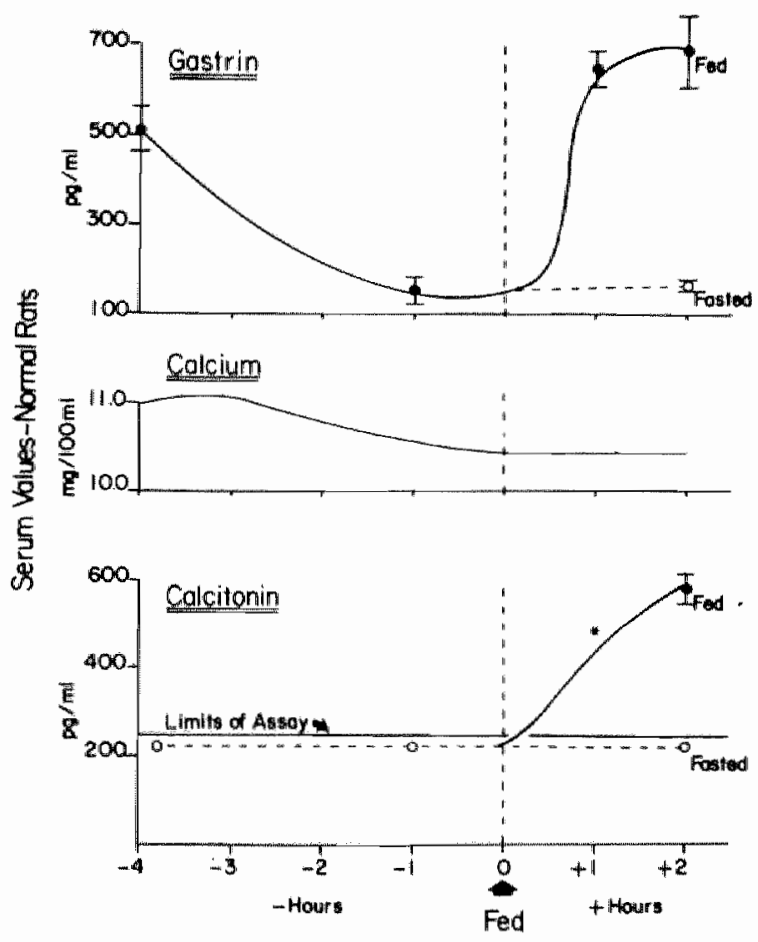

Figure VIII.5: Serum gastrin and calcitonin concentrations as influenced by the avallability of food.

Points on graphs are means \pm SEM of serum samples taken from 12 to 16 rats. Fasted not fed at regular feeding time.

* Calcitonin values at 1 hour after food became available ranged from non detectable to $>600 \mathrm{pg} / \mathrm{ml}$. From: R.V. Talmage e.a., $1975(5)$.

) Reproduced with permission of the editor. 
They theorized that the observed high serum gastrin levels $(700 \mathrm{pg} / \mathrm{ml})$ were responsible for the release of calcitonin. Thus, although gastrin and calcitonin secretion might be responsible for the continued hypocalcemia after eating, their secretion could not account for the fall which occurred before eating.

These highly interesting observations are in harmony with the data presented in this thesis. An entirely different mechanism than hormonal action might be involved in the hypocalcemia of conditioned rats. As was shown, gastric acid secretion is accompanied by a fall in serum calcium concentration which is unrelated to a change in serum levels of calcitonin or gastrin. Could this not be a type of response in which gastric acid secretion is initiated by "cephalic" vagal mediation in anticipation of a meal? The experiments described in this chapter strongly support this hypothesis since the circadian rhythm of serum calcium concentration that was created by conditioning of the rats could be completely eliminated simply by preventing acid secretion. It seems justified, therefore, to describe the events that take place preceeding and following feeding in conditioned rats in the following way.

In anticipation of food, vagal stimulation gives rise to the secretion of gastric acid which in turn is accompanied by an increase of blood $\mathrm{pH}$, the socalled alkaline tide. As a result of this, calcium release from the bone is diminished and serum calcium concentration begins to decrease even before the expected meal. This process continues for several hours after eating. Once food is ingested, the body reacts with the secretion of gastrin which triggers the release of calcitonin from the thyroid gland. Perhaps, in the rat, calcitonin further inhibits bone resorption, adding to the existing hypocalcemia.

Undoubtedly this description represents an oversimplified analysis of the events that govern normal calcium homeostasis. The present experiments relate only to conditioned rats and, thus far, have not been extended to normal calcium physiology. However, these studies seem quite conclusive that gastric acid secretion indeed may play an important role in the regulation of serum calcium homeostasis and may even be more important than the known gastrointestinal hormones.

\section{VIII.4. REFERENCES}

1. Briscoe, A.M. and Ragan, C. (1966): Diurnal variations in calcium and magnesium excretion in man. Metabolism 15, p. 1002.

2. Milhaud, G., Perault-Staub, A.M. and Staub, J.F. (1972): Diurnal variation of plasma calcium and calcitonin function in the rat. J. Physiol. 222, p. 559.

3. Perault-Staub, A.M., Staub, J.F. and Milhaud, G. (1974): A new concept of plasma calcium homeostasis in the rat. Endocrinology 95 , p. 480.

4. Talmage, R.V., Roycroft, J.H. and Anderson, J.J.B. (1975): Daily fluctuations in plasma calcium, phosphate, and their radionuclide concentrations in the rat. Calcif. Tiss. Res. 17, p. 91.

5. Talmage, R.V., Doppelt, S.H. and Cooper, C.W. (1975): Relationship of blood concentrations of calcium, phosphate, gastrin and calcitonin to the onset of feeding in the rat. Proc. Soc. Exp. Biol. Med. 149, p. 855 .

6. Hunt, N.H. and Perris, A.D. (1974): Calcium and the control of circadian mitotic activity in rat bone marrow and thymus. J. Endocrinol. 62, p. 451. 


\section{SUMMARY}

Several years ago the preliminary work to this thesis was started in the surgical endocrinology laboratory at the University of Chicago, Chicago, Illinois, U.S.A., when Edwin L. Kaplan et al. discovered that tumor extract from a human islet cell carcinoma which resulted in the Zollinger Ellison syndrome caused hypocalcemia in intact and thyroparathyroidectomized (TPTX) rats. Although the exact nature of the tumor was unknown, experiments with gastrin were undertaken since this peptide was identified with certainty from the tumor. In a series of experiments it was discovered that gastrin as well as other acid secretagogues act as hypocalcemic agents both in intact and TPTX rats. Furthermore, it was demonstrated that the hypocalcemia associated with their administration was not due to the thyroid release of the only known physiological hypocalcemic agent, calcitonin, but rather was dependent upon the presence of the fundic, acid secreting part of the stomach of the test animals.

The experiments described in this thesis are a continuation of these findings and were designed to identify the nature of this calcium lowering principle, which seemed to be related to the gastric acid secretory mechanism. Like the experiments of Kaplan et al. the experimental work described in this thesis was done at the University of Chicago.

In the INTRODUCTION a concise overview was given of the present knowledge of calcium homeostasis and of the many factors regulating it. Chemistry, secretion, mode of action and action of parathyroid hormone, vitamin $\mathrm{D}$ and calcitonin were briefly discussed.

In Chapter II, BACKGROUND DATA AND GOALS OF THIS STUDY special attention was given to the gastrointestinal influences on calcitonin secretion and serum calcium concentration. Following this, a summary was presented of the experiments that led to the conclusion that the presence of the acid secreting part of the stomach is essential to the hypocalcemic effect of gastrin, and that increased renal and intestinal excretion or decreased intestinal absorption of calcium do not play an important role. Since all experiments were performed both in thyroid-intact and TPTX animals calcitonin release from this gland does not seem to be important either. Analogous experiments were discussed in which gastrin had been replaced by histamine base, histamine phosphate, betazole hydrochloride, cholecystokinin and okta-cholecystokinin. These experiments all showed a clear hypocalcemic effect of acid secretagogues in the rat which was only demonstrable in the presence of an intact stomach. These results pose the intruiging question as to how this stomach-dependent hypocalcemia can be explained.

Maybe calcitonin is being secreted "ectopically" by the stomach; or does the hypocalcemic action of calcitonin require the presence of the stomach.

Possibly even, pentagastrin inhibits either the secretion or the peripheral action of parathyroid hormone. 
A completely different possibility is that the hypocalcemia induced by gastrin, histamine or CCK is the result of stimulation of secretion of another calcium-lowering amine or peptide from the proximal stomach. Pearse states that the fundus of the stomach contains several cells with APUD characteristics. The peptides and amines secreted from these cells remain unknown at this time.

Finally, as was suggested by the data of Kaplan et al., the hypocalcemic factor could be related to, or be a sequela of gastric acid secretion.

In the third to the eighth chapter these possibilities were analysed and the experiments that were designed to identify the mechanism of this stomach-dependent hypocalcemia, described.

In chapter III, INHIBITORS OF GASTRIC ACID SECRETION, it was demonstrated that the changes in serum calcium concentration were not the result of fluid or electrolyte shifts since serum protein and hematocrit values were lowered equally after gastrectomy and small bowel resection whilst pentagastrininduced hypocalcemia failed to occur only after gastrectomy. Moreover, it was demonstrated in this chapter that the hypocalcemic effect of pentagastrin was inhibited by administration of the gastric acid inhibitors atropine, secretin and metiamide. Likewise, the hypocalcemia of histamine was blocked by atropine and metiamide and the hypocalcemia of CCK by the administration of atropine. Finally, it was shown that after transabdominal vagotomy the calciumlowering activity of both pentagastrin and histamine was significantly reduced or even completely blocked. Thus, it seems that the acid secretory process of the stomach itself plays the dominant role in the hypocalcemia following the administration of acid secretagogues.

In chapter IV, THE ROLE OF CALCITONIN, exogenous and endogenous calcitonin were used in a series of experiments to lower serum calcium concentration. It was demonstrated that gastrectomy did not prevent this hypocalcemia. In other words, calcitonin does not need the stomach to be effective. In the last experiment described in this chapter serum immunoreactive calcitonin levels were determined and it was found that after pentagastrin administration to thyroid-intact animals serum calcitonin concentration was raised both in controls and in gastrectomized rats. In the latter group, however, no change in serum calcium concentration was recorded. Again, this indicates that calcitonin is not involved in the hypocalcemic principle.

In chapter V, A CALCIUM LOWERING AMINE OR PEPTIDE FROM THE STOM$\mathrm{ACH}$, the possibility of the existence of a new hormone produced by the cells of the fundic tissue of the stomach, and capable of lowering the serum calcium concentration was discussed. To investigate this, a system had been designed for perfusing the gastric vascular bed in situ. The blood-replacing solution used was a modified Krebs-Henseleit solution, containing no proteins. During perfusion of the stomach pentagastrin stimulation was applied and the gastric effluent, with its hypothetical calcium lowering amine or peptide, collected. This fluid was added in different concentrations to a sensitive bone tissue culturing system. No differences in bone resorption could be detected comparing solutions from pentagastrin-stimulated animals and controls. Therefore, it was con- 
cluded that the pentagastrin-induced hypocalcemia is not a consequence of the release of a calcium-lowering amine or peptide from the stomach.

In Chapter VI WHERE DOES CALCIUM GO WHEN HYPOCALCEMIA OCCURS?, the different possible pathways of the calcium ion after pentagastrin administration were studied. Various techniques were used to accomplish this.

In the first experiment simultaneous measurement of serum calcium concentration and secretion of calcium and acid into the gastric juice was performed. No direct linear relationship between the hypocalcemia and the small increase in gastric calcium secretion that was found after pentagastrin administration, could be demonstrated.

In another experiment the absence of an arterio-venous gradient of serum calcium concentration across the stomach showed that calcium influx into the gastric wall does not contribute to the hypocalcemia induced by pentagastrin.

Counting of ${ }^{45} \mathrm{Ca}$ incorporation into the gastric wall confirmed this observation.

Finally, kinetic studies with ${ }^{47} \mathrm{Ca}$ revealed a relative increase of specific activity after administration of pentagastrin. This can only be explained by assuming that calcium is discouraged to enter the circulation and not stimulated to enter it. Thus, it may be concluded that:

1. Only a small part of the calcium loss may be explained by its secretion into the gastric juice;

2. The stomach wall is unlikely to accumulate calcium ions during or immediately after induction of acid secretion.

3. In all probability, the hypocalcemia is largely a consequence of the inhibition of calcium release from bone and not of an efflux of calcium from plasma.

In chapter VII, THE ALKALINE TIDE, attention was re-focused on the gastric acid secretory process. The occurrence of a so-called "alkaline tide", synchronous with gastric acid secretion, was studied. Under varying conditions the changes in hydrogen ion and total calcium concentration in the blood were analyzed after intravenous administration of either pentagastrin or sodium bicarbonate.

After the demonstration of a rise in $\mathrm{pH}$ of the peripheral blood occuring 30 minutes after pentagastrin administration, sodium bicarbonate was shown to cause a similar shift in hydrogen ion concentration when given intravenously in doses equivalent to or only a little above the amount of hydrogen ions excreted into the gastric juice after pentagastrin stimulation $(60 \mu \mathrm{Eq})$. Finally, such doses were found to cause almost identical falls in serum calcium concentration as observed after pentagastrin administration.

It was concluded that the hypocalcemia following the administration of pentagastrin or other acid secretagogues to the rat is a result of the changes in hydrogen ion concentration of the fluid compartments bathing the bone mass and, to a lesser degree, to the small increase of calcium loss into the gastric juice that accompanies stimulated acid secretion.In the concluding experiment of this chapter the validity of above reasoning was tested in a physiologic setting. It was demonstrated that in rats with maximally stimulated acid secretion 
as a result of feeding, pentagastrin no longer lowered serum calcium concentration, presumably because no additional shift of hydrogen ions took place after its administration.

In the closing chapter, A PHYSIOLOGIC ROLE?, it was theorized how this hypocalcemic principle could apply to normal physiology in the rat. After the demonstration that oral administration of metiamide prevented both the secretion of gastric acid and, consequently, the fall in serum calcium concentration normally following pentagastrin administration, young and older rats were rigidly conditioned to a light-dark, fasted-fed schedule. If no metiamide was given, the animals were found to experience a fall in serum calcium concentration starting several hours before the expected meal and continuing several more hours after feeding had begun. Metiamide completely inhibited this fall both in the light-unfed and in the dark-fed period. The interesting conclusion of these experiments was that in rats a rhythmic variation in the serum calcium concentration seemed to be intimately related to gastric acid secretion and not to the release of gastrin and calcitonin. It was suggested that this was caused by the "cephalic" or vagal stimulation of gastric acid secretion. These surprising observations lead to the speculation that in rats the acid secretory process may play a hitherto unsuspected and important role in the regulation of serum calcium homeostasis.

In conclusion, in the rat, it seems that calcitonin is not produced "ectopically" by the stomach, nor that it needs the stomach to be effective. Therefore, since it was demonstrated before that thyrocalcitonin does not play a role either, calcitonin is not involved in the hypocalcemia that follows pentagastrin administration.

It seems unlikely that the stomach is capable of secreting an alternative calcium-lowering amine or peptide.

The hypocalcemia induced by different gastric acid secretagogues must be a sequela of the alkaline tide which accompanies the acidification of the gastric juice. This fall of the hydrogen ion concentration of the blood decreases calcium release from bone, which, in turn, lowers serum calcium concentration.

It may be that this mechanism is the most important gastrointestinal regulator of calcium homeostasis.

Although much work remains to be done to fully unravel the complex pathways of calcium homeostasis it is felt that this work has contributed a small but important step and justifies the search for a similar hypocalcemic principle in man. 


\section{SAMENVATTING}

Enkele jaren geleden ontdekte E.L. Kaplan, werkend in het laboratorium voor chirurgische endocrinologie van de University of Chicago, dat een extract uit het eilandcelcarcinoom van een patient met het Zollinger Ellison syndroom hypocalcaemie veroorzaakte bij intacte ratten. Kaplan zag dit fenomeen ook optreden bij ratten bij wie tevoren de schildklier en bijschildklieren verwijderd waren (TPTX-ratten). Omdat gastrine met zekerheid uit de tumor geisoleerd kon worden, werd de relatie tussen dit peptide en het calcium-gehalte van het serum verder onderzocht. In een aantal experimenten werd aangetoond, dat gastrine en andere stimulatoren van de maagzuursecretie in staat waren gedurende korte tijd het totale serum calciumgehalte te doen dalen. Deze verlaging was 15 tot 30 minuten na intraveneuze toediening maximaal.

Kaplan toonde in andere experimenten aan dat deze hypocalcaemie niet het gevolg was van het vrijkomen van calcitonine uit de schildklier, maar duidelijk afhankelijk was van de aanwezigheid van het zuurproducerende deel van de maag.

Het experimentele werk dat in dit proefschrift wordt gepresenteerd, bouwt op deze bevindingen voort en tracht een antwoord te geven op de vraag, waardoor deze hypocalcaemie veroorzaakt wordt. Evenals de experimenten van Kaplan werd het experimentele werk uit dit proefschrift verricht in het laboratorium voor chirurgische endocrinologie van de University of Chicago.

In het eerste hoofdstuk, INTRODUCTION, wordt een beknopte samenvatting gegeven van de huidige kennis van de calciumhuishouding met speciale aandacht voor de belangrijkste regulatoren daarvan. Chemische kenmerken, werkingsmechanisme en effecten van parathormoon, vitamine $D$ en calcitonine worden in het kort besproken.

In het tweede hoofdstuk, getiteld BACKGROUND DATA AND GOALS OF THIS sTuDY wordt in het bijzonder ingegaan op de invloed van gastrointestinale factoren op de uitscheiding van calcitonine en de calciumconcentratie in het serum. Vervolgens wordt aangegeven welke van Kaplan's experimenten hebben geleid tot de conclusie dat het zuurproducerende deel van de maag een centrale rol speelt bij het calciumverlagende effect van gastrinetoediening. Noch versterkte renale of intestinale uitscheiding, noch verminderde intestinale absorptie van calcium blijken daarbij een rol van betekenis te spelen. Aangezien alle experimenten werden verricht bij intacte zowel als TPTX ratten lijkt ook de schildklier, en dus het daaruit afkomstige calcitonine, hierbij van geen belang.

Andere stimulatoren van de maagzuursecretie zoals basisch histamine, histamine-fosfaat, cholecystokinine (CCK) en okta-cholecystokinine vertoonden een hypocalcaemisch effect analoog aan dat van gastrine. Na maagresectie was ook met deze stoffen dit effect niet meer aantoonbaar.

Voor deze maag-afhankelijke calciumverlaging zijn verschillende verklaringen mogelijk. Misschien wordt calcitonine "ectopisch" in de maag geprodu- 
ceerd; of wellicht is calcitonine alleen werkzaam in aanwezigheid van het zuurproducerende deel van de maag. Een andere goede verklaring zou zijn dat gastrine de uitscheiding of de werking van parathormoon verhindert. Een geheel andere mogelijkheid is dat gastrine, histamine of CCK een hypocalcaemie veroorzaken omdat zij de secretie van een ander, calciumverlagend, amine of peptide uit de proximale maag stimuleren. Pearse heeft in de maagfundus verscheidene nog niet nader geidentificeerde cellen behorend tot het APUD systeem beschreven. Tot op heden zijn de producten van deze cellen grotendeels onbekend. Voortbouwend op de bevindingen van Kaplan dient ook tot de mogelijkheden gerekend te worden dat de hypocalcaemische factor verband houdt met, of het gevolg is van de maagzuursecretie.

In het derde tot achtste hoofdstuk worden deze hypothesen aan een nadere beschouwing onderworpen.

In hoofdstuk III, INHIBITORS OF ACID SECRETION, wordt aannemelijk gemaakt dat hypocalcaemie na pentagastrine niet het gevolg is van verschuivingen van lichaamsvloeistoffen en electrolyten. De haematocriet- en het serum proteine gehalte veranderen immers na gastrectomie of dunnedarmresectie op analoge wijze, alleen een gastrectomie is in staat de door pentagastrine geinduceerde hypocalcaemie te voorkomen.

Voorts wordt aangetoond dat het calciumverlagende effect van pentagastrine, histamine en CCK geblokkeerd kan worden door toediening van remmers van de zuursecretie als atropine, secretine en metiamide.

Tenslotte blijkt dat transabdominale, truncale vagotomie een sterke vermindering of zelfs complete remming van het hypocalcaemische effect van pentagastrine en histamine tot gevolg heeft.

De conclusie van deze resultaten is dat het proces van de maagzuursecretie zélf in sterke mate bij het ontstaan van de hypocalcaemie betrokken is.

In hoofdstuk IV, THE ROLE OF CALCITONIN, wordt aangetoond dat gastrectomie géén invloed heeft op de hypocalcaemie die het gevolg is van exogene of endogene verhoging van de serum calcitoninespiegel. Met andere woorden, calcitonine heeft de maag niet nodig om effectief te zijn.

Voorts blijkt dat na toediening van pentagastrine aan ratten met intacte schildklier de concentratie van immunoreactief calcitonine stijgt, ongeacht of de dieren een gastrectomie hebben ondergaan. In de post-gastrectomie groep blijft een daling van het serum calciumgehalte uit, in de controle groep vindt de daling normaal plaats.

Alle resultaten uit dit hoofdstuk wijzen erop, dat calcitonine geen rol van betekenis speelt bij het ontstaan van de gastrogene hypocalcaemie.

Hoofdstuk V, A CALCIUM LOWERING AMINE OR PEPTIDE FROM THE STOM$A C H$, wordt de mogelijkheid onderzocht, of de hypocalcaemie wordt veroorzaakt door een nieuw hormoon, geproduceerd en uitgescheiden door cellen uit het zuurproducerende deel van de maag. Hiertoe werd een apparaat ontworpen voor perfusie van het vaatbed van de maag in situ. In plaats van met bloed werd de maag met een eiwitloze, gemodificeerde Krebs-Henseleit oplossing geperfundeerd. Tijdens de perfusie werd het maagweefsel gestimuleerd met ofwel pentagastrine ofwel fysiologisch zout. De efferente vloeistof (mét het hypothe- 
tische hormoon) werd opgevangen en toegevoegd aan een gevoelig botkweek systeem.

Verschillen tussen de met pentagastrine en de met fysiologisch zout gestimuleerde magen konden niet worden aangetoond, daar beide vloeistoffen een gelijke botresorptie veroorzaakten. Aangenomen mag worden dat de maag geen nieuw calciumverlagend hormoon produceert.

In hoofdstuk VI, WHERE DOES CALCIUM GO WHEN HYPOCALCEMIA OCCurs?, wordt getracht na te gaan waar de calcium-ionen blijven na injectie van pentagastrine. Uiteenlopende technieken werden toegepast.

In de eerste proef werd simultane meting verricht van de serum calcium concentratie en de calcium- en zuuruitscheiding in het maagsap. Ondanks een lichte toename van de calciumuitscheiding in het maagsap onder invloed van pentagastrine, kon geen significante relatie aangetoond worden tussen deze toename en het optreden van de hypocalcaemie.

Meting van de callcium concentratie in bloed vóór en na passage door het vaatbed van de maag toonde aan dat de maagwand geen calcium opneemt tijdens de door pentagastrine geinduceerde hypocalcaemie.

Proeven met radioactief gelabeled calcium bevestigden het ontbreken van dit mechanisme.

Kinetische studies met behulp van ${ }^{47} \mathrm{Ca}$ toonden tenslotte aan dat na toediening van pentagastrine de specifieke activiteit van het calcium groter is dan na toediening van een fysiologische zoutoplossing. Dit wijst erop dat calcium niet in verhoogde mate de bloedbaan verlaat maar daarentegen in mindere mate de bloedbaan binnen treedt.

Zo kan worden geconcludeerd dat:

1. Slechts een klein gedeelte van het calciumverlies verklaard kan worden door uitscheiding van calcium-ionen in het maagsap;

2. Er geen aantoonbare toeneming van calciumconcentratie in de maagwand plaatsvindt tijdens of direct volgend op stimulatie van de zuursecretie;

3. De hypocalcaemie naar alle waarschijnlijkheid grotendeels het gevolg is van een remming van de calciumstroom vanuit het bot naar het bloed en niet van een vlucht van het callcium uit de bloedbaan.

In hoofdstuk VII, THE ALKALINE TIDE wordt de aandacht opnieuw gericht op de maagzuursecretie. De kortstondige alkalinisering van het bloed die optreedt tijdens de secretie van $\mathrm{HCl}$, ook wel genoemd "alkaline tide" kon ook in ons proefdiermodel worden aangetoond. Hierbij werd een piekwaarde gemeten 15 tot 30 minuten na stimulatie met pentagastrine, synchroon met de hypocalcaemie. Een analoge alkalinisering kon worden bereikt door infusie van een hoeveelheid natriumbicarbonaat equivalent aan of een weinig meer dan de hoeveelheid waterstofionen welke als maagzuur uitgescheiden worden na stimulatie met pentagastrine $(60 \mu \mathrm{Eq})$. Vervolgens bleek intraveneus toegediend natriumbicarbonaat een nagenoeg zelfde verschuiving in de calciumconcentratie teweeg te kunnen brengen als pentagastrine.

De conclusie van deze experimenten is, dat de hypocalcaemie, veroorzaakt door intraveneuze toediening van pentagastrine of andere zuurstimulatoren. grotendeels het gevolg is van veranderingen in de concentratie van waterstofion 
in vloeistoffen die de botfractie omgeven. Voor een klein deel wordt hieraan verder bijgedragen door verlies van calciumionen in het maagsap tijdens de zuurproductie.

In het laatste experiment van dit hoofdstuk wordt aangetoond dat tijdens een toestand van maximale stimulatie van de maagzuursecretie, zoals na eten, pentagastrine geen verlaging van het serum calciumgehalte meer teweeg brengt. De verklaring hiervoor moet dan zijn dat pentagastrine niet meer in staat is extra zuursecretie te stimuleren en er dus ook geen verandering van de waterstofconcentratie in het perifere bloed meer kan optreden.

In hoofdstuk VIII, A PHYSIOLOGIC ROLL?, wordt getracht de hier beschreven hypocalcaemie een plaats te geven in de normale calciumhuishouding van de rat. Eerst werd aangetoond dat oraal toegediend metiamide de zuursecretie als ook de hypocalcaemie, volgend op de injectie van pentagastrine, remde. Vervolgens werden jonge en oudere ratten tot een licht-vasten en een donkereten schema geconditioneerd. Indien de dieren geen metiamide door hun drinkwater kregen vertoonde de serum calciumspiegel een spontane daling, beginnend enkele uren voor het verwachte maal en voortdurend tot enkele uren na het begin van de maaltijd. Metiamide bleek deze calciumverlaging geheel te kunnen voorkomen.

De conclusie van deze bevindingen luidt dat synchronisering bij ratten een ritmische variatie van de serum calciumconcentratie aan het licht brengt, welke nauw verbonden blijkt met de maagzuursecretie en niet met het vrijkomen van gastrime en calcitonine.Deze verrassende bevindingen leiden tenslotte tot de speculatie dat de maagzuursecretie en de daaraan gekoppelde invloed op het vrijkomen van calcium uit het bot in ratten een tot nu toe onvermoede maar belangrijke rol speelt bij de regulatie van het calciumgehalte van het bloed.

Concluderend lijkt bewezen dat in de rat de maag geen "ectopisch" calcitonine produceert en dat calcitonine de maag niet nodig heeft om hypocalcaemie te veroorzaken. Mede gezien het reeds eerder aangetoonde ontbreken van een rol voor thyrocalcitonine, kan calcitonine dus niet betrokken zijn bij de serum calcium verlaging die door pentagastrine wordt veroorzaakt.

Ook lijkt het onwaarschijnlijk dat de maag een ander calcium-verlagend amine of peptide produceert.

De hypocalcaemie, optredend na toediening van verschillende maagzuursecretoren, moet een gevolg zijn van de alkalinisering van het bloed waarmee maag. zuursecretie gepaard gaat. De calciumstroom vanuit het bot wordt door deze $\mathrm{pH}$ verschuiving afgeremd.

Mogelijk kan dit mechanisme gezien worden als de belangrijkste gastrointestinale regulator van de calciumstofwisseling.

In deze studie werd slechts een facet van de calciumstofwisseling belicht. Niettemin lijkt hiermee een waardevolle bijdrage geleverd aan de inzichten over gastrointestinale invloeden op de serum calciumregulatie. Onderzoek naar de betekenis van het beschreven hypocalcaemische mechanisme voor de mens lijkt gerechtvaardigd. 
Dominating my feelings upon completion of this thesis is the warm memory of the peoplle of the University of Chicago, in particular of the Department of Surgery. The two years that Jeannine and I spent in this great institution in beautiful Chicago, were among the happiest in our lives. Of the many who I would wish to thank I regret that space permits me to mention but a few.

Prof. Edwin L. Kaplan who took me by the hand and with his unique gentleness and intelligence transformed this impatient surgeon into a questioning and cautious researcher. II greatly admire his work and feel honored to have had the opportunity to become involved in it. His friendship and that of his charming family mean a great deal to us. Prof. David Skinner, al though not directly involved with this thesis, gave me great encouragement and support. I greatly appreciate his teaching and friendship. With gratitude I acknowledge the invaluable help of our friend Joey Czerwonka; without her our stay would not have been possible. I owe much to the technical skills and "survivalist" advice of Dr. Kaplan's technician, Roberta Lagocki.

Prof. Peter Kirschner and Prof. Francis Straus for their interest and specialist knowledge.

Bob McCauley and Jeff Sugimoto for their contribution to the experimental work. Dennis and Des for blood gas analyses. The Audio-visual Department of the University of Chicago for their beautiful art work and the Department of Prof. Paul Meier for their kind and expert help with the statistics.

I am greatly indepted to Prof. Paula Stern, pharmacologist at the Northwestern University, Medical School, Chicago, and to her indefatigable assistant, Thalia Mavreas; to Prof. Hunter Heath III of the Mayo Clinics for his radio-immunoassays of calcitonin. Chicago would not have been such a great experience without our friends Marshall and Irene Pattner who allowed us a glimpse behind the (table) screens.

My special thanks to Prof. Dr. Co Greep, under whom I received part of my surgical training, for the opportunity to complete this thesis in Maastricht (and Helsinki). His drive will always be an example to me.

Dr. Bernard Goslings, my friend and former coach for his stimulating criticism of the manuscript.

Prof. Dr. Ilarry Hulsmans for his careful reading of the manuscript and his valuable commentary.

Dr. Chris Mink and Mrs. Renée Schefman-van Veer for their careful analysis of the perfusion solution.

Chris Voskamp for his illustrations and his expert help in the lay-out.

Mieke Struik for her beautiful cover design.

Marcia Steegmans-van Puijenbroek for her accurate and intelligent typing and her splendid collaboration with Henk Jas in the mastering of the computerised type-setter. Their enthousiasm and endurance were truly amazing.

Finally, my thanks to the Staff and residents of the Department of Surgery of Sit. Annadal Hospital for their much needed support and friendship.

And, last but first, Jeannine, about whom I'll write the next book. 


\section{CURRICULUM VITAE}

Peter Klementschitsch was born on June 1, 1941 in Dordrecht. The Netherlands. He attended High School in Dordrecht and Breda (Gymnasium B) and went to study at the Medical Faculty of the University of Leiden. During these years he was involved in clinicall and research work at the Department of Thoracic Surgery (chairman Prof. Dr. A.G. Brom) and the Isolation Pavilion (head Dr. B. Speck). After his graduation in March 1970 he went to work as a general physician throughout the country. After a few months of surgical residency at the GrootZiekengasthuis in 's Hertogenbosch (chairman Dr. J.H. Meiss) his surgical training was officially started at the St. Lucas Ziekenhuis in Amsterdam (chairman Dr. J.M. Greep, later Dr. J.N. Keeman). His registration took place in November 1977. From September 1977 to September 1979 he functioned as a research and clinical fellow at the Department of Surgery of the University of Chicago, Pritzker School of Medicine, Chicago, Ill. (chairman Prof. D. B. Skinner). During his first year the experiments that underlie this thesis were performed in the surgical endocrinology laboratory of Prof. E.L. Kaplan. In his second year he joined the Department of Thoracic and Vascular Surgery (chairman Prof. T.R. DeMeester) and was instructed in patho-physiology and surgery of the esophagus. He came back in October 1979 to work as a "Chef de Clinique" at the St. Annadal Ziekenhuis in Maastricht, University of Limburg (chairman Prof. Dr. J.M. Greep). 
Druk: Crouzen B.V., Maastricht

Ontwerp omslag: Mieke Struik, Amsterdam

Illustraties:

Zetwerk:

Audio-Visual Department, University of Chicago, Chris Voskamp, Maastricht

Infonet bv., Amsterdam 
